Illinois State University

ISU ReD: Research and eData

Theses and Dissertations

7-19-2019

\title{
An Intersectional Feminist Rhetorical Reframing of Rhetorics of Efficiency Within Public Policy: Embodied Knowledge and Usability
}

Oriana A. Gilson

Illinois State University, odebord@gmail.com

Follow this and additional works at: https://ir.library.illinoisstate.edu/etd

\section{Recommended Citation}

Gilson, Oriana A., "An Intersectional Feminist Rhetorical Reframing of Rhetorics of Efficiency Within Public Policy: Embodied Knowledge and Usability" (2019). Theses and Dissertations. 1424.

https://ir.library.illinoisstate.edu/etd/1424

This Dissertation is brought to you for free and open access by ISU ReD: Research and eData. It has been accepted for inclusion in Theses and Dissertations by an authorized administrator of ISU ReD: Research and eData. For more information, please contact ISUReD@ilstu.edu. 


\title{
AN INTERSECTIONAL FEMINIST RHETORICAL REFRAMING OF RHETORICS
}

OF EFFICIENCY WITHIN PUBLIC POLICY: EMBODIED KNOWLEDGE AND

\author{
USABILITY
}

\section{ORIANA A. GILSON}

\section{Pages}

This dissertation focuses on public policies that are presented under the pretext that they benefit all members of society but that in fact reserve those privileges for those who conform to reductive policy mandates. Specifically, this project employs an intersectional feminist rhetorical methodology that is committed to identifying and challenging exclusionary rhetorics of efficiency and propelling the agentive power of those whose embodied realities places them outside of the normative user-group imagined by, and constructed through, a specific policy. This dissertation begins with a synthesis of scholarship that is key to the theorization and application of an intersectional feminist rhetorical, particularly intersectional feminist scholarship, feminist and disability scholarship, and technical and professional communication scholarship that prioritizes underrepresented groups and usability.

Building from this scholarship, the identifying features of an intersectional feminist rhetorical framing of usability and key terms for the project are articulated. Applying this methodology to public policy, the project next analyzes a case study of Baby Friendly USA to examine how the long-term goal of infant health is weakened by rhetorics of efficiency that undermine marginalized users intersectional, embodied needs. Shifting from public health policy to voting policy, the second case study examines Ohio's voter purge policy and the discourses 
that justify the purging of multiply marginalized users from voter rolls. In each of these case studies, critique of a policy is followed by descriptions and analysis of the individuals and groups already engaged in resistance. Highlighting this work as a model for intersectional feminist rhetorical approaches, this dissertation also attends to how technical and professional communication, rhetoric, and composition teacher scholars might learn from and amplify the work of those outside of academia. The final case study describes how an intersectional feminist rhetorical pedagogy informed the teaching of an introductory technical and professional communication course. This dissertation discusses both the benefits and risks of this approach, the affordance and limitations of the curricula presented in this project, and the potential usefulness of this pedagogical approach for other teacher scholars.

The project concludes by proposing future applications for an intersectional feminist rhetorical methodology for technical and professional communication, rhetoric, and communication teaching and scholarship as well as public policy and engagement with publics outside of the university.

KEYWORDS: Technical and professional communication, intersectional, feminist, usability, public policy, rhetoric 


\section{AN INTERSECTIONAL FEMINIST RHETORICAL REFRAMING OF RHETORICS \\ OF EFFICIENCY WITHIN PUBLIC POLICY: EMBODIED KNOWLEDGE AND USABILITY}

ORIANA A. GILSON

A Dissertation Submitted in Partial

Fulfillment of the Requirements

for the Degree of

DOCTOR OF PHILOSOPHY

Department of English

ILLINOIS STATE UNIVERSITY 
(C) 2019 Oriana A. Gilson 


\section{AN INTERSECTIONAL FEMINIST RHETORICAL REFRAMING OF RHETORICS OF EFFICIENCY WITHIN PUBLIC POLICY: EMBODIED KNOWLEDGE AND USABILITY}

ORIANA A. GILSON

COMMITTEE MEMBERS

Elise Verzosa Hurley, Chair

Angela M. Haas

Julie Jung 


\section{ACKNOWLEDGMENTS}

The acknowledgements on this page feel wholly inadequate to convey how grateful I am to the many people who helped me throughout this process. I hope that the appreciations that follow at least hint at the deep gratitude I feel for the individuals and communities that have made this work possible.

Thank you first to my committee members, Drs. Elise Verzosa Hurley, Angela M. Haas, and Julie Jung to whom I am profoundly grateful. Elise, I cannot thank you enough for the time, energy, and intellectual and emotional support that you invested in me and this project. I am forever grateful to you for your constant mentorship and for the invaluable experience working with you on Rhetoric Review. Angela, thank you for bringing me into your TPC community, for helping me to make my scholarship more intersectional, and for encouraging me to articulate my place in the field. Julie, thank you for helping me to recognize both the connections and gaps in my work, for introducing me to transnational feminism, and for providing me with encouragement when it was needed most. I will be a better scholar, teacher, and colleague because of the mentorship I have received from each of you.

To Lisa Dooley and Sarah Warren-Riley whose friendship, advice, and support have sustained me through this process. I don't think I could have done this without the two of you, and I look forward to many more nights on the phone as we talk through our ideas, families, worries, and successes together. To Julie Bates, Kristen Strom, Lisa Phillips, and Barbi SmyserFauble, thank you for your advice and endless kindness. Thank you to Dr. Joyce Walker whose support and encouragement were integral to my entry into ISU's graduate school. 
Thank you to Sherrie Howe, Diane Smith, and Amy Tellor who were instrumental in helping me as I moved through the $\mathrm{PhD}$ process and who went out of their way to support me in my multiple roles as mother, teacher, student, and scholar.

Thank you to my parents, Carol Alesandrini DeBord and Bill DeBord, who taught me to recognize and fight against injustice, to listen to and learn from others, and to always strive to be a kinder, more generous human being. The countless hours of childcare and myriad acts of generosity and support that you provided afforded me the time and space to see this project through to today.

To my husband, Greg, who I admire as a teacher, cherish as a friend, and adore as a husband. Thank you for believing in me even when I struggled to do so myself, for the multiple sacrifices you made these past years, and for your seemingly endless love and support. And to my children, Serafina and Angelo, who are a constant source of joy. I will never be able to adequately express how much I love you and how proud I already am of each of you. 


\section{CONTENTS}

Page

ACKNOWLEDGMENTS

TABLES

vii

FIGURES

viii

CHAPTER I: PERSPECTIVES INFORMING AN INTERSECTIONAL

FEMINIST RHETORICAL FRAMEWORK FOR USABILITY: PUBLIC

POLICY, RHETORICS OF EFFICIENCY, AND SOCIAL JUSTICE

Project Overview

Literature Review

Public Policy as Public Rhetoric

Public Policy in Technical and Professional Communication

Feminist Scholarship: Embodiment, Intersectionality, and Local

Knowledges

14

Feminist Scholarship in Rhetoric and TPC

Feminist Rhetorical Scholarship

18

Feminist Rhetorical Scholarship in TPC

19

Disability Rhetoric and Disability Studies

History of and Exigency for Social Justice Work in TPC

Usability as a Practice of Social Justice

Looking Ahead 
CHAPTER II: AN INTERSECTIONAL FEMINIST RHETORICAL

METHODOLOGY FOR EXAMINING RHETORICS OF EFFICIENCY IN

$\begin{array}{ll}\text { PUBLIC POLICY } & 38\end{array}$

Contending with My Own Positionality 41

Understanding Intersectionality $\quad 44$

Theories of Embodiment within Disability Studies and Feminist

$\begin{array}{ll}\text { Scholarship } & 48\end{array}$

Challenges to Efficiency in TPC 53

An Intersectional Feminist Rhetorical Framework for Usability 56

Key Tenets of an Intersectional Feminist Rhetorical Methodology 62

$\begin{array}{ll}\text { Conclusion } & 65\end{array}$

Applying Methodology to Other Chapters 65

CHAPTER III: RETHINKING RHETORICS OF EFFICIENCY AND

USABILITY: A CASE STUDY OF BABY FRIENDLY USA 67

Personal Exigency and the Link between BFUSA and The Code 69

$\begin{array}{ll}\text { From The Code to BFUSA } & 72\end{array}$

$\begin{array}{ll}\text { Rhetorics of Efficiency in BFUSA Policy } & 75\end{array}$

Foregrounding Embodied Experience: Examining Fed is Best 89

Rethinking Usability: Implications for Teacher Scholars 97

CHAPTER IV: SHIFTING RESPONSIBILITY FOR USABILITY: A CASE

STUY OF OHIO'S VOTER PURGE POLICY 101

$\begin{array}{ll}\text { Establishing an Exigence } & 104\end{array}$ 
Voter Purge Policies and Ohio's Aggressive Interpretation 106

Technical and Professional Communications that Authorize Ohio's

$\begin{array}{ll}\text { Purge Policy } & 114\end{array}$

$\begin{array}{ll}\text { Increasing Access: VRA and NVRA } & 117\end{array}$

$\begin{array}{ll}\text { Supreme Court Ruling } & 119\end{array}$

Defenders of Ohio's Purge Policy: Policy Failure as User Failure-

$\begin{array}{ll}\text { Efficiency versus Usability } & 123\end{array}$

Intersectional Feminist Rhetorical Response: Stacey Abrams and Fair

$\begin{array}{ll}\text { Fight Action } & 129\end{array}$

$\begin{array}{ll}\text { Implications for Teacher Scholars } & 137\end{array}$

CHAPTER V: AN INTERSECTIONAL FEMINIST RHETORICAL

PEDAGOGY: REFRAMING USABILITY IN THE TPC CLASSROOM 141

$\begin{array}{ll}\text { Personal and Institutional Context } & 145\end{array}$

$\begin{array}{ll}\text { Course Goals } & 148\end{array}$

$\begin{array}{ll}\text { Case Study } & 151\end{array}$

Course Readings and Discussions 154

$\begin{array}{ll}\text { Course Projects } & 159\end{array}$

Student Learning and Feminist Transparency 173

$\begin{array}{ll}\text { Case Study Limitations } & 179\end{array}$

$\begin{array}{ll}\text { Case Study Implications } & 180\end{array}$

Moving Forward with an Intersectional Feminist Rhetorical Pedagogy 182 
CHAPTER VI: IMPLICATIONS AND FUTURE INTERSECTIONAL FEMINIST

$\begin{array}{ll}\text { RHETORICAL PROJECTS } & 184\end{array}$

WORKS CITED 192 


\section{TABLES}

\section{Table}

1. BFUSA Policy Language and Tropes $\quad 82$

2. Potential of Moving from Standardized to Extraordinary User 98

3. NVRA, Sec. 2. Findings and Purposes 118

4. Standard versus Embodied Narratives 135

5. Course Goals and Pedagogical Supports 150

6. Excerpts of Preliminary Exercise for Team Contracts 170

7. Integrating Intersectional Feminist Rhetorical Commitments into Assessment 172 


\section{FIGURES}

Figure

Page

1. Shifting Purpose and Potential of Usability in Public Policy

2. Fed is Best Foundation Homepage

90

3. Confirmation Notice Sent to Ohio Residents

109

4. Ohio’s Online Voter Registration Homepage

112 


\section{CHAPTER I: PERSPECTIVES INFORMING AN INTERSECTIONAL FEMINIST}

\section{RHETORICAL FRAMEWORK FOR USABILITY: PUBLIC POLICY,}

\section{RHETORICS OF EFFICIENCY, AND SOCIAL JUSTICE}

The U.S. has seen a recent surge in regressive public policies that discriminate against marginalized populations and undermine the power of established policies to protect vulnerable groups. Many of these policies are conspicuous in their intent to target particular populationsfor instance, policies that allow for children on the southern border to be taken from their parents and put into detention centers, that deny transgender citizens the right to serve in the military, or that attempt to ban travelers from Muslim-majority countries from entering the U.S. ${ }^{1}$ The proponents of these policies do little to mask their intent: In each case, it is clear who the policy benefits and who it targets for the explicit denial of benefits and rights. Other public policies are more opaque in their disparate effects. Policies that describe steps to ensure that U.S. elections remain "free and fair" or that outline "baby-friendly" care for mothers and infants in hospitals seem, on the surface, to work in service of the entire public good. Healthy infants and caretakers as well as free and fair elections are end-goals that have nearly universal appeal and benefits. It is these policies - those presented under the pretext that they benefit all members of society but that in fact reserve these privileges for those who conform to reductive policy mandates - to which this project attends.

For politicians, administrators, and proponents charged with composing and overseeing these policies, rhetorics of efficiency present a facade of objectivity that downplays the material

\footnotetext{
${ }^{1}$ For more on these policies, see: "zero tolerance policy" Rhodan; pentagon transgender policy (Baldor); multiple forms of Muslim Bans ("Understanding").
} 
impacts of policy mandates that ignore, seek to reform, or do violence upon certain bodies. I define rhetorics of efficiency as the rhetorical promotion of particular acts, performed by normalized bodies, as objective and good. Rhetorics of efficiency can further an impression of policies as working for all users when they in fact are only usable for those who are able and/or willing to comply with the normative standards established within the policy itself. To address this issue, I propose an intersectional feminist rhetorical methodology that is committed to identifying and challenging exclusionary rhetorics of efficiency and propelling the agentive power of those whose embodied realities places them outside of the normative user-group imagined by, and constructed through, a specific policy. ${ }^{2}$ In so doing, I engage with public policies as technical documents that have substantial material impacts as they are taken up by and shape the experiences of, and access made available to, individual bodies ${ }^{3,4}$. Moreover, I work under the presumption that public policies should, ostensibly, serve the public good. Yet policies too often ignore pervasive issues

\footnotetext{
${ }^{2}$ In each of the proceeding chapters, I contextualize my own positionality in relation to the specific work being presented and interventions being examined. I engage in this work not to identify and offer solutions to problems outside of my own experience, but rather to contribute to the social justice imperative to engage with injustices, reveal these injustice to others, and work to address to them (Walton, Moore, Jones 6).

${ }^{3}$ My use of the term "individual" is a precarious one. Indeed, feminist and disability scholarship emphasize relationality and interdependency, noting the dangers of neoliberal, dominant discourses in which "[q]uestions of oppression and exploitation as collective, systemic processes" are "collapsed into individual characteristics" (Mohanty, "Transnational" 971). My decision to focus on the individual is not intended to diminish the reality that oppression is systemic, and I am careful to attend to this point throughout the project. Rather, I use "individual" as a direct response to public policies that portend to serve marginalized populations but do so only insomuch as marginalized individuals can be homogenized into neat categories that ease hierarchical oversight and management. Thus, my focus on the individual is intended to confront rhetorics of efficiency that ignore individual people's bodies and experiences and to push for public policies that resist categorization and homogenization of complex, intersectional, individual experience.

${ }^{4}$ Thank you to Dr. Julie Jung for highlighting this tension and prompting me to more fully articulate my rationale.
} 
such as poverty and discrimination in favor of tackling more immediately quantifiable, but substantially reductive, public initiatives all of which result in policies that fail to attend to the needs of the most vulnerable users, and efficiencies that work against rather than for those who are already on the margins. As a technical communicator, educator, and rhetoric scholar, I am concerned with the ways in which professional and technical documents contribute to a system that further marginalizes already vulnerable members of the public, and am committed to pedagogical and scholarly practices that work toward upending these unjust systems.

Ultimately, this project calls for and demonstrates a methodology whereby teacherscholars can engage an intersectional feminist rhetorical framework of usability to identify and problematize rhetorics of efficiency that ignore or oppress certain users, and learn from and amplify the work of marginalized individuals and groups already pushing back against restrictive public policies. This chapter begins with an overview of my project, my research questions, and a short introduction to my methodology (which is the focus of Chapter II). Next, I briefly describe my own exigency for undertaking this project before providing a literature review that frames public policy as public rhetoric and situates my work as contributing to social justice scholarship in Technical and Professional Communication (TPC), rhetoric, and composition. To conclude, I outline the remaining chapters of this dissertation.

\section{Project Overview}

My project considers how rhetorics of efficiency contribute to public policies that invite individuals and institutions to ignore, deny, or dismiss the embodied experiences of people who diverge from the dominant norm. Responding to calls in TPC to increasingly make evident exactly what and who is prioritized, overlooked, and/or undermined in technical discourse (Frost; 
Katz; Frost and Haas), this project engages public policies as technical documents that have material impacts on users. Drawing from intersectional feminist scholarship, and feminist and disability scholarship in TPC and rhetorics, I propose an intersectional feminist rhetorical approach to usability that focuses attention on the usability of a policy for marginalized users. Specifically, I present two public policy case studies in which rhetorics of efficiency distract from the disproportionate material impacts of the policy on vulnerable individuals and communities. The first case study analyzes Baby Friendly USA policies that link infant and maternal care, as well as "baby friendly" hospital certification, to breastfeeding initiation and duration rates. My second case study examines rhetorics of efficiency employed in the documents of, and supporting discourses around, Ohio's voter purge policy which mandates proactive removal of voters from the state's voting rolls. Guided by a commitment to extend beyond critique, I also highlight the work of those resisting reductive rhetorics of efficiency in public policy_individuals and groups such as Fed Is Best and Fair Fight Action. Highlighting and amplifying the embodied narratives of marginalized users, these organizations provide a model for reimagining how we assess the usability of a public policy. Following my public policy case studies, I analyze a pedagogical case study of how an intersectional feminist rhetorical methodology can inform the course outline, and the teaching of usability, in an introductory technical and professional communications course. To conclude the project, I propose future implications of this work.

Through the methodology and case studies, I address the following research questions: 
1. How can an understanding of embodiment that is non-linear, intersectional and extraordinary rather than homogenous and normalized influence the ways in which we read and teach about the effects of public policy on users? ${ }^{5}$

2. How might an intersectional feminist rhetorical framework recognize efficiency as both imprecise and complex? How might explicit acknowledgement of tensions and complexities potentially lead to increased usability over the long-term?

3. In what way can an intersectional feminist rhetorical approach foreground the embodied arguments made by users? What are limitations and constraints of this framework?

4. What can an intersectional feminist rhetorical framework offer pedagogical approaches to technical communication, rhetoric, and/or composition, particularly as we seek to engage students in composing documents that are usable for diverse audiences?

To address these questions, this project builds an intersectional feminist rhetorical methodology that seeks to contribute to social justice scholarship in TPC as well as in rhetoric and composition by: (1) outlining the benefits of reimagining publics as "users" of public policies; (2) articulating the benefits of redirecting policy language, and thus actions, toward long-term goals rather than more easily quantified measurements that require bodies to comply with normative standards and practices; (3) foregrounding extraordinary users; and (4) resituating traditionally marginalized users as valuable contributors to the usability of a policy and the public "good."

\footnotetext{
${ }^{5}$ A term coined by Rosemarie Garland-Thomson (Extraordinary), I describe my understanding of the term "extraordinary" at length later in the chapter.
} 
Before I begin my literature review, I want to briefly describe how I came to this project. ${ }^{6}$ My path to studying public policy was prompted by stories shared by my mother-stories of her time living in Abidjan in the 1970s and witnessing the unchecked corporate greed of infant formula companies such as Nestle who were rapidly infiltrating new "markets" with little regard for the consequences to human life. ${ }^{7}$ After reading Rebecca Dingo's concept of gender mainstreaming and Chikako Takashita's tracking of the intrauterine device, I set out to identify and trace the public policies that had allowed the unethical practices of formula companies to occur in the first place, as well as those that sought to curb the devastating effects of neoliberal pursuits on public bodies. My research subtly shifted as my analysis of revisions to, and iterations of, the original public policy composed in response to the infant formula crisis, revealed a consistent pattern in which efficiencies (savings in cost, labor, overhead, or time for instance) began to supersede the initial goals to hold industries accountable and address humanitarian needs. Invocation of efficiency-focused language and discourse distracted from or sought to excuse inequitable outcomes and the failures of the governments to address large scale issues such as gender inequality, poverty, and lack of adequate healthcare that were, alongside unchecked capitalism and greed, at the heart of the infant and maternal mortality problems.

The purview of my research extended as a wave of restrictive voting policies swept across the U.S. I noticed politicians utilizing rhetorics of efficiency in a fashion similar to that

\footnotetext{
${ }^{6}$ My positionality in relation to this project is expanded on in Chapter II.

${ }^{7}$ Instances of company representatives giving "gifts to health workers and us[ing] saleswomen dressed as 'nurses' to provide donations of formula and advice to mothers" were well documented (J. Brady 529). Publications related the steadily increasing rates of infant mortality, malnutrition, and diarrhea as corporations worked to create demand for their formula products in areas without access to clean water, refrigeration, or proper formula-preparation education (Jeliffe; Muller).
} 
which I had studied in health policies - effectively distracting from or explaining away the discriminatory effects of new voting policies by stressing that the policies increased voting "protections" would benefit all legitimate users and were necessary in order to increase efficiency and ensure accuracy. Politicians and policy makers engaged rhetorics of efficiency to place onus for effective outcomes - a counted vote or a healthy baby and body—onto the backs of individual users rather than with the politicians and administrators charged with designing and overseeing the policy. Moreover, they completely ignored the material realities that made compliance difficult and/or impossible for vulnerable users and groups. In both the health policies and voting policies I examined, short-term, easily quantifiable measurements (clean voter registration rolls or breastfeeding initiation rates) became a replacement for the long-term, inclusive goals (robust voter participation or infant and caretaker health) that had originally elicited public support for the foundational policy mandates. As the connections between these hegemonic systems of policy making and promotion became clear, my focus extended beyond health policy to consider how public policies as technical and professional artifacts are rhetorically framed as responding to and addressing the needs of the public while in fact furthering the interests of those in power via the establishment of top-down oversight and management of public bodies that further the status quo. This project is specifically concerned with the ways in which rhetorics of efficiency are employed to rationalize and defend such management, and how the effects of this structure disproportionately impacts marginalized users of public policies.

Directed by an intersectional feminist rhetorical methodology, my research seeks to understand the implications of rhetorics of efficiency on vulnerable populations and bodies and to home in on how policy makers' conceptualizations of users can expand or contract the 
potential of a policy to work in service of diverse publics. In the case of breastfeeding policies, users are almost universally understood to be heteronormative, cisgender, able-bodied, lactating women caring for a biological child. Voting policies likewise situate all potential voters as homogeneous, normative users - citizens in possession of a home and financial security, an understanding of the English language, and access to transportation. Due to the hegemonic ideologies that enable the construction of these normative user profiles, policy language and directives fail to account for the unique and intersecting hurdles that diverse users face as they attempt to access and utilize the benefits of the policy. The result is public policy that ignores, degrades, or shames those who cannot, or will not, perform according to a policy's dominant, normative directives. Rather than recognizing these shortcomings, policy proponents push forward - concerned not with making a policy more user-centered, but rather with more efficiently managing bodies to perform according to policy dictates.

Seeking to not only critique but also to propose productive ways forward, my research turned next to potential spaces of resistance and models for pushing back against public policies that further marginalize already vulnerable users. Learning from and propelling the social justice work of individuals and organizations resisting and calling attention to reductive rhetorics of efficiency is integral to this project as these individuals and groups show how embodied narratives are essential to the fight for public policies that are usable for all.

\section{Literature Review}

In identifying problematic rhetorics of efficiency in public policy, and foregrounding the work of individuals and organizations who make evident the complex and intersectional lives of those who are impacted by_-but ignored within — these policies, this project contributes to 
existing literature in intersectional feminist rhetorics, disability rhetorics, and technical and professional communication studies that are committed to amplifying marginalized voices and actively working toward a more socially just society. In the following literature review, I begin by briefly contextualizing public policy work in relation to public rhetoric and TPC. Then, I examine how scholars in feminist studies, feminist rhetorics, disability rhetorics, and TPC are engaged in work that foregrounds the need to prioritize marginalized users. To finish, I describe how I see my own project contributing to TPC scholarship that explicitly situates the field as having the potential and responsibility to engage in issues of social justice.

\section{Public Policy as Public Rhetoric}

Recognizing the complexity and rhetorical situatedness of defining "the public," I draw on rhetorical scholarship as it attends to who is (or is not) considered a member of the public in various contexts, and the spaces, actions, and modes through which "ordinary citizens" can influence public policy (Hauser x; Ackerman and Coogan). Rhetoricians have long been concerned with rhetoric's role in public and civic discourse and acknowledged that "[c]haracterizing precisely what "the public" is, and what the "public work" of rhetoric might be, is not so simple" (Bruner 60). The public, then, is not a stable concept but rather one that is flexible, contextual, and changing (Wells xi; Reidner and Mahoney). Identifying a public can be understood through assemblage, through the "collection of organizations, institutions, or individuals," associations, networks, connections, or via collaborative rhetorical work (Grabill, “On Being” 196-97; Ackerman). In the context of public policy, policy makers define a public by establishing parameters and invoking language within the policy itself that undergird who is included or excluded as members of the public. Understanding how publics are defined or 
shaped within each policy helps to reveal who stands to benefit, how, and in what way; in turn, it identifies who is to be excluded from potential benefits and the context for that exclusion. Understanding which public(s) are addressed is essential to analyzing the material effects of public policy, and demanding alternative definitions can be a powerful rhetorical tool to push back against exclusionary rhetorics.

Identifying how "the public" is constructed is also necessary to understand "the public good" toward which the policy is supposedly working. Arguments concerning "the public good" are foundational to proponents furtherance of a policy as both necessary and desirable. But just as the public cannot be reduced to a singular, stable construct, the public good is dependent on what publics are being invoked and how the values, desires, and needs of those various publics align or diverge. ${ }^{8}$ For instance, Candice Rai's study of Chicago's Wilson Yards project shows how various members of a single geographic neighborhood have very different visions for "the good" that a single policy should be working toward. Her work reminds us that what is "good" for one is not necessarily "good" for another and that public policies—via strategies such as rhetorics of efficiency—can undermine or mask these tensions.

Policies are rhetorical artifacts that have material impacts on public bodies. Thus, rhetorical approaches to public policy must attend to power dynamics and the ways in which public policies are employed to exert control over marginalized and vulnerable populations (Dingo, Networking; Ross; Ross and Solinger; LaDuke; Takeshita). And though policies themselves are often fairly rigid, the terms and concepts cited within an individual policy—so often assumed to be objective or stable — can "shift and change depending upon the contexts in

\footnotetext{
${ }^{8}$ And even within a unified group, intersectional identities and needs further complicate the notion of a singular "good."
} 
which policy makers and development experts use them" (Dingo 7-8). These subtle but powerful mutations of terms can result in oppressive practices that are veiled as contributions to the public good (Dingo 31). Thus, tracing or mapping policies is important to identify the political structures, systems of power, and cultural norms that inform a policy.

\section{Public Policy in Technical and Professional Communication}

Technical and professional communication scholars have taken up public policy as an area of study understood as rhetorical, discursive, and often highly technical. In 2000, and again in 2008, Technical Communication Quarterly published issues dedicated to linking TPC with public policy (Discourse; Science). Arguing that TPC scholars are ideally "suited to influence policy matters" and have an opportunity and obligation to use research and pedagogy "to make a difference in the way our communities deal with the complexities of . . public policy," the authors clearly situate public policy work in the realm of TPC (Rude, "Guest" 5). Integral to this project is TPC research that demonstrates the use of technical and/or legal language to veil discriminatory or inhumane practices forwarded through public policies, and the role of current technical and professional communicators to push back against these rhetorical practices (Williams, From Black; Katz; Jones and Williams; Hannah). Recognizing that the material effects of public policy are not always made clear to the public, the discipline of TPC is particularly well suited to make this information more accessible through our scholarship, pedagogy, and practice. Mundane technical documents such as regulatory writing, memos, forms, and reports give shape to, and outline oversight of, public policy but are often difficult to comprehend. Thus, technical and professional scholars have an opportunity to engage with 
seemingly mundane documents to further scholarship aimed at uncovering how public policy is both shaped by those in power and taken up by various public bodies (Williams, From Black).

Social justice minded TPC research illustrates how technical and professional documents - imbued with presumptions of objectivity — are allowed to circulate without much critical analysis of the values being promoted within and through these documents. Analyzing policy documents drafted by and for governments (Frost, "Apparent Feminism as a Methodology"; Katz; Williams, From Black; Richardson), healthcare entities (Gouge; Segal; Frost and Haas; Koerber, Breast or Bottle), and educational institutions (Smyser-Fauble), critical TPC scholarship uncovers societies' fealty to science, technology, efficiency, and professional discourse as value-neutral thus allowing for a system in which technical and professional discourse can distract from the inequitable material effects of policies and practices. Via technical language, policy makers can avoid or downplay public scrutiny—masking oppressive policies in inaccessible or unclear language and maintaining their roles as neutral arbiters of the public good. And despite TPC's historical complicity in furthering impressions of technical and professional information as objective and neutral, scholars are increasingly highlighting technical and professional discourse "as always rhetorical and involved with potentially conflicting agendas and interests" (Ornatowski 91). ${ }^{9}$ TPC research is increasingly foregrounding questions of: Good for whom? And, good according to what benchmarks and whose set of values? TPC analysis of public policy must continue to acknowledge these historical tensions and explicitly identify who stands to benefit from a particular policy and who is excluded, disenfranchised, and/or oppressed. Embracing an understanding of TPC that is not neat, neutral, and objective but

\footnotetext{
${ }^{9}$ As discussed more fully at the end of this chapter, however, there is still much work to be done on this issue (see Jones, Moore and Walton, 213).
} 
rather rhetorical, complex, and messy, I now turn to the work of TPC scholars who highlight the centrality of users to any understanding of effective, "good" technical and professional work (Jones, Moore, and Walton 223).

An intersectional feminist rhetorical methodology values listening to, engaging with, and learning from users in order to make policies more usable (thus, "good") for all users. TPC scholars whose engagement in community and public works foreground the "values, emotions, and concerns of all involved parties" and particularly "the input of the less powerful (e.g., citizens, particularly those typically underrepresented)" is essential to my commitment to TPC work that makes our field and society increasingly inclusive by foregrounding the voices and experiences of those traditionally marginalized within and by TPC research (Grabill and Simmons 414). Advocating for an active role for "non expert" citizens in local decision making (Grabill and Simmons; Simmons and Grabill), learning from the interventionary tactics of marginalized community groups (Bates), and educating for "civic-minded and rhetorical approach[es] to professional and technical communication courses and program design" (Eble and Gaillet), this project contributes to TPC work that argues for inclusive, responsive public policy.

Thus, I call on TPC research into civic engagement and public works to foreground the importance that public policies be usable ${ }^{10}$ for all members of the public, and that this goal for usability is only possible when users are understood as important contributors. Rather than passive recipients of expert knowledge, then, everyday citizens are recognized as essential sources for understanding the diverse material impacts of public policies. For instance, Grabill

\footnotetext{
${ }^{10}$ I examine the concept of usability in TPC and my own usage of this term later in the chapter.
} 
and Simmons's focus on power differentials and varied "truths" (423), critique of decontextualized, quantifiable measurements (419), and emphasis on how technical communicators can engage in responsible research practices that leverage user/citizen knowledge, all inform my exigency for critiquing rhetorics of efficiency and are also essential to my understanding that TPC scholars must draw on, and learn from, the experiences and voices of marginalized users in order to propose more inclusive ways forward. This project reflects my understanding of the work of TPC as that which seeks to "critique, intervene in, and create communicative practices and texts that positively impact the mediated experiences of individuals," and my belief that TPC practitioners committed to such work have both an opportunity and a responsibility to engage with public policies as technical and professional artifacts that can either further or hinder progress toward an increasingly socially just society (Jones 344).

\section{Feminist Scholarship: Embodiment, Intersectionality, and Local Knowledges}

Feminist scholarship focused on embodiment, intersectionality, and the centering of marginalized voices and bodies is vast. The overview I provide here will be necessarily brief, highlighting within the body of feminist research that which most aligns with my project goals to prioritize multiply marginalized users and layered, complex systems of oppression. Theories of embodiment are essential to a problematizing rhetorics of efficiency as embodiment recognizes discourse as always in relation to the bodies and experiences of those who stand to be impacted, and draws attention to systems in which certain ways of knowing and being are privileged over others (Johnson et al.). Unlike traditional notions of technical and professional writing as neutral and objective, feminist theories of embodiment make evident that all communication and 
experience is "contextual, enmeshed within the specifics of place, time, physiology, and culture" (Hayles 196). Embodiment calls on technical and professional practitioners to "notice things that make a difference to one's lived experiences" in order that our discourse and work is responsive to and usable for our audiences (Phillips 56). Thus, when public policies are written in a way that ignores embodiment, users become disembodied — units to be managed rather than human lives that stand to be impacted. Rather than policies shaped by diverse users' complex needs and experiences, policies that ignore user embodiment engage in disembodied rhetorics that "bolster the epistemic authority of the currently dominant groups" and "discredit the observations and claims of subordinate groups" (Jaggar 385).

Women of color theories of embodiment are particularly important as they reveal how attempts by marginalized groups to call attention to the injustices enacted on their bodies are undermined by those in power (Anzaldúa; hooks; Hill-Collins; Mohanty; LaDuke). In the case of public policy, the disproportionate burden of certain efficiencies on women of color, indigenous people, and other multiply marginalized communities are ignored or dismissed by policy makers as disconnected, inconsequential, or unreasonable. This disconnect allows public policy makers to separate themselves from the negative impacts of the policy. ${ }^{11}$ Women of color feminists show how those in power call upon disembodied rhetorics to shape and justify educational (hooks); governmental (Williams, From Black); professional (Hill-Collins; Jones, "Rhetorical”); environmental (LaDuke); and academic (Mohanty) policies and practices that fail to account for

\footnotetext{
${ }^{11}$ Indigenous scholar Malea Powell, for example, describes how Euroamerican colonizers disembodied, or allowed themselves to "un-see" indigenous bodies. This separation from action and human consequences "gave (and still gives) Euroamericans a critical distance from materiality and responsibility, a displacement that is culturally valued and marked as "objectivity" (Powell qtd in Cushman 11).
} 
or address the embodied realities of marginalized users. Such rhetorics allow for the ill effects of these policies to be framed as the result of unruly user-practice rather than the result of inherently flawed policies. Users who oppose the discriminatory impacts of the policy are presented as irrational and their grievances touted as further evidence of the need for oversight and management by the dominant group. Thus, rather than examining how policies can better respond to the embodied realties of diverse users, those in power too often disavow the validity of what they consider to be non-normative experiences. Theories of embodiment are essential to disrupting this cycle.

Feminisms' embrace of complexity and ambiguity, of "location and positionality...as multiple and with varying degrees of mobility," are foundational to countering reductive rhetorics of efficiency that homogenize user experiences (Alcoff 489). For instance, Gloria Anzaldúa's la mestiza and Sandoval's concept of the in-between space highlight the ways in which complex cultural historical contexts are inseparable from the ways in which bodies experience and are read in modern contexts. These theories are important for understanding how diverse users might experience and take up the mandates outlined within public policies. Of particular significance for this project is the Black feminist theory of intersectionality as it illustrates how marginalized users' experiences inherently elude neat categorization.

Emerging from the labor of the Black feminist activists of the civil rights era, intersectionality became widely recognized as an identifiable term following Kimberlé Crenshaw's 1991 Stanford Law Review article in which she articulates intersectionality "to denote the various ways in which race and gender interact to shape the multiple dimensions of Black women's employment experiences" (Hill-Collins and Bilge; Crenshaw, "Mapping" 1244). Intersectionality, she explains, seeks to "disrupt the tendencies to see race and gender as 
exclusive or separable" and posits that "the concept can and should be expanded by factoring in issues such as class, sexual orientation, age, and color" (1244). Thus, intersectionality serves as a theoretical lens to prompt practitioners to recognize multiple, overlapping oppressions. Moreover, it outlines how a failure to account for intersectionality is systemic, shaping our policies in a way that disproportionately impacts those whose intersecting embodiments make them particularly and uniquely vulnerable: "[T]he failure to embrace the complexities of compoundedness is not simply a matter of political will, but is also due to the influence of a way of thinking about discrimination which structures politics so that struggles are categorized as singular issues. This structure imports a descriptive and normative view of society that reinforces the status quo" (Crenshaw, "Demarginalizing" 31). Categorizing and norming identities and oppressions as isolated entities dissuades and/or distracts from meaningful policy initiatives to address the struggles of those whose intersectional identities cannot be reduced to a singular marker. $^{12}$

Engaging feminist theories of embodiment and intersectionality, an intersectional feminist rhetorical methodology is committed to "bring[ing] the 'margins' to the 'center,' [and to] legitimate and nurture ... marginalized ways of knowing [and] speaking" (Bordo 41). Understanding the recognition of user embodiment as integral to the production, circulation, and effects of discourse, this approach rejects notions of neutrality, objectivity, and efficiency that undermine the potential of those perceived as outside of the dominant norm to contribute to

\footnotetext{
${ }^{12}$ Demonstrating that intersectionality also has transnational concerns and implications, transnational feminist scholar Chandra Mohanty explicitly counters the homogenization of women's' experience, noting that "[i]t is only by understanding the contradictions inherent in women's location within various structures that effective political action and challenges can be devised" (Mohanty, “Transnational" 971; "Under Western” 346).
} 
knowledge work. Foregrounding marginalized users intersectional embodied experiences as integral the creation of truly usable public policy, I build on the work of feminist scholars who

prioritize the recognition of gender, race, ethnicity, ablebodiedness, location, economics, cultural beliefs, political standing, and sexuality as integral to understanding the diversity of users' experiences and oppressions. Such an approach highlights not only how vulnerable populations are undermined by those in power, but also the ways in which feminist theories have been, and continue to be, employed as a means for effectively pushing back against hegemonic institutions that universalize the experience of women and other marginalized communities.

\section{Feminist Scholarship in Rhetoric and TPC}

\section{Feminist Rhetorical Scholarship}

Feminist rhetorics scholars have taken up theories of embodiment and intersectionality to show how "[a]rguments are made by and through bodies that are located in systems of power" and to argue that an attentiveness to embodiment "results in a more complex picture of the argumentative terrain within which these bodies are embedded" (Barr 210). Such work informs my commitment to intervene in "practices that sustain asymmetrical relations of power between differentially embodied human beings" and to make evident that "everyone's experiences are unique and, therefore, we must desist from framing some experiences as standard and some as anomalous" (Booher and Jung 5; Cedillo, n.p.). I consider public policies and the discourses that further them to be an important site for such intervention.

Feminist rhetorical attention to the network of documents and discourses that often inform a single rhetorical act make evident that the rhetorical significance of public policy is much larger than any single artifact. Understanding an individual public policy as part of a much 
larger web, my research considers how rhetorics of efficiency are employed in policies, supporting documents, and dominant discourses to further a narrative in which "development always leads to growth, progress, one-way assistance, and empowerment" (Dingo and Scott 3). Feminist rhetorical work is essential to scholarship invested in "demonstrating the connection between what is said or written and the material effects" and "inventing practices through which elements might come to be assembled otherwise" (Dingo and Scott 3; Booher and Jung 5). Analyzing rhetorics of efficiency in public policy, then, must go beyond the language of the document in order to trace how promises of efficiency, ease, or growth materialize; what human costs are required in order to achieve these gains; and how both the costs and gains are distributed across different sectors of the public. In order to problematize positions of neutrality, to "unravel that which appears to be common sense," those engaged with analysis of public policy must trace the history and circulation of the rhetorics that inform a policy to uncover the "power than can be found in the contexts behind these rhetorics" (Dingo and Scott 4, 2). Finally, revealing how rhetorical engineering can engage widely lauded ideas (such as "empowering women"), feminist rhetorical scholarship is integral to an intersectional feminist rhetorical commitment to problematizing rhetorics of efficiency and to "resituating...taken-for-granted term[s]" that further public acceptance of oppressive policies and/or promote the continuation of the status quo (Dingo 31).

\section{Feminist Rhetorical Scholarship in TPC}

Feminist TPC scholarship is essential to disrupting dominant notions of objectivity, neutrality and efficiency in technical and professional discourse and is foundational to TPC work committed to the foregrounding of marginalized users. Feminist TPC research uncovers 
historical and contemporary examples of the normative, hegemonic, gendered assumptions about who uses professional and technical artifact, how these are used and why, and the knowledges that might help researchers and practitioners improve upon their research and designs. In the case of public policy, feminist TPC scholars have shown how normative assumptions become embedded in the policies and guidelines of medical, academic, and private sector institutions that oversee the use of these technologies and the employment, medical care, or legal rights of women and other marginalized users (Brady; Jack; Frost; Frost and Haas; Koerber, "Toward").

Feminist TPC work is important in recognizing the complicity of technical and professional communication and research in promoting problematic notions of objectivity, neutrality, and efficiency that undermine the lived experiences and needs of marginalized communities. In her 1991 article "Feminist Theory and Redefinition of Technical Communication," Mary Lay describes the historical framing of TPC as "initially [understood] as the objective transfer of information" which sought out and forwarded only the "cleanest, hardest, most scientific" thinking and practices $(348 ; 358)$. Countering these historical notions of TPC, Lay explains that feminist TPC scholarship finds strength and potential in the very aspects of research that previous practitioners feared revealed weakness: “(1) celebration of difference, (2) theory activating social change, (3) acknowledgement of scholars' backgrounds and values, (4) inclusion of women's experiences, (5) study of gaps and silences in traditional scholarship, and (6) new sources of knowledge" (350). Feminist TPC scholarship disrupts the myth of technical and professional work as somehow inherently objective and thus expands notions of who is capable of contributing knowledge; what is considered to be a credible theory, methodology, or technological artifact; and the potential of the field to engage with diverse users (Durack; Gurak and Bayer; Flynn). In the context of public policy, feminist TPC makes apparent 
that all discourse and artifacts — including technical and professional ones — are inescapably imbued with the values and biases of their creators (Haas, "Race"; Frost).

Feminist TPC scholarship is essential to understanding rhetorics of efficiency in public policy which often cite users access to certain technologies (for instance, breast pumps or electronic voting machines) to undermine or dismiss the concerns of marginalized users (such as working women or voters of color). Making apparent how historical and contemporary technologies and discourses were, and continue to be, designed for and cater to men (Brady, "Interrupting," "Tinkering”; Hallenbeck "User"; Moeller and Frost; Petersen; Teston; Jack; Reilly), feminist TPC research illustrates that technical and professional artifacts are "always ideological [and] can be used to both oppressive and empowering ends" (Takayoshi 132). Tracing technologies and the discourses that surround them reveals that for marginalized users, "new technologies are often touted as liberating but seldom live up to their presumed liberating potential” (Koerber, "Toward a Feminist” 60). By engaging feminist scholarship in TPC, this project joins in the work of pushing back against practices and policies that discredit or exclude the needs, contributions, and work of marginalized groups by making apparent the disproportionate material impacts of technical and professional artifacts and the guidelines for their use.

Pushing feminist TPC work to extend beyond gender as the sole consideration of power disparity, TPC scholars employing critical race rhetorics and decolonial rhetorics inform an intersectional approach as they highlight the multiple, and often overlapping identities and experiences that mark practitioners and users for exclusion or repression. This work extends feminist TPC scholarship dedicated to disrupting power dynamics and "opens up more spaces and places to talk about a range of experiences, bodies, and communities" (Frost and Haas 101). 
As I engage in critiquing public policy and teaching for usability, decolonial theories make my work more intersectional as they prompt an understanding of "rhetorical practices and technologies as fluid and dynamic in accordance to cultural context" rather than adhering to practices that seek to standardize and discipline bodies deemed non-normative according to hegemonic Western standards (Del Hierro 166). Decolonial TPC work, then, is crucially important to intersectional feminist work as it "demonstrates how race and place... are key to what can be imagined, what gets imagined, and who imagines in our profession" (Haas, "Race" 279). Decolonial frameworks push feminist TPC research and pedagogy to more fully address how cultural histories inform who and what is legitimized within and through TPC scholarship and discourse, reminds practitioners to "be critical of our own approaches, question our insider posture..., and be humble in our contacts with participants," and makes evident the exigency for intersectional work in the field of TPC (Agboka 299; Haas, "Intersectionality").

Recognizing that public policy impacts those multiply marginalized, I engage TPC scholars who recognize that marginalization via technical and professional discourse "is never just [about] gender, just race/ethnicity, just class, just ability, just geography but rather the intersections of all of these, which means that including and listening to many bodies, voices, and perspectives is crucial" (Shivers-McNair and San Diego 108). For example, Williams and Pimentel's special issue in the Journal of Business and Technical Communication and Bridgford, Salvo, and Williamson's issue of Programmatic argue that increased attention to race and ethnicity is needed in TPC scholarship, practices and pedagogy. ${ }^{13}$ And though numerous scholars are doing the important work of examining the responsibility of and potential for TPC scholars

${ }^{13}$ A call that the editors note was made by Cynthia Selfe eight years prior (2). 
and activists to counter historically discriminatory practices (Haas, "Race"; Jones; Edwards; Williams, "Reimagining), there are still "[r]elatively few TPC scholars [who] explicitly mention race and ethnicity" in their work (Jones, Moore, and Walton 5). Intersectional feminism, then, is concerned with gender but "remind[s] us that people who occupy multiple positions of disadvantage...experience compounded powerlessness" (Walton, Moore, and Jones 24). An intersectional feminist rhetorical framing of usability acknowledges this issue and makes explicit that a user's experience of a public policy is informed by gender, but also by the layered oppressions users experience based on their race, ethnicity, sexuality, and ability among other factors.

This project contributes to feminist TPC scholarship aimed at moving the discipline beyond traditional notions of "a field that advocates for the user [toward] a new and exciting level by focusing on historically marginalized groups and issues related to race, class, gender, and sexuality because these identity factors are not mutually exclusive" (Williams, "A Survey" 87-88). This project is committed to examining public policies as technical and professional artifacts that have material impacts on all users, but an intersectional feminist rhetorical methodology specifically prioritizes the feedback of, and usability for, marginalized users. In this way, I hope to contribute to TPC scholarship dedicated to moving the field beyond traditional notions of users in order to foreground the need for public policies to reflect the concerns and perspectives of vulnerable and marginalized populations whose intersectional identities and experiences have historically been (and continue to be) ignored, denied, or undermined by those in power. 


\section{Disability Rhetoric and Disability Studies}

Complimenting and extending feminist work, disability rhetorics recognizes that "rhetoric is always embodied" (Dolmage Disability 89) and that "perspectives on embodiment decenter the logic of equality, of a mean, ideal or normal embodiment" (117). Disability theories and perspective are essential to work aimed at disrupting socially constructed identity categories and discourses that marginalize those bodies and embodiments deemed to be "other" than the normative standard constructed through dominant culture. Disability scholars argue for the centrality of embodiment and uncover the long history of discomfort and distrust of bodies that diverge from the white, male, able-bodied norm; their work shows how bodies that reject or diverge from the established dominant norm are perceived as particularly weak, vulnerable, or untrustworthy within dominant discourse. (Dolmage, Disability; Dolmage, "Metis"; GarlandThomson). By constructing differently abled bodies as untrustworthy, unreliable, and/or nonnormative, those in power point to "deviant" physical bodies as the source of the unjust treatment that marginalized individuals are afforded. Rejecting rhetorics that frame deviation from a norm (such as those related to able-bodiedness) as inherently negative, disability rhetorics scholars understand bodily and embodied difference as rhetorically generative (Jung; Garland-Thomson, "Integrating Disability"; Selznick; Dolmage; Dolmage and Lewicki-Wilson; Snyder, Brueggemann, and Garland-Thomson) and embrace "ambiguity, in its indeterminate boundaries" (Brueggemann 319). Work in disability rhetoric and disability studies is integral to this project as it "is about integration in the widest sense": Rather than deviant, "non-normative" bodies are situated as rhetorically generative, extraordinary, "dynamic, relational, and emergent" (Kerschbaum 57; Snyder, Brueggemann and Garland-Thomson; Dolmage). 
An intersectional feminist rhetorical methodology engages the concept of "extraordinary" in order to foreground users marginalized by a policy's normative constructs: Measures of usability do not begin and end with "ordinary" users as imagined within the policy or artifact, but rather extend — and indeed begin — with "extraordinary" users. My use of the term extraordinary is contextual and based on Rosemarie Garland-Thomson's articulation of the concept as one used to "denaturalize the cultural encoding" of certain bodies and identities that "support the privileged norm" (Extraordinary 5). Although Garland-Thomson's use of this term centers on social constructs of disability, her framing of extraordinary extends an intersectional feminist approach as it exposes how "the ways that bodies interact with the socially engineered environment and conform to social expectations determine the varying degrees of disability or able-bodiedness, of extra-ordinariness or ordinariness" (Extraordinary 6, 7). Thus, in the case of public policies, the policy language constructs notions of extraordinary and ordinary: My use of extraordinary does not suggest an "otherness" of any bodies or identity: rather it calls attention to the bodies and experiences that are framed as non-normative via reductive, normative assumptions about "ordinary" users. Rhetorical constructs of "ordinary" or "normal" users are called upon to justify the exclusion or marginalization of users who do not reflect or conform to the dominant social expectations reflected in and through the policy. Recognizing that the default, "ordinary" user in the U.S. is assumed to be a white, heteronormative, affluent, ablebodied male, this approach attends to the nuances of how "ordinary" users are constructed through each individual policy. Extraordinary, then, is explicitly intended as a response to the normate positions written into a policy.

The idea of the normate position in disability studies is foundational to challenging rhetorics of efficiency. The normate: 
designates the unexamined and privileged subject position of the supposedly (or temporarily) able-bodied individual. As with concepts of male privilege, of whiteness, or of heteronormativity, the individual assuming the normate position occupies a supposedly preordained, unproblematic, transparent, and unexamined centrality. A normate culture, then, continuously reinscribes the centrality, naturality, neutrality, and unquestionability of this normate position (Dolmage and Lewiecki-Wilson 24).

The concept of the normate prompts my research to be attentive to the ways in which assumptions of normalcy are integrated into public policies and how these assumptions work on bodies and shape parameters for measuring the usability of a policy. When a user is understood as a universalized, homogenous being, then a "usable" policy need only serve the needs of those bodies that align with these narrow definitions. Examining the normate position is integral for identifying how policy discourse seeks to justify the exclusion of marginalized individualsattributing inequities to individual deviance rather than unjust policy. Identification of the normate position advances work committed to making public policies more usable for marginalized audiences.

Increased attention to disability rhetorics and theories is essential to TPC work committed to disrupting reductive notions of objectivity and necessary for tracing the material impacts that unchecked rhetorics of neutrality have on marginalized users (Palmeri; Smyser-Fauble; Yergeau; Knight; Kerschbaum). Disability scholarship can help reimagine the ways in which "technical communication participates in the discursive processes of normalization: legitimating and subjugating knowledges, examining and controlling workplace practices, forming subjectivity, and marking bodies as normal or deviant" (Palmeri 49). Making apparent how normative 
frameworks and obsessions with efficiency, modernity, and rationality have served as justification to ignore, oppress, or eliminate those bodies positioned as in conflict with these goals, disability scholars make evident how constructs of the norm "grant power, privilege, and status" to those bodies framed as within the bounds the norm (Garland-Thomson, "Integrating" 4; Dolmage; Selznick) and show how normative frameworks allow for terms - terms such as objective, efficient, or neutral — to go unquestioned and escape examination (Jung; Duffy and Yergeau).

Disability rhetoric and theories also further my understanding of usability as they situate "choice" as inseparable from embodied individuals and societal contexts from which they emerge. Rhetorics of efficiency framed through choice hide ideologies that privilege and oppress - demanding that the "atypical" find a way to fit in and allowing "beliefs concerning what is typical" to remain unchallenged, and thus unchanged (Jung 163). In this context, the user is held responsible for the usability of the policy, as inefficiencies and failures are attributed to an individual's choice rather than a policy that never adequately considered them in the first place. Informed by this caution, disability studies make apparent the exigency for technical communicators to problematize and examine taken-for-granted terms and systems that shape public policies. For instance, Julie Jung's analysis of "reasonable" accommodations shows how institutions avoid enacting meaningful change by creating policies that place onus for accommodation, or the usability of the spaces and services of the university, onto the individual student rather than the administrators and faculty charged with creating an inclusive university environment ("Textual”).

By focusing on individual will and action, problematic rhetorics of "choice" shift responsibility away from those occupying positions of power and onto the individual user. 
Analyzing disability and reproductive politics, Rickie Solinger shows that the "choices" made available to individuals are "shaped by laws and policies" that "express a high valuation of some kinds of bodies and devaluation of others" (Reproductive Politics 2; 130). Within the realm of public policy, not all bodies have equal access to the same "choices." Solinger's articulation of the shift from rights to choice is essential to both case studies in this project as it exposes how "rights" have historically indicated the "privileges or benefits to which a person is justly entitled and that can be exercised without access to any special resources such as money [while] choice has come to be intimately connected to the possession of resources" (156-7). Ensuring rights, then, is widely accepted as both a societal obligation and a fundamental responsibility of an institutional entity. By shifting to rhetorics of choice, however, politicians and policy makers rhetorically free themselves from the responsibility to ensure that all users have access to and can draw benefit from the guarantees outlined within a public policy.

Finally, disability rhetoric and theories are essential to recognizing potential ways forward, to engaging in critique not as an end in itself, but rather as a starting point for proposing how things might be made otherwise. Duffy and Yergeau describe this process:

$[\mathrm{R}]$ hetoric functions as a powerfully shaping instrument for creating conceptions of identity and positioning individuals relative to established social and economic hierarchies. A function of the rhetorical scholar is to identify such powerfully shaping instruments and their effects upon individuals, including disabled individuals. Yet this perspective on rhetoric is incomplete if it does not acknowledge the capacity of individuals to respond to and re-imagine such shaping rhetorics" (n.p.). 
Disability rhetoric informs an intersectional feminist rhetorical approach to identifying and critiquing normalizing rhetorics of efficiency and simultaneously propels the potential of this methodology to further issues of social justice by reimagining how public policies can be made usable for all. In the following section, I situate an intersectional feminist rhetorical project as explicitly contributing to technical and professional communication work that foregrounds the potential of TPC scholarship to enact social justice.

\section{History of and Exigency for Social Justice Work in TPC}

Current social justice work in TPC builds on the work of scholars who drew attention to the cultural and material impacts of TPC (Scott and Longo; Scott, Long, and Wills) and the social justice-minded TPC predecessors such as Gerald Savage and Cynthia Selfe who laid a foundation for TPC as a field that has the potential and willingness to engage with issues of social justice. As is evidenced by the growing body of scholarship explicitly centered on the role of TPC in relation to social justice (Haas and Eble; Walton, Moore and Jones; Agboka and Matveeva; among others), the TPC field has experienced a social justice turn "toward a collective disciplinary redressing of social injustice" (Haas and Eble 5).

Recent TPC scholarship, however, makes evident the urgency for research and pedagogy that explicitly targets injustices and inequities created or serviced by technical communication work. For example, the social justice implications of technical and professional discourses are made evident by apparent feminist critiques that understand efficiency as dependent upon the inclusion of diverse audience (Frost, “Apparent Feminism and Risk Communication”); disability studies research that highlights vulnerable populations as often absent or marginalized in usability discourse and accommodation documents (Smyser-Fauble; Palmeri); and medical 
rhetorics that examine how narratives of normalcy become "authorized and solidified" in medical documents (Moeller 216; Segal; Gouge). Yet despite these examples of progress, "[r]ecent challenges to racial, class, gender, disability and economic issues raise significant concerns and provide excellent opportunities for our field to engage, forge relationships, and build new relationship with communities" (Agboka and Matveeva xxviii). An intersectional feminist rhetorical project reflects my own desire to enter into and contribute to TPC communities and coalitions committed to identifying and redressing inequities. This methodology does so by explicitly identifying and foregrounding users whose intersectional experiences and persons are ignored and/or oppressed through policies' rhetorics of efficiency, and by learning from and propelling the rhetorical agency of marginalized users. Recognizing the usability of public policy as a social justice issue, my framing and teaching of usability through an intersectional feminist rhetorical lens endeavors to contribute to the enactment of social justice as it "works to transform the social and cultural structures that have permitted injustices to exist, that have in fact made injustice invisible, or worse, have denied its existence" (Savage $\mathrm{x})$. An intersectional feminist rhetorical understanding of usability directly uncovers rhetorics of efficiency that shape, yet subtly seek to hide, inequitable and/or oppressive acts. As a pedagogical practice, this methodological perspective explicitly asks teacher-scholars and students to consider how their own understandings of users and usability can either contribute to or detract from a more socially just future.

\section{Usability as a Practice of Social Justice}

An intersectional feminist rhetorical methodology that challenges rhetorics of efficiency and foregrounds vulnerable users directs me toward a reframing of usability that focuses on 
social justice goals and those users situated as extraordinary according to policy dictates.

Usability in technical communication traditionally functioned as a process to help users "realize their goals with the greatest possible efficiency" (Skeen 95; Dumas and Redish). Focusing on measures such as speed, error recovery, and task completion and often occurring late-stage or post production, usability testing too often relies on a homogenized user profile and focuses attention on the product and marketing rather than ways to improve the experience for the user and expand notions of potential users (Salvo 273; Sun). Similarly, clear hierarchies are often in place: the users framed as non-experts to be observed, and designers and testers as experts to interpret, respond, and revise. For instance, Michael Salvo notes how producers have used "[u]sability testing...not to create a better technological product, but to market the same faulty product" (278). Similarly, policy makers and administrators may employ usability testing to garner information on how to better "sell" the policy to the public rather than improve user experience. Thus, it is essential to understand and frame user knowledge as valuable, and to use this information in a way that is responsive to (rather than manipulative of) users' input.

Even when usability is attentive to user experience, it often fails to consider how gender, race, ethnicity, ablebodiedness, and other factors - as well as their intersections - might inform how users respond to, and take up, an artifact. This failure "can create many negative consequences, such as disregarding some types of users, inhibiting others from becoming users, disadvantaging nondominant users, and blending what variety does exist into universals, which decrease the resulting usability" (Bowie 135-36). Universalizing user experience, and privileging certain users, establishes a normate who becomes the only one imagined, and thus designed for. In response to this tendency, an intersectional feminist rhetorical lens directs attention to the 
ways in which "actual user[s] can be ignored for users with power" and foregrounds those currently ignored or discredited (Bowie 139).

Even when those in positions of power have good intentions, designs often fail to work for marginalized users as they are left out of the design process. Emma Rose's research on the usability of transportation in Seattle is one such example. Rose describes how local officials, charged with shrinking the public transport budget, sought to reduce transportation costs while still supporting the needs of Seattle's unhoused population. The revised policy, utilizing technologies and targeted routes to keep buses "usable" for unhoused riders, focused almost exclusively on cost and routes as the central concerns. Conversely, user narratives reveal a relationship between homeless individuals and the transportation system that is much more complex than the efficient transfer from point A to B. For instance, riders used the bus as a space of refuge and escape, where they could be "just another rider" rather than a marked body (436). Unaware of this use, policy makers designated certain buses for free rides_once again marking certain users as separate from the unmarked, paying public. Policy makers did consider marginalized users but failed to engage them as important sources of knowledge. The result was a policy that did not reflect the values of the users.

By acknowledging how policy makers can (even when well-intended) deter or silence the experiences and responses of marginalized individuals and groups from being recognized and understood, technical communicators must better situate themselves to consider usability approaches that guarantee that vulnerable users are not only acknowledged but also included in the design, revision, and usability of public policies (Bates; Simmons and Grabill). The goal is that users should help shape what "usability" means in order that policies can extend beyond functionality, access, and efficiency to actually reflect and respond to the values and needs of 
marginalized populations. Newer approaches such as participatory design, productive usability, and user-centered design, expand the purpose and process of measuring usability, particularly by disrupting the traditional expert/non-expert dichotomy and bringing users into the design process. In participatory design, technical communicators and users work together to identify goals and problems, construct data, and respond to usability issues (Spinuzzi; Grabill, "Shaping"). Productive usability supports "technical literacy, productive inquiry, collaboration, and a multidimensional perspective" that can make technical information more usable and useful for the public (Simmons and Zoetewey 251). User-centered design is similarly focused on "inviting users to be active participants and co-decision makers in an iterative design process" (R. Johnson 32).

Based on the work of these and numerous other technical communication, rhetoric, and composition scholars (R. Johnson; Scott, "Practice"; Shivers-McNair, et al., "User-Centered"; Schneider; Sun; Miller-Cochran and Rodrigo), this project promotes usability practices that engage users as active participants, strives to empower users, is collaborative rather than hierarchical, and is an iterative process. Alongside these goals, and of particular investment for this project, is the need for policies to better engage and serve users whose complex, intersectional bodies situate them as disenfranchised or oppressed users. An intersectional feminist rhetorical approach to usability; (1) foregrounds the limited scope of bodies and embodiments currently envisioned as users of technical and professional discourse, ${ }^{14}$ and (2) aims to contribute to the growing call for user- and human-centered design approaches that foreground bodies historically marginalized or ignored by traditional notions of usability and

\footnotetext{
${ }^{14}$ I use discourse here as described by Meloncon and Frost as it includes "oral, written, visual, and technological" artifacts, one of which is regulatory documents ("Charting" 7).
} 
efficiency (Rose, et al.). Put another way, an intersectional feminist rhetorical approach to usability understands marginalized, intersectional identities and experiences as essential to the creation of more usable documents and discourse, and responds to current public policies that fail to account for users whose bodies and experiences are outside of what policy makers and administrators deem "normal."

An intersectional feminist rhetorical methodology aims to contribute to work dedicated to making technical and professional discourse increasingly usable for those on the margins. Presenting theoretical lenses for usability such as queering consent, multilingual user experience, and women of color in design, contributors to "Social Justice in UX: Centering Marginalized Users" from the 2018 Proceedings of The 36th ACM International Conference on the Design of Communication, posit theoretical approaches to usability that center "overlooked, vulnerable, or marginalized audiences [as this] leads to different design considerations, methods, practices and resulting designs" (Rose, et al.). Contributors argue that "humans should be the focus of design and decision making when creating technology and information products. However, when certain types of people are consistently centered, others are intentionally or unintentionally pushed to the margins or left out altogether" (n.p.). An intersectional feminist rhetorical methodology contributes to these social justice goals by reframing usability to prioritize embodied realities that influence the context in (and purposes for) which an individual engages with an artifact; it works toward policies and documents that are usable for all bodies, but particularly those currently framed as extraordinary and thus ignored or burdened by a policy or discourse. 


\section{Looking Ahead}

I have chosen to focus specifically on scholarship that lays the foundation for the methodology I describe in Chapter II and that drive the analysis of my case studies and pedagogy chapters later in this project. The rhetoric, composition and technical communication scholars discussed above interrogate normative frameworks and stress the importance of TPC teacherscholars and practitioners to learn from those whose bodies and ways of being challenge the validity of privileged, hegemonic concepts that promote acceptance of "normal" or "efficient" as singular, definable, universal concepts. Although certainly incomplete, the scholarship in this chapter is integral to my framing of policies as important sites for critique, and for challenging the normative constructs forwarded by policy makers in order to justify the oppression and management of certain bodies. Ultimately, I consider the foregrounding of vulnerable people to be an essential aspect of TPC and an essential goal for user-centered work as a practice of social justice. In pursuit of this goal, I offer an intersectional feminist rhetorical methodology as one possibility for teacher-scholars invested in researching and teaching usability through a social justice lens.

Chapter II is dedicated to the development and articulation of an intersectional feminist rhetorical methodology. Tracing rhetorics of efficiency within public policy, this methodology reimagines how policies that purport to further the public good can, through the leveraging of user-embodiment, become more inclusive of and usable for diverse publics. Engaging GarlandThomson's concept of "extraordinary" and theories of usability in TPC, this methodology calls for the intentional and ongoing incorporation of marginalized users' experiences. This chapter will address the benefits of this methodology to scholarship, pedagogy and practice in TPC as well as acknowledge the limitations of this methodological approach. 
In Chapter III, I conduct an intersectional feminist rhetorical analysis of Baby Friendly USA (BFUSA) — particularly the organization's “Guidelines and Evaluation Criteria for Hospital and Birthing Center Implementation of the U.S. Baby-Friendly Hospital Initiative"- to examine how the long-term goal of infant health is weakened by rhetorics of efficiency that seek to manage bodies to perform in normalized, "good" ways. Turning to the embodied rhetorics of marginalized users as essential knowledge, I identify user-narratives shared through the organization Fed Is Best as indicative of the disproportionate material impacts of rhetorics of efficiency, and as models for the ways in which marginalized users are pushing back against restrictive constructs of policy users and desired outcomes.

Transitioning from health to civic issues, Chapter IV shows the versatility of an intersectional feminist rhetorical reading of public policy. This chapter is grounded in a case study of Ohio's Voter Purge policy that constructs normative assumptions of voters to deny marginalized users' access to participate in elections. Analyzing how policies manage whose, and in what circumstances, votes are allowed, I consider how rhetorics of efficiency justify certain individuals assuming responsibility for shaping and maintaining the public good, while others are denied this privilege. Turning to the work of Stacey Abrams's Fair Fight Action, I examine how marginalized users' narratives disallow proponents' claims that the purge policy is reasonable and easy to use (and thus impacting only those who "choose" not to vote) and instead show its disproportionate impact on vulnerable voters.

In Chapter V, I outline a pedagogical approach for incorporating an intersectional feminist methodological framework within an introductory technical and professional writing course. I describe a course plan for engaging an intersectional feminist rhetorical understanding of usability as a sustained focus for the course with the goal that students consider the material 
impacts and social justice potentials of their future work. Outlining specific projects and readings, I discuss student reactions that suggest both the potential and limitations of this approach for an introductory course. To conclude the chapter, I propose how an intersectional feminist rhetorical pedagogy might inform other technical and professional writing and rhetorics courses.

The final chapter of my dissertation suggests possible extensions for this work as I move forward in my research and teaching, and proposes ways that technical communication, rhetoric, and composition scholars might engage an intersectional feminist rhetorical framework within their own work. 


\section{CHAPTER II: AN INTERSECTIONAL FEMINIST RHETORICAL METHODOLOGY FOR EXAMINING RHETORICS OF EFFICIENCY IN PUBLIC POLICY}

As argued in Chapter I, a central goal of this project is to make apparent how normative frameworks are constructed through rhetorics of efficiency that promote an unquestioning acceptance of "efficiency" as both objective and good, and downplay existing and potential tensions within, and between, differently embodied realities. When integrated into public policies, I posit that rhetorics of efficiency can function to: (1) include and exclude certain bodies from potential societal and institutional benefits; (2) manage and control bodies to perform in sanctioned ways; (3) further the status quo in that certain bodies are privileged and others oppressed; and (4) effectively authorize violence against vulnerable bodies. In this chapter, I outline an intersectional feminist rhetorical methodology toward reframing efficiency and usability in ways that account for intersectional embodiments, bodies and frameworks deemed non-normative.

Drawing on feminist rhetoric, disability studies, technical communication, women of color feminist, and transnational feminist scholarship, I construct an approach that critically engages with, and responds to, rhetorics of efficiency that exclude certain bodies from being recognized within, or beneficiaries of, public policy. Foregrounding multiply marginalized users, an intersectional feminist rhetorical methodology frames usability according to a policy's capacity to respond to the embodied and intersectional needs of extraordinary users. This approach identifies and challenges exclusionary rhetorics of efficiency that ignore, disenfranchise, and/or oppress bodies and embodiments that do not conform to the normative constructs reflected within the policy language. As noted in Chapter I, this methodology is also committed to moving beyond critique in order to propose more socially just ways forward. Thus, 
this methodology engages with, learns from, propels, and aims to contribute to the agentive power of those marginalized by rhetorics of efficiency. As Chapter III and IV will demonstrate via application, this methodology requires a critical consideration of how public policies rhetorically construct "normal" users, thereby justifying practices, spaces, and institutional structures that can privilege and oppress.

The intended audience is technical and professional communication, rhetoric, and composition teacher scholars invested in contributing to and furthering social justice through their scholarly and pedagogical practices. Specifically, my work is intended to be useful for TPC, rhetoric, and composition scholars engaged with, or invested in: (1) social justice as a foundational aspect and integral purpose of these field that requires resolute, sustained, and reflexive practice, (2) amplifying the work of underrepresented scholars and publics in their scholarship and practices, (3) the material impacts of everyday, seemingly mundane, discourses on the lives of vulnerable publics, (4) usability as an important framework for challenging exclusionary rhetorics of efficiency, (5) intersectionality as a critical theoretical lens for understanding usability as both a framework and a tool. With this audience in mind, I offer an intersectional feminist rhetorical methodology that:

- identifies and problematizes the constraints that rhetorics of efficiency place on embodied rhetorical agency;

- reframes difference as generative and productive rather than burdensome and inefficient;

- recognizes and builds on models of resistance to policies that manage bodies toward performing in normalized, "good" ways; and

- presents a framework of usability that is inherently feminist, intersectional, and embodied 
This project builds from and contributes to: disability studies scholarship and its emphasis on embodied experience (Garland-Thomson; Jung; Selznick; Dolmage); scholarship in technical communication that foregrounds the importance of social justice approaches to technical communication (Agboka; Bates; Frost; Haas; Jones; Moore; Rude; Savage and Mattson; Savage and Matveeva; Haas and Eble; Walton, Moore, and Jones; among others); and intersectional feminist scholarship that amplifies marginalized voices (Crenshaw; LaDuke; Hill-Collins; hooks). In the following sections, I will: (1) situate my positionality as it informs my methodological commitments; 2) discuss key scholarship on intersectionality that contributes to my understanding of and dedication to an intersectional approach; (3) outline how theories of embodiment within feminist scholarship and disability studies shape this methodology; (4) examine how social-justice focused work in technical communication informs my analysis of efficiency and normative frameworks; (5) articulate an intersectional feminist rhetorical methodology that can reframe the ways in which we understand and teach usability ${ }^{15}$ in rhetoric and technical communications classroom; (6) recap the key tenets of an intersectional feminist rhetorical methodology; and (7) forecast how I intend to apply an intersectional feminist rhetorical methodology to the case studies and pedagogy chapters of this dissertation.

\footnotetext{
${ }^{15}$ Although expanded on later, I begin with Huatong Sun's understanding of cultural usability in relation to intersectional feminism in TPC. Specifically, understandings of usability must be grounded in understandings of local users and their experiences and must account for the multiple and overlapping cultural and embodied contexts that inform the ways in which users engage with and experience a discourse.
} 


\section{Contending with My Own Positionality}

I was born into, and continue to occupy, a fairly privileged position. I am a white, heterosexual, able-bodied, cisgender female who is educated, financially secure, with a partner and family who are gainfully employed and supportive. I feel it is important to acknowledge these multiple sites of privilege, as the public policy structures that I critique are often designed to benefit me and those who are similarly situated-heterosexual, educated, financially secure, healthy, and white. As such, I recognize that the depth of my commitment might be met with skepticism given the privilege with which I am entering into this conversation. But as I hope to make apparent here, and to expand upon with each case study, my dedication to an intersectional feminist rhetorical approach emerges from my embodied experiences as a member of the Peoria, IL, East Bluff community where I grew up as a child and later as a teacher in the Chicago Public and Tazewell County school systems. My commitment to intersectional, embodied scholarship is shaped by a childhood in which I was surrounded by layered systems of inequality and an early career in which the frameworks that construct and maintain such inequalities became increasingly apparent to me. I recognize that these systems often privilege(d) me, but I saw repeatedly the damaging effects of systemic and compounded oppressions on those for whom I cared. Thus, I enter into this work recognizing that policies and systems often seem to hurt the very people they are purportedly designed to serve; and as one who hopes to contribute to social justice work aimed at dismantling oppressive practices - in part, by making explicit how inequitable distribution of power creates, maintains, and perpetuates frameworks that both privilege some and oppress others.

My childhood neighborhood in the East Bluff is inseparable from my understanding of my positionality. Given that a central goal of this dissertation is to make apparent how policies 
can privilege some and oppress others, I consider it important to acknowledge the system of violence and inequity that transpired in the "founding" of Peoria. Peoria now sits on the ancestral lands of the Peoria Tribe, descendants of the Algonkin and members of the Illini Confederacy. Public policy and regulatory writing were integral to the removal and genocide of Native people from the land on which I was raised and now live. In 1818, the United States government used the Treaty of Edwardsville to take the lands of the Peoria Tribe in Illinois: The disease, war, and genocide brought on by the ensuing forced "relocation" decimated the Peoria Tribe, prompting members of the Kaskaskia, Peoria, Piankashaw, and Wea tribes to form a new confederacy under the Peoria name in 1854. Recounting this history is important to acknowledge as the rhetorics of "progress"- a concept saturated with Western ideals of efficiency, and frequently invoked in the narratives of white colonization of native lands and bodies—-were, and continue to be, cited as justification for the inhumane treatment of indigenous peoples.

My own experience in the East Bluff of Peoria informs my commitment to working for social justice. Growing up, the neighborhood was diverse with individuals and families of various races, income levels, occupations, abilities, and beliefs living next door to each other: my family, with two, white, college-educated, heterosexual, able-bodied, parents and four children, lived across the street from two white women who worked as prostitutes, down the street from an unmarried biracial couple with three children, and next door to a widow who had spent decades in that home as a homemaker. My friends from this neighborhood grew up and traveled along a myriad of paths; some of these paths intersected and overlapped, while others did not. Some grew up and went to college; some made their livings dealing drugs; some became stay-at-home moms; some became victims of violence; and others became victims of the criminal justice system. These are not my stories to tell. But they are individuals whose experiences and stories 
have shaped my understanding of the world and my own place within it. I grew up in a neighborhood and went to schools shaped by diverse bodies and ways of being—and those knowledge-building frameworks informed my commitment to the importance of embodiment and intersectionality within my work.

Yet, it was not until I taught in the K-12 teaching system in Chicago that I began to more fully recognize the deeply ingrained systems and policies that privilege certain positionalities and oppress others. And that the policies, even the ones that explicitly attempt to disrupt discriminatory practices, are often woefully inadequate and fail to acknowledge how marginalized and overlapping identity markers are weaponized by, and used in service to, systems of privilege and power. Repeatedly, those charged with developing, writing, and administering educational policies to address issues of social justice do so by attempting to standardize, oversee, and manage student bodies. These policies, and those who design and enforce them, ultimately mark student bodies—-shifting the focus on making students better fit within a framework of normativity, and thus situating differences as deficits. Within such a framework of deficit, human struggle and potential is ultimately reduced to a modifier-one of gender, race, physical or intellectual abilities, income levels, ethnicity, or faith—and the social justice goals too often lost.

When I left secondary education to pursue a doctoral degree, it was with the strong desire to learn from and contribute to others who were invested in changing systems that oppress some bodies while propelling others. I knew that policies which only recognized individuals according to race, socioeconomic level, gender, language or disability were failing to acknowledge how these overlap in ways that simply could not be accounted for when addressed separately. I had witnessed, and listened to firsthand accounts of, the ways that oppressions are magnified for 
individuals whose bodies and lived experiences situate them in multiply marginalized positions. What I lacked was a theoretical framework that seemed adequate to respond. An intersectional feminist rhetorical methodology is this framework—one that makes apparent the material impacts of rhetorics of efficiency on multiply marginalized users and the potential of reframing usability to privilege extraordinary users.

\section{Understanding Intersectionality}

Without frames that allow us to see how social problems impact all the members of a targeted group, many will fall through the cracks of our movements, left to suffer in virtual isolation. But it doesn't have to be this way.

—Kimberlé Crenshaw, "The Urgency of Intersectionality"

As intersectionality is integral to this project, I want to first articulate how I understand, and thus situate, this concept within the theoretical framework of this project. Intersectional work foregrounds the recognition that social categories and identities intersect and overlap in complex ways and that experience is inherently contextual and constantly in-progress even as is it always historically situated. Intersectionality recognizes that individuals do not experience vectors of power only as gendered, racialized, sexualized, disabled, or economized bodies but rather at the intersections of these, and other, positionalities. The ways in which such intersections are recognized (or not) and experienced have tangible, material effects on bodies. Intersectionality as a framework focuses my attention on how systems of power function inequitably—creating both pathways for opportunity and blockades to oppress, often in tandem. Within the context of this particular project, an intersectional lens allows for a clearer illustration of the inadequacy and potential destructiveness of policies and discourses that are informed by and promote simplistic, 
singular, homogenizing categorizations of individuals, and the material impacts that such categorizations propel. It is also a tool for pushing back.

An intersectional approach is not simply an invitation to become more inclusive in our language, but a tactic to challenge policies that seek to categorize in order to manage. Recognizing that identity is multilayered, an intersectional approach accounts for the multiple and complex ways that individuals experience overlapping oppressions informed, for instance, by intersecting locations of race, ethnicity, gender, disability, income, sexuality, education, or faith (Crenshaw; Cho, Crenshaw and McCall; hooks; Jones; McCall; Mohanty; Sandoval). Intersectionality emerged as a response to systems which ignored that Black womenmarginalized by race and gender — were falling through the cracks of a legal system which failed to recognize the multiple sites of discriminatory practice against them. Thus, it is important to note that "[w]hile 'intersectionality' has become a scholarly buzzword, the notion that identity is formed by interlocking and mutually reinforcing vectors of race, gender, class, and sexuality has pervaded black feminist scholarship for decades" (Nash 89). Intersectional work originated through the work of Black Feminist activists and scholars fighting for social justice and pushing back against second-wave feminism that conflated the experience of white women with the experience of all women, and situated race as a less important category of analysis for understanding systems of power (hooks; Crenshaw; Hill Collins).

When Kimberlé Crenshaw first coined the term, intersectionality provided an "explicitly interventionist response to the institutional and political discourses" that rendered the experiences of Black women as "partial unrecognizable, something apart" from either the narratives of Black men or white women (Cho, Crenshaw, and McCall 791). In a system that refused to acknowledge the overlapping injustices informed by both gender and race that Black 
women experienced, intersectionality provided a necessary tool of resistance. An intersectional approach provided a methodology for describing how women of color are discriminated against on multiple levels and made evident the inadequacy of systems that aim to address and protect against discriminatory practices when these systems rely on identity markers such as race or gender "as mutually exclusive of the categories of experience and analysis" (Crenshaw 23; Cho, Crenshaw and McCall).

Privileging, but cautious to not appropriate, the contributions of multiply marginalized voices, I engage intersectionality as it foregrounds complex user embodiments and pushes back against systems that seek to understand or redress oppressions based on singular categorizations of identity and reductive understandings of power. I engage intersectionality as both a theoretical framework and a tool for recognizing and drawing attention to the limitations, and limiting effects, of rhetorics of efficiency. Specifically, I attend to rhetorics of efficiency that require marginalized users to fight against, rather than benefit from, public institutions and policies. In this way, rhetorics of efficiency can shift responsibility for the usability of a policy away from those charged with composing the policy and onto the public for whom the policy is purportedly designed to serve. Reevaluating efficiency through an intersectional feminist rhetorical framework prompts recognition to the needs of, and obstacles faced by those occupying multiple and overlapping positions of marginality. For example, rather than efficiency in terms of "the best for the most," an intersectional understanding consciously, purposefully strives to create policies that are usable for those individuals whose embodiments make them particularly vulnerable and at risk of "fall[ing] through the cracks." 
Although the disciplines engaging intersectional methodologies and theories are wideranging and the potential for concentrations is vast, ${ }^{16} \mathrm{I}$ focus specifically on intersectionality as it is theorized, practiced, or reflected within feminist theory, women and gender studies, and feminist studies — particularly scholarship by women of color feminists (Crenshaw; Hill Collins; Anzaldúa; Mohanty) and disability studies (Selznick; Dolmage; Garland-Thomson). These disciplines challenge the patriarchal, masculinist, ableist ideologies that underwrite the objectivist claims of rhetorics of efficiency in public policies. Intersectional feminist and disability studies scholarship focus on embodiment; interrogate hegemonic, neoliberal pursuits of normalization; and point to historical and contemporary examples of "everyday" people resisting rhetorics of efficiency and normalization (Garland-Thomson; Dolmage; Bates; Selznick). ${ }^{17}$

Rosemarie Garland-Thomson, in her "Integrating Disability, Transforming Feminist Theory" notes that: "Integrating disability into feminist theory is generative, broadening our collective inquiries, questioning our assumptions, and contributing to feminism's intersectionality" (4). Working alongside each other, the two fields push my research to be more intersectional by making the gaps in each more apparent (Dolmage and Lewiecki-Wilson; Garland-Thomson). Thus, with a focus on embodiment, I draw on intersectional feminist rhetorics and disability studies scholarship that challenges homogenizing, normative frameworks that privilege those whose bodies and ways of being further the dominant status quo. This

\footnotetext{
${ }^{16} \mathrm{Cho}$, Crenshaw and McCall, for instance, note that intersectionality "has been deployed in disciplines such as history, sociology, literature, philosophy, and anthropology as well as feminist studies, ethnic studies, queer studies, and legal studies... [as well as] fields such as geography and organizational studies" (787). Additionally, intersectionality as explored in critical race theory, cultural rhetorics, decolonial rhetorics, or queer theory has much to offer this and ongoing conversations but is beyond the scope of this particular project.

${ }^{17}$ A relationship and history examined more fully in Chapter I.
} 
relationship is articulated by Hilary Selznick, whose dissertation brings together feminist rhetorics and disability studies in order to problematize taken-for-granted assumptions about pain and disability: "What these fields have in common is their commitment to working for social justice by challenging the inequities found in normalized language practices and by recovering subjugated, marginalized, and oppressed populations who have been silenced and deemed by dominant society as both failed rhetors and failed human beings" (14).

Selznick situates embodiment as knowledge producing, articulating an "alternative rhetoric of chronic pain [which] defines rhetoric as the study of how embodiment produces knowledge, identity, and ways of being-in-the-world" (5). Theories of embodiment make evident how certain bodies are normalized and others excluded, but they also are sites of productive insight. When policies do acknowledge the existence of non-normative bodies (which is certainly not a given), it is often done in order to articulate how to best manage such bodies-in turn further framing them as requiring additional oversight and thus inherently inefficient. Nonconforming bodies, then, are presented as "posing an unnecessary burden ... [and] intrinsically needy and flawed"-seen as a hindrance to the efficient allocation of time, money, and resources (K. Jung qtd. in J. Jung 163).

In the following section, I examine how theories of embodiment can shift the ways in which we understand efficiency and push back against normative frameworks that resist recognition of intersectional identities.

\section{Theories of Embodiment within Disability Studies and Feminist Scholarship}

I argue that challenging normative constructs requires a reframing of efficiency in which "extraordinary bodies" (Garland-Thomson, Extraordinary) rather than "standard, tacit" 
(Dolmage, "Metis" 11) bodies are central and suggest that the most efficient approach is, indeed, the one that, by design, "challenges simple constructions, reductions, or dismissals of the important role of embodied intelligence" (Dolmage, "Metis" 8). In this model, non-normative bodies (for instance, those deemed "abnormal" based on gender, race, sex, abledbodiness, or age, among other identity markers) are not merely accommodated; rather, they are the point from which initial concepts of efficiency begin. This flexible model anticipates varied and divergent embodied experiences and thus understands that efficiency itself will be inherently non-linear and non-normal. Acknowledging that which is most efficient for one body can come into tension with that which is most efficient for another, this approach foregrounds the importance of recognizing that when decisions are based on what is best for the most bodies, the benefits of efficiency are rarely realized by bodies deemed non-normative.

Thus, I propose a reframing of efficiency that considers how an approach that focuses on that which is most efficient for the most serves to forward a system that oppresses bodies and embodiments deemed outside of the enforced, standardized, dominant norm. Scholarship in disability studies (e.g., Garland-Thomson; Jung; Dolmage; Selznick) and feminist rhetorics (e.g., Dingo, Frost $)^{18}$ are integral to this work as they tease out the historical ways in which the oppression of certain bodies based on gender, ability, race, economics, education, religion, as

\footnotetext{
${ }^{18}$ In Chapters I and III, I describe work within critical and cultural theory (hooks; Sandoval) and Science and Technology Studies (Gouge; Takeshita, Jung) that critique policies categorizations of individuals as either within, or outside, societal constructs of "normal" and how this is important to problematizing rhetorics of efficiency that rely on constructs of normed bodies and that promote certain acts as indicative of "normal" behavior.
} 
well as other identity markers, is inextricably linked to a fidelity to efficiency as a moral value and to the concept of disability, of "non-normative" bodies, as a strain on this efficiency. ${ }^{19}$

An intersectional feminist rhetorical approach rejects the mind-body split and the rational-irrational dichotomies on which hegemonic efficiencies are premised. Work by feminist, feminist rhetoric, and disability studies scholars trace the historical distrust of certain bodies and ways of being and how this practice springs from a desire to separate and categorize certain bodies as unpredictable and irrational, and others as rational and thus justified in assuming increasing authority (Anzaldúa; Jung; Dolmage, "Metis"; Selznick). Theories that are grounded in beliefs of a mind/body split (a dichotomy long promoted within Western thought) ${ }^{20}$ set up the mind and body in opposition — with the mind representing rationality and trustworthiness, and the body understood as both unpredictable and unruly. Bodies that do not reflect the white, heterosexual, male, able-bodied norm are read as inefficient and unreliable—as somehow particularly bodied and in need of oversight. Institutional policies and discourses often reflect a distrust of bodies that diverge from hegemonic norms and invoke these antiquated assumptions to frame certain bodies as hindrances to efficiency and in need of explicit management by "rational" minds (Anzaldúa; Hill Collins; Dolmage, Disability; Dolmage, "Mapping"; Jaggar). Theories of embodiment, however, problematize the separation of mind and body and the ways in which this approach has been used to undermine the agency and authority of marginalized groups.

\footnotetext{
${ }^{19}$ Douglas Baynton argues that "[while] disability has functioned historically to justify inequality for disabled people themselves. . . the concept of disability has been used to justify discrimination against other groups by attributing disability to them" (33).

${ }^{20}$ Plato lectured that "we shall continue closest to knowledge if we avoid as much as we can all contact and association with the body (Phaedo 67a)."
} 
An intersectional feminist rhetorical methodology draws on theories of embodiment as they: (1) acknowledge that "our bodies inform our way of knowing" (Bates, McCarthy, WarrenRiley, n.p); (2) recognize the "physical body as an entity with its own rhetorical agency" (Johnson, Levy, Manthey and Novotny 39); and (3) situate embodiment as both valuable and having generative potential (Wysocki and Arola 3). Foregrounding embodiment—-the complex and vastly different ways in which individuals experience themselves and the world around them—opens a space to recognize and examine inequitable power dynamics (hooks; Hill Collins; Enoch); to problematize taken-for-granted terms (Dingo; Frost); and to question who benefits from maintaining the status quo (Addison).

An intersectional feminist approach draws attention to both systemic inequities and individual realities, revealing how certain bodies-for instance, gendered, sexualized, racialized, disabled — are always already embodied within normative frameworks. For instance, in her argument for critical embodied pedagogy, Christina Cedillo notes: "My distinctive embodied identity is why I focus on relationships between rhetoric and bodies, on those ways that rhetorics of embodiment compel us into corporeal configurations deemed socially acceptable and how we comply or contest these constraints. In my case, I cannot help but pose a challenge to order" (n.p.).

Without explicitly examining the role of embodiment in power dynamics, we risk reinforcing the status quo and normalizing dominant ways of being. Embodiment, as Lisa Phillips articulates, focuses our attention on the fact that individual experience cannot be homogenized as it is informed by individual, community, and environment; embodiment "cares to notice things that make a difference to one's lived experiences" (56). Yet certain bodies are afforded a choice in making embodiment explicit, while for others, their embodiment is always 
already marked. Citing Haraway's argument that "only those occupying the positions of the dominators are self-identical, unmarked, disembodied, unmediated," Liz Barr explains that "the ability to remain 'unmarked' is a position of privilege; ignoring embodied differences reinforces systems of domination" (208). Although not terming it embodiment, bell hooks explores this power differential in the classroom, noting that " $[\mathrm{t}]$ he person who is most powerful has the privilege of denying their body" (Teaching 137). hooks' and Barr's descriptions reinforce the idea that the choice to ignore or foreground embodiment is not a luxury afforded to those bodies deemed non-normative within certain spaces.

Drawing on the work of these scholars, I understand embodiment as critical to an examination of efficiency because it focuses attention on the ways that bodies privileged by dominant social constructs are allowed to move through the world as "unmarked" and thus normalized, while those who occupy marginalized status are not allowed this privilege. In problematizing rhetorics of efficiency in public policy, then, explicit acknowledgement of embodiment is essential to identifying how some ways of being are established as the normhow certain corporeal and experiential ways of being are assumed, and thus written in as the standard, while others are framed as divergent and/or in need of oversight. As disability studies, activist, and feminist rhetoric scholars have shown (and as I explore more fully in Chapter III), embodiment draws attention to injustices but can also be understood as both powerful and generative (Dolmage, Anzaldúa, Cedillo, Phillips).

Alongside scholarship within feminist rhetorics and disability studies that disrupts normalized frameworks through articulations of embodiment, I also draw on scholarship from transnational feminist studies that extends my consideration of how bodies are constructed as agents or subjects, and how taken-for-granted rhetorics of efficiency either explicitly or 
implicitly justify neoliberal solutions that reside in the reformation, or management of, certain bodies and distract from the negative material impacts that such efficiencies have on certain bodies. Focusing specifically on how rhetorics of efficiency can be employed to manipulate public bodies, I draw on transnational feminist work that considers how technologies, rhetorics, policies, and visuals are employed as tools to manage and control bodies - to reflect, maintain, or further national and market interests as well as "cultural norms around gender, sexuality, and family" (Takeshita 22; Dingo Networking; Hesford). Such work uncovers how technologies, terms, and images are massaged and shaped in order to bolster subjective policies and positions; distract and deflect attention away from large scale issues such as racism, sexism, ableism and poverty; and frame solutions in terms of individual agency (both that of "victims" and "saviors") rather than through fundamental change.

\section{Challenges to Efficiency in TPC}

In this section I shift my focus from discussion of the scholarship that informs my methodology to a consideration of the affordances of an intersectional feminist rhetorical methodology in the context of this project. By examining rhetorics of efficiency, I aim to contribute to the ongoing work of technical communicators who problematize the promotion of efficiency as a prized characteristic of technical writing and a desired goal for technical documents, who challenge normative frameworks that serve to oppress, and who are invested in socially-just technical communication scholarship and practices. In particular, my work is informed by feminist technical communication scholar Erin Frost who, in her critique of efficiency, notes that the "explicit analysis of the term efficiency does not often happen [within the discipline of technical communication] precisely because efficiency is a concept so highly 
valued in technical communication circles that it seems to require no justification" ("Theorizing" 4). In addition to her critique of efficiency, Frost's apparent feminist methodology, among other goals, "encourages a response to social justice exigencies" and seeks to "[make] apparent the ways in which efficient work actually depends on the existence and input of diverse audiences" (5). An apparent feminist position—which argues that efficiency should be concerned with effects on people first, before energy expended, and that the inclusion of diverse audiences is a necessary component of, rather than a hindrance to, efficient work-opens a space in which an intersectional feminist rhetorical methodology can be applied to further disrupt limited notions of efficiency.

An intersectional feminist rhetorical methodology compliments Frost's apparent feminism as it brings attention to the material impacts of public policies, particularly on users situated as outside the constructed norm of the policy. In order to do so, the methodology engages usability as a framework to illustrate how public policies, like all rhetorical artifacts, are never objective or neutral but rather embedded with the particular values and unwritten aims of its composers and administrators. Additionally, an intersectional feminist rhetorical approach reveals how the seemingly neutral promises of public policy are frequently contingent on certain bodies acquiescing to oversight and management. Oversight is too often the result of efficiencies that hinge on individuals agreeing to perform in sanctioned, "normal" ways in order to participate in, and reap the benefits of, that which is outlined in the policy. Thus, Frost's call to make apparent that all discourses promote certain cultural values over others, and her critique of efficiency, are important to my own work.

Another compelling critique of efficiency is technical communication scholar Steven Katz's analysis of rhetorics of efficiency within the technical documents of Hitler's Third Reich. 
Katz's work provides critical insight on the risks of allowing "technical criteria [to be privileged as] a means to an end" (257) and models of efficiency that fail to acknowledge or account for human lives (258). Ultimately, Katz's work addresses how efficiency can evolve into an ethos such that it is allowed to take precedence over the human experience and, at times, over human life (270). Although grounded in technical documents from the Holocaust, Katz's work points to multiple contemporary examples in which models of efficiency are taken to such extremes that human bodies are partially or fully discounted in the name of efficiency — examples in which felicity to efficiency becomes normalized and the accepted status quo.

Rhetorics of efficiency as explored by scholars such as Frost and Katz, then, are used as weapons to construct normative frameworks that include or exclude certain bodies, justify unjust practices, and seek to manage particular ways of being. When efficiency is normalized, it becomes a standardized framework that is called upon to categorize and manage. This type of explicit examination of the presence and power of such normative frameworks is integral to technical communication scholarship engaged with issues of social justice. Similar work by scholars in technical communication have questioned how oppressive representations and artifacts can become normalized, and the role that technical communicators can assume in order to push back against oppressive policies forwarded through normative frameworks that employ rhetorics of efficiency (Katz; Ward; Moore). Such scholars argue for the discipline of technical communication to increasingly engage practices that challenge norms and that reimagine traditional notions of what it means to be an effective technical communication scholar, instructor, and student (Almjeld and Blair; Durack; Frost; Frost and Haas; Haas; Jones; Reilly; among others). And as it specifically pertains to this project, many of these social justice-minded technical communication scholars focus their critiques on the hierarchical relationships between 
policies and the publics that these policies are ostensibly designed to serve or protect (Agboka; Frost; Frost and Haas).

Technical communication scholarship focused on issues of social justice serve as a model for my work both as it presents methods for critique and proposes actionable ways forward. Honoring the work of these scholars, an intersectional feminist rhetorical methodology is motivated by, and aims to contribute to, work that critiques oppressive policies through challenging normative frameworks and rhetorics of efficiency, as well as points to theoretical extensions and pedagogical possibilities. Thus, this methodology aims to be both useful and generative. ${ }^{21}$ For instance, by making discrepancies apparent — the values, bodies, and embodiments that are privileged and those that are marginalized—rhetoricians and technical communicators place themselves in a better position to recognize, acknowledge, and learn from those outside of academia who contest and fight against discriminatory policies that are made efficient through the exclusion or modification of certain embodied experiences.

In the next section, I propose that reframing usability to more fully account for users intersectional, embodied identities holds potential for reimagining efficiency within public policy.

\section{An Intersectional Feminist Rhetorical Framework for Usability}

This methodology proposes an intersectional feminist rhetorical framework to recognize the push back against rhetorics of efficiency that undermine and disenfranchise marginalized users. In this framework, then, usability is gauged according to a policy's capacity to respond to

\footnotetext{
${ }^{21}$ Judy Segal's describes as $u s e f u l$, work that scrutinizes language in order to discover that which is left unarticulated or assumed (4). Useful research can then be applied.
} 
and reflect the needs of multiply marginalized users. Instead of asking how bodies might be prompted to behave in sanctioned ways, this framework instead examine how the rhetorics, technical documents, and/or policies might better reflect the bodies and embodied experiences of those who might use and/or be impacted by them. ${ }^{22}$

Figure 1 outlines how this shift might enhance the manner in which TPC, rhetoric, and composition scholars engage with analysis and practice of usability in their scholarship and pedagogy. In the context of this project, this model proposes that attention shift to reframe 1) the purpose of policies: from management of bodies, to service to users, and 2) the potential of users: from obstructions to a policy's success to integral contributors to a policy's user-friendly design, and in turn, success.

Why do certain bodies refuse to conform, or take advantage of, the benefits outlined within a policy?

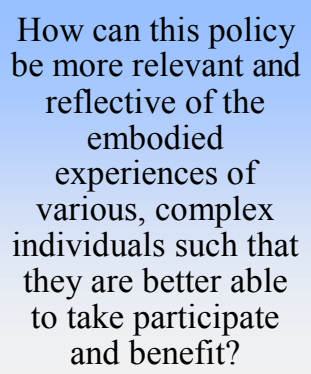

How can this policy be more relevant and reflective of the embodied experiences of various, complex individuals such that they are better able to take participate and benefit?

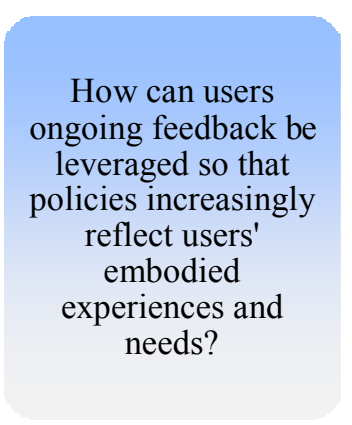

Figure 1: Shifting Purpose and Potential of Usability in Public Policy

To explore what this shift might offer, I first want to consider the concept of usability as it is taken up within the disciplines of rhetoric and technical communication. Although a term grounded in technical communication, the concept of usability has also been theorized by many within rhetoric and composition (Selfe and Selfe; Blythe; Eyman; Reilly; Chong; Dolmage

\footnotetext{
${ }^{22}$ The type of shift is modeled by Patricia Hill Collins who proposes: "Rather than trying to explain why Black women's work and family patterns deviate from the seeming normality of the traditional family ideal, a more fruitful approach lies in challenging the very constructs of work and family themselves" (47).
} 
“Disability, Usability”; Miller-Cochraon and Rodrigo). Aware that, as Miller-Cochran and Rodrigo note, "the discussion of usability is somewhat marginalized in the broader field of rhetoric and composition" (3), an intersectional feminist rhetorical methodology argues for the value of usability not only in the technical communication classroom but for rhetorical theories and practices. Usability is rhetorical, concerned with issues of "power, knowledge, and access" and thus essential to the ways in which we theorize efficiency (Skeen 102).

Although integral to much theory, practice, and pedagogy within the field, definitions of, and approaches to, usability are neither singular nor stable within technical communication. ${ }^{23}$ Recognizing the scope of usability research within the discipline, I focus specifically on usability research that, whether explicitly or indirectly, furthers the goal of reimagining rhetorics of efficiency. In particular, I draw on usability scholarship that problematizes the user/designer dichotomy and/or hierarchy, and that resituates what elements of usability are prioritized when designing a "user-friendly" text. Drawing on such work, an intersectional feminist rhetorical methodology calls for a reframing of efficiency that is explicitly invested in the usability of a policy or document for those whose embodied realities situates them as outside of the "normal" or primary target audience. I argue that an expanded understanding of usability that more fully accounts for individual, intersectional, and non-normative user-experience helps to reframe efficient documents and policies as those that are both usable and satisfying for extraordinary users.

\footnotetext{
${ }^{23}$ For instance, Huatong Sun notes that usability studies origins in cognitive science and computers engineering which focused on "measurable qualities of a product" but have since undergone four major design shifts: "from product quality to context quality, from user representation to user participation, from use to consumption, and from developer localization to user localization" $(31 ; 33)$.
} 
Similar to Simmons and Zoetewey's productive usability, an intersectional feminist rhetorical approach to usability stresses user satisfaction over more traditional efficiency-centric measurements such as speed or ease of use. Likewise, it recognizes users as important contributors to the process rather than uninformed consumers seeking only ease and speed. ${ }^{24}$ Simmons and Zoetewy note that "[u]sefulness is, in its most fundamental form, a form of ensuring satisfaction" (269). Yet engagement with usability often formulates user-satisfaction as a bonus rather than a foundational component of usability. And while the consideration of diverse audiences is increasingly noted as an important element of usability, too often this is constrained by limited terms that fail to account for intersectional embodiments. For instance, user profiles frequently invite sweeping generalizations rather than thoughtful consideration of how different unique situatedness might inform an individual user's engagement with a document, or the documents impact on the user. Even attempts to account for diverse audience needs — such as through universal design —often disregard, dissuade or disadvantage certain users and ultimately fall back on normative frameworks (Bowie 135; Dolmage "Disability, Usability"). An intersectional feminist rhetorical methodology seeks to avoid such pitfalls by making intersectional identities and experiences essential to the creation of usable documents, and recognizing that embodied realities will influence the context in, and purposes for, which an individual engages with a text. This approach —one that accounts for and honors varied user experience — can ultimately lead to "better," more effective, policies and documents. Central to

\footnotetext{
${ }^{24}$ The historical connections between expediency and technical documentation is explored more fully in Chapter I. Additionally, Dilger's "Extreme Usability and Technical Communication" points to a history of viewing users/consumers as benefiting from simplistic design, thus removing users from complexity and instead assigning "agency and control to external experts" (52).
} 
this success, however, is the prioritizing of usability as an ongoing, responsive, and always improvable endeavor. Usability testing and consideration of diverse user-needs should occur early and be examined thoroughly prior to a document being released to the public, but it should also be embraced as a recursive practice.

Ongoing usability is a central tenet of an intersectional feminist rhetorical approach as it shifts from an understanding of usability focused on immediate outcomes and compliance to one that is inextricably "tied to the users, wants, desires, and needs" (Dobrin, Keller, and Weisser 308). Rhetorics of Health and Medicine (RHM) has much to offer here. RHM studies examine the benefits of ongoing usability testing in relation to patients' experiences engaging with medical paperwork (Meloncon; Gouge); wearable technologies (Kessler; Gouge and Jones; Jack); or with medical personnel (Segal) to name just a few. Although ranging in their theoretical approaches, the focus on patient experience has significant implications for the ways in which we approach usability in other rhetorical situations. For instance, when analyzing patient experience, RHM scholars have noted "the strong impulse [among technical communicators] to want to fix critical information prior to circulation and close it off to modification" (Gouge 8). This inclination often, by design, cuts off those users or experiences that cannot be, or simply are not, predicted in advance. Ongoing engagement with usability is essential in order to be responsive to users - to document, and address, unforeseen interactions between users and artifacts. ${ }^{25}$ Ongoing usability assessment is essential to public policy because like medical

\footnotetext{
${ }^{25}$ See, for instance, River's and Sunderland's speculative usability or Gouge's article (which builds from speculative usability) examining the usability of at-home-care documents in which she argues that such documents must "be designed to work with that which exceeds prescribed and predetermined plans, plans that cannot possibly anticipate all of the contingent variables (“Improving Patient" 435).
} 
rhetorics, the stakes are high and a single communication or document is inseparable from the broad, complex systems (involving layers of stakeholders, priorities, and institutions) in which it exists. Thus, I also draw on RHM scholars as they strive to improve user/patient experience not through universalizing or streamlining, but rather by recognizing that "[a]ambiguity is not a problem to be solved but a resource to be mined" (Segal 16).

Scholarship within RHM also informs my public policy analysis as it can direct attention toward ways in which rhetorics of efficiency are framed through discourse of "choice"-a particular form of rhetorical maneuvering that shifts attention away from societal inequities and institutional inadequacies, and instead places onus and/or blame on individual users/bodies. Public policies too often rely on a top-down approach that is centered on an outcome of compliance rather than user-experience (Gouge; Segal; Melencon): Mirroring medical documents that focus on patient compliance over patient experience, public policies frequently outline goals in terms of management and oversight rather than steps designed to improve participation or user satisfaction. One way that RHM scholarship addresses this shortcoming, is through rhetorical examination of patient choice and desired outcomes. I draw on this work as it considers how choice and the public good are tropes that structure meaning and thus effects in particular ways. Within public policy, choice is invoked to downplay inequities and situational constraints experienced by individual users, and to tie undesirable outcomes to a lack of individual motivation and/or a failure of an individuals to adequately invest in the good of self, family, or society. Differentiation between policies that expand possibilities for choice, and those that serve to limit, then provides exigency for learning from everyday acts of resistance by prompting us to inquire: When presented with no "choice" but to comply with normative 
frameworks, how do certain bodies push back against public policies that engage rhetorics of efficiency that ignore or devalue their embodied experience?

Although arguably requiring more time upfront—writing for a generic, homogenized, disembodied stereotype of a user demands less labor than creating for a myriad of complex, contextualized individuals—rethinking a policies' efficiency through a lens of usability foregrounds individual user-satisfaction as ultimately leading to designs that adhere to long-term goals and expanded notions of success. Thus, including usability within our understandings of efficiency can result in the creation of documents and policies that are increasingly beneficial for diverse, complex, individual users.

\section{Key Tenets of an Intersectional Feminist Rhetorical Methodology}

Thus far, I have explained how scholarship in feminist theory, disability studies, feminist rhetorics, and technical communication inform my approach to critiquing rhetorics of efficiency within public policy and provide models for imagining more socially just ways forward. In the following section I summarize the key affordances of this methodology. An intersectional feminist rhetorical methodology for analyzing public policy:

\section{Recognizes embodied experiences that diverge from the dominant norm as generative and productive}

Recognizing that Western society has a long history of discomfort and distrust of the body—particularly those bodies that diverge from the white, male, able-bodied norm—an intersectional feminist rhetorical methodology draws on the work of disability studies and feminist scholars who acknowledge the rhetorical agency and generative potential of the body. Disability studies articulates how "cultures [of hegemony] demand normalcy and enforce norms, 
both marking and marginalizing those bodies and minds that do not conform" and call for scholarship that challenges "the idea that bodily differences ... can have only negative rhetorical value" (Dolmage and Lewiecki 25). An intersectional feminist rhetorical methodology aims to reflect the values of disability and feminist rhetorical methodologies that "seek ways of understanding bodily differences as rhetorically generative" (Dolmage and Lewiecki 28) and that aim to "legitimate and nurture ... marginalized ways of knowing, speaking" (Bordo 41).

\section{Focuses on usability as an intersectional feminist rhetorical practice}

Approaching user-centered design as an inherently intersectional feminist practice—one that recognizes individual embodiment as always intersectional; that values individual, nonexpert experience, and voice; and that rejects dichotomies in order to embrace diversity and complexity — this methodology critiques traditional measures of efficiency (for instance, increased speed and conformity), and argues that a document's usability be measured by its success in reflecting and responding to complex, contextualized individual user needs. The goal of this understanding is that it prompts a move away from language directed at a homogeneous population to be managed, and toward a fuller accounting of varied users whose input, satisfaction, and productive resistance are understood as integral to the creation, and evolution, of usable policies. Central to the productive potential of this methodology is the leveraging of users' embodied experiences - of making more usable policies through the centering of embodied knowledge ${ }^{26}$ — particularly users whose experiences are not reflected in policy language, but who make their embodied realities known through everyday acts of resistance.

\footnotetext{
${ }^{26}$ For instance, Barr's embodied vernacularity which is expanded on in Chapter III centers on the "hope" that "listening to [marginalized/"non-expert"] bodies can result in better scientific practice" (222).
} 


\section{Redirects policy language toward long-term results}

An intersectional feminist rhetorical methodology is invested in work that results in furthering the long-term "good" of varied, individual users. Thus, considering how public policies engage traditional rhetorics of efficiency in a way that jeopardizes the realization of long-term public goods is essential and is made more apparent through the study of acts by individuals and organizations who resist policies that rely on singular, normative constructs of "the good" and tend to focus on short term fixes, rather than long-term shifts. Turning to historical and contemporary instances in which everyday people reshape public understandings of what it means for a policy to serve the public "good," this methodology aims to learn, and contribute back to, those demanding more diverse reimaginings and implementations of public policies in order that become increasingly inclusive of extraordinary embodiments.

\section{Prioritizes multiply marginalized users in the teaching of usability}

A tenet expanded on extensively in Chapter V, I argue that the values of an intersectional feminist rhetorical methodology hold potential for the ways in which we discuss and teach usability in the classroom. Specifically, I argue that an intersectional feminist rhetorical approach to examining rhetorics of efficiency within public policies can open spaces for technical communication and rhetoric students to engage with specific rhetorical moves that might lead to increasingly user-friendly documents. This approach foregrounds the value of teaching about document effectiveness in in terms of usability and prioritizing diverse user satisfaction over traditional measures of efficiency such as ease of implementation or readability. It invites increased consideration of how rhetorics of efficiency within public policy discourse (and beyond) function as tools to manage bodies and creates pedagogical space to imagine ways that it could be otherwise. Thus, this work also aims to address calls by scholars in technical 
communication — and increasingly within rhetoric and composition—for increasing discussion and work focused specifically on usability practices in the classroom. ${ }^{27}$

\section{Conclusion}

\section{Applying Methodology to Other Chapters}

In the remaining chapters, I engage an intersectional feminist rhetorical approach to usability by examining two public policy case studies and outlining a pedagogical approach for teaching usability in a technical communication classroom. Chapter III discusses my first case study, which applies an intersectional feminist rhetorical analysis to Baby Friendly USA (BFUSA) policy to argue that the policy disproportionately places responsibility for the public good on a single, normalized body and practice - specifically that of a lactating, cisgender female body. I consider how the policy's long-term goal of improving infant health is undermined by rhetorics of efficiency that ignore competing expert and user feedback and reject different bodies, embodiments and practices. Drawing on the generative potential of user voices, I look to everyday acts of resistance that reshape the narratives of usability and efficiency. I propose how policies such as BFUSA might further scholarly and pedagogical approaches to usability theories in rhetoric and technical communication.

In my second case study in Chapter IV, I examine how Ohio's voter purge policy—and surrounding discourses - place an undue burden on certain users access to "the public good." Focusing on how rhetorics of efficiency distract from the long-term goal of a free and fair voting

${ }^{27}$ Felicia Chong's "The Pedagogy of Usability: An Analysis of Technical Communication Textbooks, Anthologies, and Course Syllabi and Descriptions" details ample evidence of this ongoing exigency. 
process, I consider how the policy discourse justifies the suppression of certain users - namely poor, non-white, transient, and/or homeless individuals — as necessary for protecting the public good. Pointing to embodied acts of resistance by both individuals and activist groups, I again theorize the scholarly and pedagogical potential of this case for engaging with and teaching usability.

In the Chapter V, I describe the course plan for my Spring 2018 technical communication and professional writing course in which I implement an intersectional feminist rhetorical framework to engage students in projects that analyze and examine the effects of language that disproportionately place onus for usability and "the good" on certain bodies. I reflect on the successes and challenges of implementing this methodology and present potential uses for this pedagogical framework in other technical communication, rhetoric, and composition courses.

Finally, in Chapter VI, I explore the implications of an intersectional feminist rhetorical methodology for future scholarship and praxis. 


\section{CHAPTER III: RETHINKING RHETORICS OF EFFICIENCY AND USABILITY:}

\section{A CASE STUDY OF BABY FRIENDLY USA}

In Chapter II, I discussed the merits of an intersectional feminist rhetorical approach that reflects a commitment to challenging exclusionary rhetorics of efficiency and aims to learn from and magnify the agentive power of those whose embodied realities places them outside of imagined or targeted user-groups for a specific policy. In this chapter, I present a case study that applies this methodology to Baby Friendly USA (BFUSA) policy. BFUSA is the "accrediting body and national authority ... responsible for coordinating and conducting all activities necessary to confer the prestigious Baby-Friendly ${ }^{\circledR}$ designation and to ensure the widespread adoption of the [Baby Friendly Hospital Initiative] in the United States" (Baby Friendly). My analysis centers on BFUSA's "Guidelines and Evaluation Criteria," for hospitals, but extends to the supporting documents that reinforce the principles and calls to action forwarded by BFUSA, and thus required to be taken up and/or implemented by hospitals seeking BFUSA designation. In order to acquire and maintain Baby Friendly certification, hospitals must have documented policies that reflect BFUSA guidelines ${ }^{28}$ and BFUSA notes that the "Guidelines and Evaluation Criteria" is "the most important tool hospitals will use to guide their work through the BabyFriendly designation process" (Baby Friendly, "Practice Guidelines").

To contextualize this work, I first trace how BFUSA policy emerged from The International Code of Marketing of Breastmilk Substances—a United Nations policy that was

\footnotetext{
${ }^{28}$ The first "Guideline Tenet" listed for facilities interested in BFUSA certification notes the requirement for [w]ell-constructed, comprehensive policies [that] effectively guide staff to deliver evidence-based care; the third is the [m] onitoring of practice ... to assure adherence to policy" (Baby Friendly). As is discussed more fully later in this chapter, the BFUSA organization provides clear guidance on what constitutes "evidence based care" and, thus, what must drive policy within BFUSA certified facilities.
} 
written in response to a growing public health crisis. Tracing this rhetorical history is significant to my argument that BFUSA guidelines interpret the Code in narrow and problematic ways and important to making my personal exigence in relation to this particular case study apparent. These introductory sections allow me to establish my position that BFUSA has selectively taken up only those elements of The Code that center on breastfeeding management and oversight, resulting in a policy that fails to attend to the broader social justice goals of the original policy. Following this foundational analysis, I next employ an intersectional feminist rhetorical methodology to guide my critique of specific BFUSA guidelines and discourses that influence the treatment of caregivers and infants in the U.S., illustrating how public policies purported to serve user needs employ rhetorics of efficiency that can result in already vulnerable users being harmed rather than helped. Then, to highlight how individuals and organizations are resisting the homogenizing, reductive rhetorics and subsequent material impacts of BFUSA policy, I examine the work the Fed Is Best organization. Fed is Best—-a non-profit, volunteer organization of health professionals and parents who study the scientific literature on infant feeding and real-life infant feeding experiences of mothers through clinical practice and social media connections"illustrates how an intersectional feminist rhetorical integration of extraordinary user-experience can generate productive reimagining of a policy, its users, and the relationship between these two. My analysis of Fed is Best illustrates the ways in which an intersectional feminist rhetorical methodology that foregrounds embodied experience and embraces difference as both generative and productive can validate the experiences of those whom a policy seeks to manage and/or exclude. Finally, I consider how an intersectional feminist rhetorical methodology might contribute to existing usability scholarship in technical communication and disability studies to open potentials for improving BFUSA policy. Ultimately, I offer this case study as both an 
example and a contribution to intersectional feminist rhetorical work that uncovers the violence of hegemonic rhetorics, and to technical and professional communication research that directly links usability to issues of social justice.

In the next section, I contextualize the Code and my embodied positionality in relation to infant feeding policies before tracing how BFUSA policy emerged from, and continues to draw upon, the International Code for the Marketing of Breastmilk Substitutes- a context I argue is important for appreciating both the origins and limitations of current BFUSA policy. ${ }^{29}$

\section{Personal Exigency and the Link between BFUSA and The Code}

My research into infant nutrition policies and BFUSA begins with an historical moment in public policy, and one that I initially understood to be an important moment of social justicethe World Health Organization's (WHO) passage of the International Code of Marketing of Breastmilk Substances (hereafter referred to as the Code). This understanding was founded in the stories my mother has shared with me about her time in Abidjan in the 1970s: Stories in which she recounted the horrible consequences of companies aggressive promotion of infant formula in communities that lacked consistent access to the necessary elements to safely shift from breast to bottle feeding. At the time, companies such as Nestle were documented giving "gifts to health workers and us[ing] saleswomen dressed as 'nurses' to provide donations of formula and advice to mothers" (Brady 529). Publications at the time related the steadily increasing rates of global infant mortality, malnutrition, and diarrhea as corporations rapidly expanded the use of infant

${ }^{29}$ The idea of working backward and tracing the history of a policy is informed both by Vicki Tolar Collins method outlined in the The Speaker Respoken and Rebecca Dingo's concept of gender mainstreaming - of "consider[ing] how meanings shift and change due to context, history and even intention" (Networking 19). 
formula in the 1970s (Jeliffe; Muller). In many targeted sales areas, the infrastructure did not exist to support commercial formula as a breastmilk substitute: contaminated water rendered formula preparation unsafe, a lack of refrigeration made storage impossible, illiteracy and economic hardship led to the watering down of formula and a reduction in nutritive value, and unstable or nonexistent health services rendered impossible the education, support, and treatment of mothers who switched from breastfeeding to formula.

My research into the Code, then, was prompted by a desire to examine the rhetorical moves that effectively pushed public and political actors to respond to this humanitarian crisis, to examine the oppressive practices of Western corporations, and to view infant nutrition issue as a public health issue. Thus, I entered into my analysis of the Code seeking the ways in which public policy could help relieve human suffering and reduce global inequities prompted by capitalistic greed. As I read the Code, and even more so BFUSA policy, I recognized that this research was also influenced by my positionality as a new mother and friend to others with infants and a personal investment in the ways that technical documents can script the interactions between caretakers, infants, physicians and medical staff. Briefly stated, I was concerned that the original, and broad goals of the Code - to curb unethical practices and improve the health and well-being of infants and mothers - were being undermined by newer policies that focused almost exclusively on the role of breastfeeding in achieving these ends. For me and many around me, it seemed that regardless of the unique struggles, pains, or pleas, we increasingly encountered a medical profession that was inflexible at best, and at times grossly negligent due to a nearly singular dedication to the idea that "breast is best." 30

\footnotetext{
${ }^{30}$ It is important to note that assumptions about, and messages shared with, caretakers regarding infant nutrition vary greatly by race, income, gender-identity, and ablebodiedness among other
} 
My focus, then, began to shift—examining not only how the Code was constructed as a means for addressing a public health crisis but also how this foundational document is taken up in problematic ways that foreground the management of, rather than service to, users and their needs. One such example is BFUSA policy that narrowly takes up the Code such that infant and maternal health are reduced to the singular act breastfeeding — an act presented as a universally superior choice for all users. In response to, and compliance with, BFUSA policy, maternity hospital practices in the U.S. are directed to prioritize breastfeeding in nearly all situations, a move that I argue undermines patients unique circumstances, individual needs, and expressed desires. And though the "breast is best" message is certainly not universally dispersed within the U.S., ${ }^{31}$ policies designed to undermine the agency of new mothers have material consequences for all infants and caretakers. My intersectional feminist rhetorical analysis of BFUSA is not informed by a desire to weigh in on the breast versus bottle debate in which one approach is framed as "better" or right for all users, ${ }^{32}$ rather it seeks to make apparent how the bodies,

factors. As an educated, financially and home secure, heterosexual, cisgender, able-bodied, married, and insured white woman living in an urban area, the message to breastfeed - from medical professionals, my family, community, and the media - is strong. At the same time, ready access to healthcare, clean water, refrigeration, a breast pump and accessories, family support, and educational resources (among other factors) allowed me a flexibility in my choices that many are not afforded.

${ }^{31}$ See the work of organizations such as the Black Mothers Breastfeeding Association (blackmothersbreastfeeding.org), The National Association of Professional and Peer Lactation Supporters of Color (napplsc.org), Birthing and Breast or Chestfeeding Trans People and Allies (www.facebook.com/groups/TransReproductiveSupport), as well as regional organizations such as the Oregon Inter-Tribal Breastfeeding Coalition (oitbc.com) and the Native American Breastfeeding Coalition of Washington (facebook.com/NABCWA) for information on how cultural, historical, economic, and environmental histories and contexts in which each individual is situated have a significant impact on the infant feeding messages they receive and the supports they are afforded.

${ }^{32}$ Although not central to this project, combative terms such as debate, war, or controversy, which are regularly invoked in infant feedings discourse, can serve to distract from, rather than further, projects aimed at making infant feeding policies increasingly inclusive. See Amy 
experiences, and voices of those most immediately impacted by infant feeding policies are increasingly distanced from the discourse of public policy.

Borrowing from Rebecca Dingo's practice of tracing policies in order to see how "arguments shift" as policy makers selectively take up and reframe terms and ideas to better fit their solutions centered on the reformation of women's individual behavior $(31 ; 64-65)$ and responding to Haas and Eble's call for technical communicators to "ascertain how ... networks are constructed, by whom, toward what ends" (4), in the next section I trace the history of infant feeding policy from the International Code of Marketing of Breastmilk Substances as well as the subsequent Innocenti Declaration. I do so in order that I can then highlight how the initial, global goals of The Code - to address the dangerous and unethical practices of formula companies and increase infant and maternal health — are being lost as this policy is taken up and redistributed on the national level through BFUSA.

\section{From The Code to BFUSA}

Ratified in a 1981 conference of the World Health Organization, the Code was intended to provide governments with guidelines to monitor and restrain corrupt marketing practices by infant formula companies and as an initiative to outline global policies to "improve the health and nutrition of infants and young children" (International 5). Since its adoption, The Code has served as a point of reference for nearly every breastfeeding guideline, policy, and study that has emerged from meetings of global organizations engaged in issues of infant nutrition and

Koerber's Breast or Bottle?: Contemporary Controversies in Infant-Feeding Policy and Practice for an extensive analysis of this history. 
women's health. ${ }^{33}$ Read in its entirety, the Code is a rich document with extensive treatment of the five main themes that emerged from talks between the WHO and UNICEF representatives regarding childhood feeding: the encouragement and support of breastfeeding; the promotion and support of appropriate and timely complementary feeding (weaning) practices with the use of local food resources; the strengthening of education, training and information on infant and young child feeding; the promotion of the health and social status of women in relation to infant and young child health and feeding; and the appropriate marketing and distribution of breast milk substitutes (4-5). Among the many recommendations in the twenty-four page document, the first three commitments outlined in the body of The Code, quoted below, are crucial:

- Affirming the right of every child and every pregnant and lactating woman to be adequately nourished, as a means of attaining and maintaining health;

- Recognizing that infant malnutrition is part of a wider problem including a lack of education, poverty, and social injustice; [and]

- Recognizing that the health of infants and young children cannot be isolated from the health and nutrition of women, their socioeconomic status, and their roles as mothers. (International Code 6)

Reflected in these commitments is the idea that childhood health goes beyond the breast milk versus formula debate, that infant malnutrition is the product of social and economic issues that cannot be reduced to breastfeeding choices alone, and that maternal and infant nutrition and

\footnotetext{
${ }^{33}$ Such as UNICEF's Innocenti Declaration: On the Protection, Promotion and Support of Breastfeeding (1990); The Baby Friendly Hospital Initiative (1991); WHO/UNICEF Global Strategy for Infant and Young Child Feeding (2003); World Health Assembly Resolutions 33.32, 34.22, 35.26, 37.30, 39.28, 41.11, 43.3, 45.34, 46.7, 47.5, 49.15, 54.2, 55.25, 58.32, 59.11, 59.21, 61.20 , 63.23, 65.6, 69.9; The International Code of Marketing of Breast-milk Substitutes, Frequently Asked Questions (2017).
} 
health are intricately linked. Certainly, the promotion of breastfeeding was, and remains, a central tenet of the Code: On behalf of the authors of WHO and UNICEF, the original document clearly articulates breastfeeding as the "ideal" practice for both infant and mother and encourages governmental and nongovernmental agencies to actively work to grow and support this practice (International Code 6). Yet, breastfeeding is framed as one part of a larger mission to improve the health of infants and their mothers. The Code recognizes multiple entities and practices as necessary for ensuring infant health—noting that infant health is inextricably linked to social issues of poverty, education, and social justice, and that infant morbidity [at the time] was clearly tied to the unsafe marketing practices of formula companies (International 10, 11). ${ }^{34}$ Following The Code, policymakers from UNICEF and the WHO ratified the Innocenti Declaration in 1990, an agenda designed to, among other objectives, "[g]ive effect to the principles and aim of the International Code of Marketing of Breast-milk Substitutes and subsequent relevant Health Assembly resolutions in their entirety" (Innocenti Declaration 2005). The Innocenti Declaration proposed that each government establish national breastfeeding coordinators and committees; ensure that hospitals and maternity facilities promote and monitor breastfeeding and enact the principles and aims of the Code; and increasingly enact and enforce breastfeeding-friendly laws at the national level. ${ }^{35}$ Within the United States, BFUSA is this national authority charged with this enforcement. BFUSA policies are, I argue, a vital site for analysis: As of October 11, 2018, "539 U.S. hospitals and birthing centers in all 50 states, the

\footnotetext{
${ }^{34}$ To illustrate this, in the "Preamble," the term breastfeeding does not appear until the fourth tenet - the first three stressing the relationship between infant and maternal malnutrition and issues of poverty, education, and social justice (International 10).

${ }^{35}$ To read the 1990 tenets and the operational targets added in 2005, see the Innocenti Declaration 2005: On Infant and Young Child Feeding (unicef.org/nutrition/files/innocenti2005m_FINAL_ARTWORK_3_MAR.pdf) .
} 
District of Columbia, and the Commonwealth of Puerto Rico hold the Baby-Friendly designation. $26.8 \%$ of annual U.S. births (approximately 1,034,2000 births) occur at these BabyFriendly facilities" (Baby Friendly; "Find"). BFUSA policy, then, is increasingly shaping the experience of, and care provided for, individuals within the United States hospital systems and health care facilities. My methodology calls on me to critique this policy because, although ostensibly aimed at improving the health of infants and mothers, BFUSA guidelines and surrounding documents—documents that directly shape hospital policy and staff practicesemploy rhetorics of efficiency that increasingly shift the focus from responsiveness to user-needs to management of users' bodies.

In the following section, I engage an intersectional feminist rhetorical critique of BFUSA policy and discourse to reveal how rhetorics of efficiency in BFUSA literature shift the focus of infant feeding policy toward the management of bodies rather than service to users. The effect is an increasingly normative framework that narrows the range of embodied realities accounted for, and users imagined, within the policy and surrounding discourse. I suggest that rhetorics of efficiency within BFUSA policy result in the privileging of certain bodies and ways of being while ignoring, demeaning, or oppressing others.

\section{Rhetorics of Efficiency in BFUSA Policy}

As described more fully in Chapters I and II, I understand efficiency as a rhetorically and culturally situated concept—emerging from, and reflected through, the values of a society (Frost; Katz). In this section I argue that BFUSA policy fails to adequately acknowledge that what is framed as most efficient—for baby, family, and society—relies on a disproportionate investment 
of time, energy, and self on the part of women ${ }^{36}$ and disregards individual embodiment through recurrent references to efficiency and success in relation to expenditure of time, money and resources. Such an approach devalues embodiment, disregards diverging medical evidence, and disproportionately places onus for the public health on the bodies of certain women. ${ }^{37}$

This section enacts intersectional feminist rhetorical values as it is focused on identifying and disrupting rhetorics of efficiency that function to include and exclude certain bodies from potential societal and institutional benefits; manage and control bodies to perform in sanctioned ways; and further the status quo in which certain bodies are privileged and others oppressed. I focus particularly on how BFUSA policy and surrounding discourse engage rhetorics of efficiency in a way that:

- Frames the performance of certain normative acts as directly linked to positive outcomes for individual, infant, and public health and "good"

- Ignores or undermines competing and/or nuanced views in order to further an image of the policies goals and guidelines as universally applicable to all individuals and situations

- Stresses measurable outcomes (such as target numbers or set goals) rather than responsiveness to individual users ${ }^{38}$

\footnotetext{
${ }^{36}$ Current breastfeeding policies place this responsibility on heteronormative cisgender women and their biological offspring.

${ }^{37}$ I use the terms "women"/"woman" to reflect the language of the Code and related breastfeeding policies. However, as K.J. Rawson explains, the term "woman" privileges white, heterosexual, gender-normative, able-bodied identities (Rawson 46). Within breastfeeding policy, "women" are additionally assumed to possess lactating breasts. Thus, as I examine later in this chapter, this term fails to account for the myriad identities and positionalities of caregivers charged with infant feeding decisions.

${ }^{38}$ Breastfeeding policies have many potential users, but I focus specifically on the "user" as the individual tasked with deciding how an infant will receive nutrition. "Users" as currently represented within breastfeeding policy language is nearly universally limited to lactating, cisgender women who are the biological parent of an infant. As I stress throughout this chapter,
} 
- Relies on reductive rhetorics of "choice" that downplay inequities and situational constraints, and instead point to individual motivation or ignorance as the barriers to successful outcomes.

An intersectional feminist rhetorical analysis reveals that BFUSA's policies and guidelines rely on rhetorics of efficiency that establish constructs of a "normal" body, noting that: "[a]lmost all mothers can breastfeed successfully"; that "breastfeeding is the normal way to feed an infant"; and that breastfeeding is a natural process for "mothers of normal infants" (27, 19). The bodies of mother and infant are normalized as breastfeeding is framed as a natural biological event for the mother and a necessary process to ensure the normal and natural development of a child. This then frames individuals who cannot or do not breastfeed — such as women whose bodies do not lactate and/or whose milk is unsafe due to environmental contaminants $^{39}$; adoptive or foster parents; or those who choose not to breastfeed due to material constraints or embodied desires — as abnormal and thus deviant, untrustworthy, or in need of fixing. ${ }^{40}$ The first of three tenets informing BFUSA's organizational philosophy clearly frames a lactating cisgender female body and the act of breastfeeding as the normal and ideal point of reference in infant nutrition:

this exclusionary language within breastfeeding policy demands increased attention as it ignores myriad identities and bodies who are the primary users of the policy.

${ }^{39}$ Winona LaDuke's study of the Akwesasne Mothers' Milk Project revealed how the Mohawk of northern New York and Canada addressed the dangers of PCBs in their water and food and, in turn, their bodies. In a study of fifty mothers over the course of several years, the project "documented a 200 percent greater concentration of PCBs in the breast milk of those mother who at the fish from the [contaminated] St. Lawrence River as opposed to the general population" (19).

${ }^{40}$ Disability studies scholarships by Dolmage, Garland-Thomson, Jung, and many others include extensive examination of how norms frame certain bodies as abnormal or unfit. 
There is no question that breastfeeding is the optimal feeding and caring method for the health of the baby and the mother. An abundance of scientific evidence concludes that mothers and babies who breastfeed experience improved health outcomes and lower risks for certain diseases. Breastfeeding is the natural biological conclusion to pregnancy and an important mechanism in the natural development of the infant. (Baby Friendly, "Our Philosophy")

Through the homogenization and norming of maternal and infant bodies, the policy assumes that all caretakers experience the arrival of an infant in the same way.

An intersectional feminist rhetorical critique of the policy makes apparent the reductive nature of rhetorics of efficiency that measures success according to rates at which bodies and practices perform within the normative frameworks established through policy language. For example, the first part of this statement states that "there is no question" that breastfeeding is the best way to nourish and care for an infant. This information is presented as indisputable, objective fact, despite the considerable body of work that calls into question the extent and scope of beneficial health outcomes directly linked to the practice of breastfeeding versus other indicators (e.g., socioeconomic status or family dietary habits), and reflects what many argue is a tendency of breastfeeding proponents and policies to conflate correlation with causation. ${ }^{41}$ In addition to arguing for the superiority of breastfeeding for infant nutrition, the policy positions

\footnotetext{
${ }^{41}$ Scholarly literature such as Wolf's Is Breast Best and published medical studies including "Unintended Consequences of Current Breastfeeding Initiatives:" (Bass, et al.); "Association between infant breastfeeding and overweight in young children" (Heideger, et al.); Breastfeeding, Cognitive and Noncognitive Development in Early Childhood: A Population Study" (Girard, Doyle and Tremblay); "or "Is breast truly best? Estimating the effects of breastfeeding on long-term child health and wellbeing in the United States using sibling comparisons" (Colen and Ramey) are a few in the growing body of research that reflects such critiques.
} 
breastfeeding as the "optimal" caring method: Thus caring is reduced to the identifiable, singular act of breastfeeding. Caretaker bodies which cannot or do not breastfeed, then, are framed as un-, or at a minimum under-, caring.

The latter part of the statement shifts from breastfeeding as a medicalized practice supported by quantifiable, unquestionable scientific evidence, to breastfeeding as the natural, concluding phase of pregnancy itself. Not only are bodies that do not breastfeed situated as unnatural, but through the act of not-breastfeeding, these individuals also foster "unnatural" infants since breastfeeding is articulated as "an important mechanism in the natural development of the infant." By limiting the scope of imagined users, then, to a lactating, cisgender female body occupying the role of a biological mother, BFUSA limits the scope of users whose bodies and embodied experiences are reflected within the policy and, thus, the usability of the policy itself.

Indeed, individuals and organizations have argued that, among other things, BFUSA and other breastfeeding policies fail to anticipate or address individual patient needs and do not adequately account for the complexities of motherhood and infant care ${ }^{42}$-yet BFUSA defends its position. ${ }^{43}$ Countering claims by organizations such as Fed Is Best that BFUSA policies undermine a mother's ability to choose what is best for her and her infant, BFUSA argues that its policies "are designed to be responsive to a mother's choice," but that—-it is expected to be her informed choice" (Baby Friendly, BFUSA "Response"). Despite situating infant feeding decisions as ultimately residing with the mother, BFUSA literature makes evident that it is the

\footnotetext{
${ }^{42}$ See "Unintended Consequences of Current Breastfeeding Initiatives" by Bass, Gartley and Kleinman in JAMA or "Breastfeeding at any Cost?" by Lopez in The Atlantic as two examples. ${ }^{43}$ The Baby Friendly USA website provide ample links to articles, publications, and testimonials supporting their positions.
} 
BFUSA certified hospital staff — not the mother—who decides what constitutes an "informed choice." This public response, prominently posted on BFUSA's website, is an example of how the organization uses supporting documents and discourse to further promote a particular stance - particularly that informed, caring mothers choose to breastfeed. This same understanding, however, is similarly developed within policy guidelines: For instance, if a mother indicates a desire to use formula, guideline 6.1 directs BFUSA certified staff to "first explore the reasons for this request, address the concerns raised, and educate [the mother] about the possible consequences to the health of her infant and the success of breastfeeding" (Guidelines 19). The underlying message is that a woman in possession of scientific evidence and motherly instincts will choose, or potentially be persuaded, to breastfeed. A mother who does not conform to the normative practice outlined in the policy—indicated via her request for formula — is required to justify her reasoning and submit to a lecture about the benefits of breastfeeding and risks of formula feeding. ${ }^{44}$ Even then, a woman's "choice" must be further defended as she must convince subject experts (in this case the hospital personnel) of her aptitude to reasonably make said choice. Thus, a woman's embodied knowledge can be disregarded by certain "experts": Her understandings of her own body, needs, and desires require confirmation by an "expert" before they are recognized (through documentation) as reasonable and sound. ${ }^{45}$

\footnotetext{
${ }^{44}$ It is important to point out that the risks and benefits presented are garnered from materials that adhere to the "unquestionable" superiority of breastfeeding (as noted earlier); for instance, literature that links formula feeding to risks ranging from allergies and obesity in children to cancer and weight gain in mothers.

${ }^{45}$ The requirement for a mother/caretaker to convince "experts" about their ability to make an informed choice can be particularly challenging for those who are already discriminated against within the U.S. medical system. For example, a 2015 study in the American Journal of Public Health notes that "[m]ost health care providers [in the U.S.] appear to have implicit bias in terms
} 
Within BFUSA policy and literature, the concept of "choice" is constrained through rhetorics that situate breastfeeding as both normal and good for maternal and infant health. As I argue in the following section, the idea of "choice" is further reduced as breastfeeding is explicitly lauded as the efficient and good choice for financial, community, and environmental health. The Preamble to the U.S. Baby Friendly Guidelines and Criteria begins by stating that "[h] uman milk provided by direct breastfeeding is the normal way to feed an infant" (5), after which it outlines various reasons that breastfeeding is advantageous for mother and baby. The focus then shifts to tie breastfeeding to cost-effectiveness—or efficiency—-for family, community, and nation:

The diverse benefits of breastfeeding translate into hundreds of dollars of savings at the family level and billions of dollars at the national level through decreased hospitalizations and pediatric visits. Researchers have estimated that were the national initiation and 6 months goals (above) to be met, between 3.6 and 13 billion dollars would be saved on pediatric health care costs ... Consequently, activities to promote the national objectives are clearly among the best and most cost-effective health promotional strategies available. (7)

Supporting documents on BFUSA's website reinforce the tropes outlined in the policy, particularly those of breastfeeding as medically superior, empowering for women, and economically advantageous. For instance, the "Importance of Breastfeeding" page on the BFUSA website lists the following five benefits: (1) Breastfeeding offers an unmatched

of positive attitudes toward Whites and negative attitudes toward people of color ... [and that] [i]mplicit attitudes were more often significantly related to patient-provider interactions" (Hall, et al.). Studies also point to varied physician-patient interactions based on gender, weight, income-level, language, and disability among other factors. 
beginning for children; (2) Mothers who breastfeed are healthier; (3) Families who breastfeed save money; (4) Communities reap the benefits of breastfeeding; and (5) The environment benefits when babies are breastfed. BFUSA recurrently frame breastfeeding in the following ways:

Table 1

BFUSA Policy Language and Tropes

\begin{tabular}{|l|l|}
\hline \multicolumn{1}{|c|}{ BFUSA Policy Language } & Tropes that Ground Policy Language \\
\hline $\begin{array}{l}\text { "Human milk provides the optimal mix of } \\
\text { nutrients and antibodies necessary for each } \\
\text { baby to thrive" }\end{array}$ & Medically superior \\
\hline $\begin{array}{l}\text { "[Women] are empowered by their ability to } \\
\text { provide complete nourishment for their } \\
\text { babies" }\end{array}$ & Empowering \\
\hline $\begin{array}{l}\text { "Breastfeeding uses none of the tin, paper, } \\
\text { plastic, or energy necessary for preparing, } \\
\text { packaging, and transporting artificial baby } \\
\text { milks. Since there is no waste in } \\
\text { breastfeeding, each breastfed baby cuts down } \\
\text { on pollution and garbage disposal problems." }\end{array}$ & Environmentally Friendly \\
\hline Source: "Importance of Breastfeeding." Baby-Friendly USA, www. bfusa.org. \\
\hline
\end{tabular}

By consistently linking breastfeeding to efficient, ostensibly desirable outcomes, BFUSA policy forwards the idea that a series of singular, logical outcomes and experiences will result from the practice of breastfeeding. Compliance is promoted by appeals to self, family, environment, and society. Of particular note, and thus quoted at length, are arguments that tie the practice of breastfeeding to efficiencies in the home, workplace, and school:

\section{Families Who Breastfeed Save Money}

In addition to the fact that breast milk is free, breastfeeding provides savings on 
health care costs and related time lost to care for sick children. Because breastfeeding saves money, fathers feel less financial pressure and take pride in knowing they are able to give their babies the very best. ${ }^{46}$

\section{Communities Reap the Benefits of Breastfeeding}

Research shows that there is less absenteeism from work among breastfeeding families. Resources used to feed those in need can be stretched further when mothers choose to give their babies the gift of their own milk rather than a costly artificial substitute. Less tax money is required to provide assistance to properly feed children. Families who breastfeed have more money available to purchase goods and services, thereby benefiting the local economy. Research also shows that breastfed babies have higher IQ scores, as well as better brain and nervous system development. When babies are breastfed, both mother and baby are healthier throughout their lives. This translates to lower health care costs and a reduced financial burden on families and third-party payers, as well on community and government medical programs. ${ }^{47}$ (Baby Friendly, "Importance of Breastfeeding," emphasis added)

The Families Who Breastfeed Save Money statement ignores the expenditure of time, energy and emotion by bodies who breastfeed. It assumes that breastfeeding individuals either do not work outside the home or are employed in an environment that provides the time, space, support, and

\footnotetext{
${ }^{46}$ BFUSA includes a note that directs the reader to the following citation: Tuttle, C.R. et al. J Am Diet Assoc 1996; 96(9): 885-90.

${ }^{47}$ BFUSA includes a note that directs the reader to the following citation: Montgomery et al. $\mathrm{J}$ Am Diet Assoc 1997; 97(4): 379-85.
} 
resources to breastfeed or pump at work. ${ }^{48}$ It fails to acknowledge the monetary and time investment by those who are unable to breastfeed their infant but who commit to obtaining breastmilk through other means. ${ }^{49}$ It implies that to not breastfeed is: monetarily frivolous, reduces a family's savings, requires parents to use additional sick-days, and causes stress and diminished pride for partners/"fathers." Use of the term "father" assumes a heteronormative couple ${ }^{50}$ Equally problematic, by arguing that "fathers feel less financial pressure and take pride in knowing they are able to give their babies the very best," the policy forwards patriarchal ideologies in which the "man of the family" assumes financial responsibility, and it conflates a woman's choice over her body with a father's access "to give" his family the best.

The Communities Reap the Benefits of Breastfeeding statement frames a decision not to breastfeed as a choice that: denies nutrition to those "in need;" unduly burdens taxpayers; and hurts local businesses, communities and governments. In this way, those who are unable or decide not to breastfeed are rhetorically situated as complicit in the financial, medical, emotional, and productive wrongs of family and society. The embodied experiences of users are discounted while the efficient financial and labor functioning of family, community, and nation are prioritized and, the policy insists, either furthered or diminished by breastfeeding decisions.

${ }^{48}$ This ignores, for instance, that only a small fraction of full-time workers in the U.S. have access to paid leave. See Jenna Sauers "Why Women Really Quit Breastfeeding" for an overview and myriad relevant sources to the issue of breastfeeding in the workplace.

${ }^{49}$ Organizations such as the Human Milk Banking Association of North America as well as numerous groups started via social media (groups like Eats on Feets or Only the Breast) connect individuals looking to purchase or sell, obtain or share breastmilk with those for whom - as adoptive parents, due to physical or psychological reasons, and/or myriad other circumstancesbreastmilk is a priority but breastfeeding is not possible.

${ }^{50}$ As Ricki Solinger notes from the 2010 census data, only one in five U.S. households are considered a "traditional household - a mother, a father and a child or children" and "increasing numbers of American are creating domestic and familial relations that violate prescriptive norms" (Reproductive Politics 99). 
BFUSA's website and literature further disconnects infant feeding from an embodied choice by citing at length a 2017 position paper from the American Association of Family Physicians, which states that "[w]ith all of the health advantages of breastfeeding for mothers and children, as well as its economic and ecological impacts, breastfeeding is a public health issue, not merely a lifestyle choice" (Baby Friendly, "Breastfeeding Resources"). Citing breastfeeding as a practice that "protects a child against abuse and neglect" and "helps protect the environment because it involves no use of grazing land for cows, no product transportation or packaging, and no waste," the study, and BFUSA's endorsement of it, suspends breastfeeding from an embodied choice made by an individual and their support system and into the realm of managed efficiency. In this context, breastfeeding is framed as a singular, discernable act that can be separated out from complex societal concerns that seem to elude satisfying oversight and resolution - that can be managed both on the individual and the societal level.

Reinforcing the economic efficiency of breastfeeding, BFUSA's 2016 Revised Guidelines and Evaluation Criteria note that "[t]he diverse benefits of breastfeeding translate into hundreds of dollars of savings at the family level and billions of dollars at the national level" (6). Presented in this context, breastfeeding is again distanced from embodied realities and is instead "translated" into simple dollars and cents. The "choice" to breastfeed reflects a commitment not just to the infant, but to the economic and social health of family and community: Breastfeeding becomes the act of a responsible family member and citizen. Yet this ignores that individual experience and choice always occur in relation to others. A person's cultural contexts, health, work and family life, and myriad other positionalities and experiences are inseparable from breastfeeding decisions; the suggestion that breastfeeding is an individual choice made in isolation ignores and undermines this reality. 
BFUSA Guidelines and Evaluation Criteria further manages choice by outlining directives for all who interact with new infants and their caregivers within BFUSA certified facilities. For instance, BFUSA policy mandates that in order to receive and maintain Baby Friendly designation, hospitals must ensure that "all health staff member who have any contact with pregnant women, mothers, and/or infants"-from anesthesiologists to housekeeping staffare trained to promote "the importance of exclusive breastfeeding" and to "provide evidencebased care" (8). The Guidelines leave little room for the experiences, desires, or knowledges of the patient to influence the interactions between staff and patients: medical advice is dispensed according to clear guidelines that establish "normal" interactions between infants and their caregivers. For example, the first sentence of the Guidelines and Evaluation Criteria Preamble reads: "Human milk provided by direct breastfeeding is the normal way to feed an infant" (5). The responsibility of staff to promote breastfeeding is furthered through statements noting that the "scientific evidence overwhelmingly indicates" the superiority of breastfeeding and that "breastfeeding is the single most powerful and well-documented preventative modality available to health care providers to reduce the risk of common causes of infant morbidity" (5). "Normal" behavior is outlined as singular and medical evidence is framed as "overwhelmingly" clear; thus staff are left with little space to address each situation and patient as complex. The potential, then, for varied patients and their practices to be recognized as "normal" and/or desirable within the context of the policy is limited at best. The guidelines are prescriptive of, rather than responsive to, user needs.

Further reflecting the normative constructs of the policy, consideration for those who cannot, or choose not to, breastfeed does not appear until guideline six within BFUSA policy: "The health care delivery environment should be neither restrictive nor punitive and should 
facilitate informed health care decisions on the part of the mother and her family" (8). In addition to its placement, the wording of the directive is important: The guideline does not prompt staff to advocate for, be supportive of, or care for each patient. Unlike the clear directives for what hospital staff should do to promote breastfeeding (such as in the section above), this portion of the guideline fails to give explicit directives as to how this goal should be achieved. For instance, it does not require that staff, as a measure to safeguard against restrictive interactions with patients and their families, be versed in the cultural, environmental, biological, and/or personal contexts that influence an individual's desire to bottle rather than breastfeed. And though this guidelines notes that the environment "should be neither restrictive nor punitive," the follow-up that the system should "facilitate informed health care decisions" must be read in context with the earlier description of what constitutes an informed health care decision: As noted above, BFUSA policy generally recognizes breastfeeding as the only decision indicative of an "informed decision."

An intersectional feminist rhetorical approach to analyzing BFUSA policy illustrates how absolutist language, a lack of diverging medical opinions, and the requirement that patients defend and justify their embodied knowledge and individual choice to personnel (who then must document that this decision was made despite counseling) distances the guidelines from a userfriendly design. The current form of BFUSA policy is more focused on obtaining a singular outcome - increased breastfeeding rates - than it is on responding to individual patients. Through this narrow focus, usability is reflected through quantitative data (initiation rates, duration rates) and traditional notions of efficiency (savings in money, time and resources) rather than on the policy's capacity to create in environment in which medical personnel can anticipate, listen to, and respond to individual patient needs. I argue that distancing users embodied 
experiences from usability assessments ultimately distracts from, and limits the potential of, the long-term goal of healthy infants and caregivers. The construction of normative frameworks situates individual patients and their needs as challenges to, rather than the focus of, BFUSA policy goals. The policy, then, serves as a model to bring bodies into line with the norm established via the organization rather than as a framework for engaging with, and responding to, the embodied, contextualized needs of individual users.

An intersectional feminist rhetorical analysis of BFUSA policy points to language that aims to bring bodies into alignment through traditional, patriarchal rhetorics designed to persuade, to intentionally and consciously convert or change another (Foss and Griffin 362; Gearhart 53). By promoting a single practice performed by a normalized body as the goal—and explicitly or implicitly ignoring or undermining varied embodiments and alternative approaches-BFUSA policy distances itself from the long-term public-health goal of infant nutrition policies that improve outcomes for all infants. Put another way, I argue that rhetorics of efficiency within BFUSA policy emerge from, rely on, and forward the ideological constructions of normed bodies. In the pursuit of efficient outcomes, policy guidelines are designed such that individuals and institutions can ignore, deny, or dismiss the embodied experiences of individuals who diverge from the norm.

Because an intersectional feminist rhetorical methodology also values the work of those whose individual and collective acts can serve as models of resistance to policies that seek to manage bodies, in the next section I point to the potential of organizations such as Fed is Best in resisting the normative frameworks and efficiencies of BFUSA policy. Fed Is Best considers BFUSA policy through a user-centered design approach in which subject experts honor and incorporate ongoing user feedback - a practice that, at its best, is grounded in feminist rhetorical 
practices that value "understanding rather than persuasion," and engage "across boundaries"

(Glenn 10; Royster and Kirsch 42) and technical and professional communication approaches to usability that foreground the importance of user involvement in public policy design (Grabill, "Shaping").

\section{Foregrounding Embodied Experience: Examining Fed is Best}

As outlined in Chapter II, two central goals of an intersectional feminist rhetorical methodology are reframing embodied difference as both generative and productive, and recognizing and building upon the work of those outside of academia whose individual and collective acts serve as models of resistance to policies that seek to manage bodies. I now turn to Fed is Best as a second case study that illustrates these goals. As international groups such as UNICEF and the WHO, medical staff and institutions, and organizations such as La Leche League each focus on establishing breastfeeding as the "normal" and best practice for all caretakers in every circumstance ${ }^{51}$, other organizations are emerging to make explicit that for many, there is more than one "normal," safe, and healthy way to feed an infant. ${ }^{52}$ One such group is Fed Is Best, which grew out of a personal experience that prompted one individual to work against a system that did not recognize her embodied realties and a desire to share with others that an issue as personal and complex as parenthood did not lend itself to a singular, simple answer.

\footnotetext{
${ }^{51}$ Examples include UNICEF's "Improving breastfeeding, complementary foods and feeding practices," the WHO's "Health Topics: Breastfeeding," or La Leche League's "Philosophy." ${ }^{52}$ Infant nutrition options are considerably limited for those who lack access to clean water, sanitation, or refrigeration.
} 
The Fed is Best Foundation was founded by Christie del Castillo-Hegyi, M.D., a Board Certified Emergency Physician, and B. Jody Segrave-Daly, an International Board Certified Lactation Consultant (IBCLC) and Newborn Intensive Care Unit Registered Nurse (Fed is Best, “About"). The organization's website includes links for both caretakers and hospitals alongside links to the foundation's blog and various reports from the media (Figure 2).

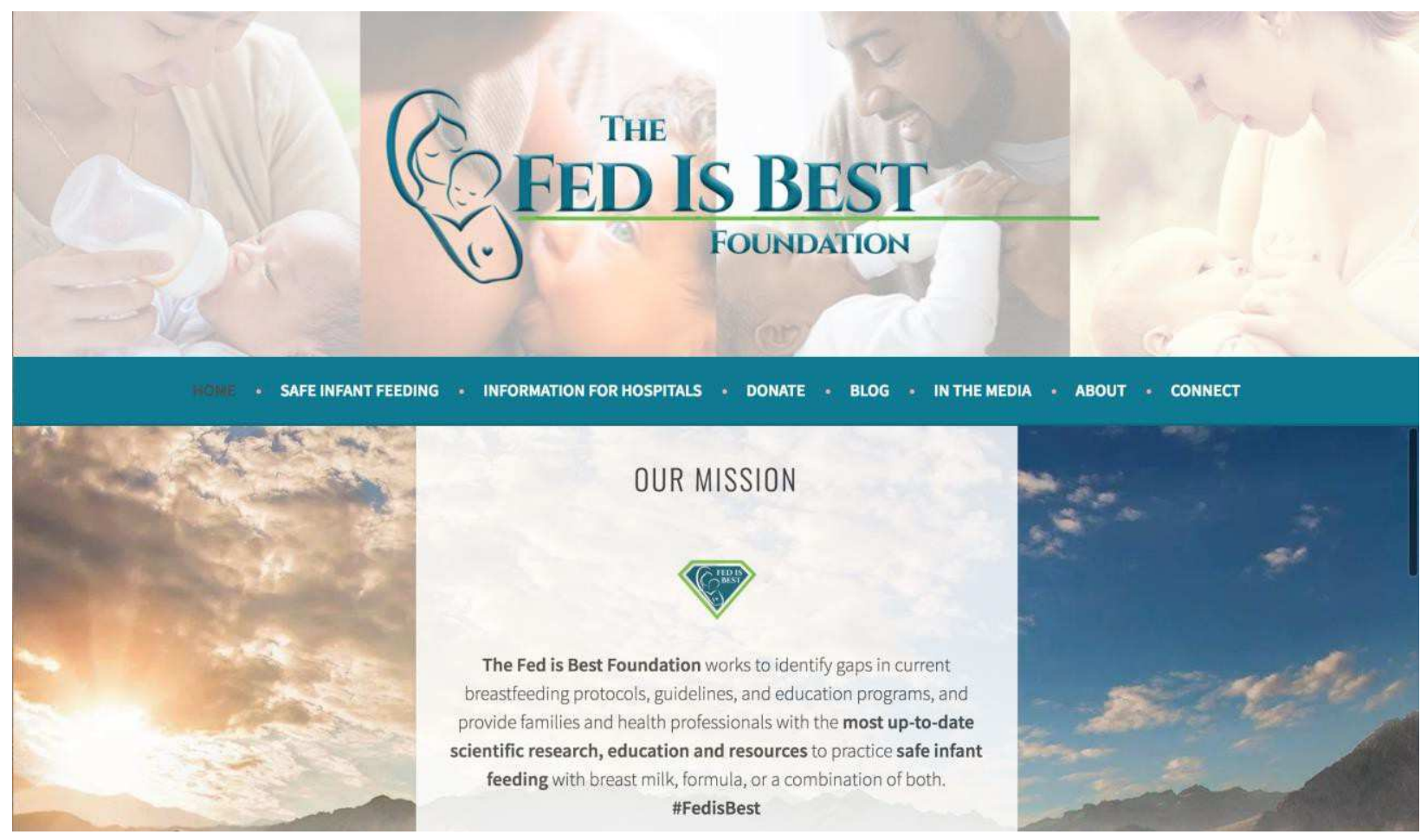

Figure 2: Fed is Best Foundation Homepage

Source: The Fed Is Best Foundation, https://fedisbest.org.

As the banner pictures suggest, the foundation has a clear mission to promote the value of both breast and bottle feeding, a mission which is prominently displayed in the center of the website's homepage (Figure 2):

The Fed is Best Foundation work to identify gaps in current breastfeeding protocols, guidelines, and education programs, and provide families and health 
professionals with the most up-to-date scientific research, education and resources

to practice safe infant feeding with breast milk, formula, or a combination of both. Navigating the Fed Is Best website, it becomes clear that the site recognizes their mission as a direct challenge to "Baby Friendly" policy and medical discourse that promotes breastfeeding as the unquestionably superior infant feeding option: The website includes numerous links to scientific studies that challenge the idea that breast is always best and that point to the often noted conflations of correlation with causation in breastfeeding studies. And while the organization cites ample scientific studies to back up their positions, the values of my methodology direct me to focus on the ethos that emerges from the organization's use of individual narratives shared by caretakers whose infants suffered complications from malnutrition while under directives to exclusively breastfeed ("Information for Hospitals/Complications from the Baby Friendly Protocol"). I argue that this collection of narratives is an example of spaces that draw on and project the embodied experiences of users which can contribute to scholarship invested in feminist approaches to usability as it propels the importance of understanding individual, contextualized user experience. Individual contributors, as well as the community created by and through this platform, reframe difference such that it is embraced as both generative and productive rather than dealt with as burdensome and inefficient.

These stories challenge narratives that prescribe and normalize one way to engage with infant feeding and, by directly pointing out the dangers of not questioning those in power when individual circumstances and context go unaccounted for, undermine policies that aim to force compliance. These accounts, which, with one exception, are told through a first person perspective, shift the message away from a debate over what is "best" and instead provide exigency for a policy approach that foregrounds embodiment, individual difference, and context 
as essential. The individual narratives shared within the Fed Is Best community make apparent that every situation is unique and that policies which compel all individuals to succumb to a universalized but singular framework fail individual users.

Because my methodology calls on me to amplify diverse, underrepresented, and nonnormative embodied experiences, I point to the ways in which Fed is Best makes apparent different ways in which individuals experience the process of infant feeding. For instance, under the "Information for Hospitals" tab is a link to "Complications from The Baby-Friendly Protocol." This section includes a brief introduction composed by the foundation, but the remainder is a collection of stories shared by those who have experienced complications they attribute to the Baby-friendly protocol. The organization explicitly notes that by sharing these stories, these individuals are attempting to make the Baby-Friendly policies more usable: "They have shared their stories in order to prevent it from happening to other newborns and raise awareness among health professionals to provide breastfeeding support that prioritizes patient autonomy and safety" (“Complications”).

These stories exhibit the values of an intersectional feminist rhetorical approach by calling attention to the import of individual, "non-expert" experience, and voice in gauging the usability of a policy. Each story is unique, but nearly all note a disconnect between local embodied knowledge (that of the caretaker and their family) and "expert" knowledge (that of medical staff, informed by studies cited within BFUSA policies and accompanying documents). As exhibited earlier, the expert/non-expert dichotomy is both established and promoted via BFUSA policies as they create a clear delineation between caretakers who require education and medical personnel whose job it is to educate. By undermining the value of individual embodied knowledge and rejecting the possibility that not breastfeeding might be a productive, informed, 
beneficial choice, BFUSA policies designed to promote breastfeeding too often hinder an individual caretaker's ability to communicate effectively with staff. To illustrate, in a narrative titled "Just One Bottle Would Have Kept My Baby Off Life Support: The Failure of BabyFriendly (BFHI) in Canada" the writer explains that "[i]t came to the point we had to yell at them to stop and to understand we want formula for our baby because attempting to exclusively breastfeeding pretty much killed him. They finally backed off from the breastfeeding comments!" (Fed is Best). Individual narratives regularly note how bodies and embodiments are inadequately accounted for within current policies: "What fed is best is doing matters. It's empowering. It will save the lives of mothers who feel overwhelmed and distraught with bodies that just don't work perfectly, or empower mothers who simply don't want to breastfeed with the correct information, so they can feel confident in their choice" (Fed is Best, "My Baby was Starving"). Writers point to the generative, activist potential of sharing these deeply personal experiences: "I hope that sharing my struggles will help other families see that formula feeding can be the best option for them, and that it need not involve any shame. I don't want others to experience what we experienced" (Fed is Best, "Breast is Best Failed Me"). The message in each avoids any suggestion that one experience is universal. Rather, the thread that ties each narrative together is that policies, such as BFUSA, that reduce a complex situation into one manageable act— the act of breastfeeding — do so to the detriment of individual users.

A central tenet of my methodology is the focus on usability as feminist practice—one that foregrounds varied users whose input, satisfaction, and productive resistance as essential to the creation and maintenance of usable policies. As noted in Chapter II, the leveraging of users' embodied experiences—-highlighting complex, intersectional, contextualized embodied knowledges - is essential to making policies more usable, particularly for bodies currently 
situated on the margins of a policy's imagined user population. Thus, this methodology learns from, and builds on, the shared experiences of individuals experiences not reflected in policy language, but already engaged in everyday acts of resistance. I argue that the individual contributors to the Fed is Best organization exhibit this potential as they explicitly situate embodied narrative as an integral component to changing BFUSA policy. In the section titled "Writing Your Hospital and the Joint Commission about Baby's Feeding Complications" the organization argues that "[ $t]$ he only way hospitals and health organizations responsible for patient safety know to make their infant feeding policies safer is through patients raising awareness" (Fed is Best, "Connect"). This statement is followed by a call for patients to write to "your hospital's CEO, the Joint Commission on Patient Safety in the U.S. and your health insurance company." Fed is Best provides a letter template and link to the Joint Commission Patient Safety reporting page. The letter template is particularly telling in the way it stresses narrative as essential to the exigency of the letter. In addition to prompting patients to include details about the birth such as date, type (C-section, vaginal), and complications, the majority of the suggestions are focused on "details [the patient] feel[s] are important for the hospital/practice to know." And though much of the letter template centers on outcomes for the infant, it also foregrounds the impact of BFUSA policy on caregivers and clearly situates their embodied experience as important to how the delivery and practices of this health care can be improved upon. For example, users are encouraged to describe "[h]ow the experience affected you as a parent emotionally, and if it negatively impacted your desire/ability to continue breastfeeding or nursing," and to provide "constructive feedback" such as: "What could your health care providers have done differently to help prevent this situation? What education on breastfeeding and/or formula supplementation do you wish you had received beforehand?" ("Writing Your 
Hospital"). The individual, contextualized, and embodied experience of the patient is the central source of knowledge; making this experience known is in itself an act of resistance.

Drawing on feminist methods that question traditional approaches to research by challenging notions of what counts as knowledge (Kirsch and Ritchie, "Beyond the Personal" 140) and who dispenses it (Sullivan, "Feminism and Methodology" 132), I argue that by making narratives focused on embodied experience central to the organizational ethos, Fed is Best extends notions of where valuable knowledge about infant nutrition practices can be located: The organization includes a blog, Facebook page, and Parent Support Group to demonstrate this. Additionally, the organization expands representations of who constitutes an "expert": Narratives of how BFUSA policy uniquely impacts various caregivers and their infants is integrated alongside published studies and information from medical personnel. In this way, Fed Is Best creates a space in which the embodiments currently undermined, discounted, or dismissed within BFUSA policy are foregrounded; the organization purposefully recognizes individuals, embodiments, and spaces currently marginalized within BFUSA policy as rich sources of knowledge and potential; it amplifies the voices and embodied knowledges of those who are too often not heard by policy makers and academics - those who are not in traditionally recognized positions of authority nor sharing their work in traditionally privileged spaces (Royster and Kirsch 63-66).

In contrast to BFUSA's reliance on rhetorics of efficiency, Fed Is Best resituates measurements of "success" to focus more on long-term outcomes (infant and caregiver health) than on short-term statistics (initiation and duration rates of breastfeeding). In addition to this reframing of success, I argue that by providing a platform for petitioning, letter writing, and creating community, Fed Is Best also creates pathways for marginalized individuals to 
"successfully" engage in acts of resistance. Although BFUSA policy remains, and is indeed expanding, the work of those contributing to and working within the Fed is Best organization serve as models for how everyday individuals are pushing back against reductive rhetorics of efficiency that discount their experiences. ${ }^{53}$ This focus on micro-level change is prominent in the work of feminists such as Julie Bates, whose examination of activist responses to contaminated water in Flint, Michigan does not end with the "success" of Flint residents via clean water for all and government accountability, but does, Bates argues, exhibit successful resistance. Bates invites an understanding of success that focuses on specific instances and particular acts as evidence of success that accumulates over time and renders more traditional measures of success possible; she argues that rather than understanding success as represented only through macrolevel change, "success [is] better gauged by recognizing the effectiveness of even the smallest interventions that lead, however incrementally, to something larger" ("Toward" 130). Through this lens, then, the work of those involved with Fed Is Best is impacting those within their shared community as well as those outside. This, in turn, can lead "incrementally, to something larger" on the scale of policy. ${ }^{54}$

I suggest that by incorporating user knowledge alongside scientific, "expert" knowledge, Fed is Best reflects an understanding that rhetorical discourse is always, already cultural and embodied. By engaging individual narrative as central to successful

\footnotetext{
${ }^{53}$ See, for instance, Royster and Kirsch's examination of Katrina M. Powell's research into letters written by women whose homes were threatened by the establishment of a national park as an example of how letter writing campaigns by everyday people challenge "our standard measures for success" (64) - as well as Jessica Enoch's research centered on the 1976 class action civil rights suit Madrigal v. Quilligan.

${ }^{54}$ Fed is Best is also gaining increasing attention in the media (see the link to Fed is Best in the media: fedisbest.org/fed-best-media/).
} 
resistance, Fed is Best represents a framework in which everyday users push back against restrictive policies: the organization foregrounds the contextualized and complex embodied experiences that inform infant feeding practices and should, in turn, inform policies.

\section{Rethinking Usability: Implications for Teacher Scholars}

Fed is Best is one example of how individuals' diverse, embodied knowledges hold potential for informing the ways in which we create, maintain, and revise policies so that they are continuously measured according to their usability for all audiences. Learning from the work being done by Fed is Best—-both via individual contributor's posts and the organization as a whole-my commitments to an intersectional feminist rhetorical methodology call on me to reconsider the process for theorizing the usability of breastfeeding and other public policies. Specifically, I suggest that Catherine Gouge's exploration of improvisation that foregrounds practices and approaches to documentation that are "capable of responding to unpredictable and, perhaps, messy details" could help shape policies and practices that are able better able to reflect and respond to complex user needs. Demonstrating activist research, Jeff Grabill shows how scholarly research can engage users as integral participants to intervening in public policy ("Shaping"). And theorizing policies that are increasingly usable for, and responsive to, differently bodied and embodied users, Jay Dolmage's concept of bridging universal design (which "provides a means for making difference central") and user-centered design (which prioritizes "feedback from users - the idea that users must be actively involved in the continued redesign of products, interfaces, and spaces") ("Disability, Usability" 173) likewise can contributes to work invested in more accessible, user-friendly, and socially just public policy. 
These ideas complement an intersectional feminist rhetorical approach as they disrupt top-down hierarchies that seek to universalize and/or construct normalized users; value divergent views as they can further usability; recognize usability as an always in-process endeavor; and foreground multiple, varied users working in a variety of contexts as essential contributors to the process of making policies increasingly usable. These approaches can broaden policy language (and thus effects) to more fully account for the myriad varied embodiments, contexts, and goals of its users.Both Dolmage and Gouge present concepts of usability that begin with extraordinary users. ${ }^{55}$ Dolmage suggests that when thinking of usability through a rhetorical lens, that we begin our conceptualization by considering end users with disabilities (170). In the case of BFUSA policy, this would require that we alter assumptions about potential end-users. For instance: Table 2

Potential of Moving from Standardized to Extraordinary User

\begin{tabular}{|l|l|}
\hline Current: Standardized User & Revised: Extraordinary User \\
\hline Healthy, lactating & $\begin{array}{l}\text { Not in possession of lactating breasts; milk } \\
\text { may be unsafe due to environmental, medical, } \\
\text { or other contamination }\end{array}$ \\
\hline $\begin{array}{l}\text { Employment allows for feeding on demand } \\
\text { and/or the maintenance of regular } \\
\text { feeding/pumping schedule }\end{array}$ & $\begin{array}{l}\text { Employed outside the home and not afforded: } \\
\text { maternity leave; access to, support for, or } \\
\text { security in nursing/pumping at work }\end{array}$ \\
\hline Identifies as cisgender female & $\begin{array}{l}\text { Biological and/or social identity presents } \\
\text { challenges for breastfeeding }\end{array}$ \\
\hline $\begin{array}{l}\text { Experiences breastfeeding as empowering, } \\
\text { satisfying, and "good" }\end{array}$ & $\begin{array}{l}\text { Cultural history and or current community } \\
\text { complicates the practice of breastfeeding as an } \\
\text { assumed "good"; experiences (such as, abuse } \\
\text { or mental health) influence their relationship } \\
\text { to their body and/or breastfeeding; user who } \\
\text { (for myriad possible reasons) does not desire } \\
\text { to and/or enjoy breastfeeding }\end{array}$ \\
\hline
\end{tabular}

${ }^{55}$ See Chapter I for contextualization of my own use of this term. 
As outlined in Table 2, by anticipating embodiments that reside outside normative frameworks erected by hierarchical power structures, usability that begins with extraordinary bodies invites recognition of "the complexity of everyone's needs and knowledges" (Dolmage 170).

In another argument for the benefits of increased of complexity, Gouge notes how too many studies focused on improving patient experience and health "isolate variables in order to measure the relative effectiveness of specific interventions over others" rather than aiming to solve problems through approaches that are "flexible and comprehensive" (426). In her examination of the usability of patient discharge communication (PDC), Gouge notes: "Acknowledging and accounting for improvisation in the enactment of PDC is not what makes such events complex; rather, acknowledging and accounting for the enactment of documents allows the existing complexity to be made visible" (429). I argue that the same is true of breastfeeding policy: The myriad of factors that inform an individual's decision to breastfeed are embodied, unique, and at times messy and uncertain. Whether policies such as BFUSA recognize this complexity does not alter the reality of their existence; it does, however, greatly impact the usability of the policy for those it is ostensibly intended to serve. Although arguably emerging from a necessary and socially-justice-focused document (the Code), the policies and supporting documents promoted via BFUSA reflect a considerably narrower focus than their foundational source: By isolating breastfeeding as the sole indicator of "Baby Friendly" practice, BFUSA limits the potential of other practices (and interventions) to be recognized as valuable to the maintenance or improvement of infant and maternal/caretaker health and well-being.

Conversely, by explicitly situating varied practices and experiences as contributing to the overall goal of infant and mother/caretaker health, the Fed is Best foundation opens space for the experiences and practices of individual caretakers and their infants to be recognized as "good". 
The Fed is Best mission, which states that the organization is premised on the belief that "babies should never go hungry and mothers should be supported in choosing safe feeding options for their babies," reflects the type of flexible, comprehensive approach that Gouge advocates (Fed is Best, "Mission"). Via such approaches, usability is gauged according to the capacity of a policy to be responsive to individual embodiment, context, and complexity. Such an approach helps to ensure that policies can be attentive to, and focused on, long-term goals; without this flexibility, usability can easily become a tool for measuring compliance and managing short term goalsexpanding "without continued recalibration and, therefore, without real direction" (Dolmage, "Disability, Usability" 175).

If we view a policy's usability as beginning with bodies that defy normalizing categorizations and simplistic solutions - with extraordinary bodies — then the usability of these policies can increasingly become "participatory ecosystems that ...allow for flexibility and responsiveness" (Potts 2). A shift toward more responsive, flexible, user-friendly design holds potential for making guidelines and policies more inclusive of all, and less oppressive toward some. Still recognizing the value of medical personnel and public policy experts, an intersectional feminist rhetorical approach calls on much larger and more diverse discourse communities to be engaged in shaping policies and in the assessment of a policy's usability. In this way, "users" experiences and knowledges are intentionally viewed as working alongside, and with, "expert" knowledge, helping policies to not only gauge efficiency but also user satisfaction and success. 


\section{CHAPTER IV: SHIFTING RESPONSIBILITY FOR USABILITY:}

\section{A CASE STUDY OF OHIO'S VOTER PURGE POLICY}

In Chapter III, I examined infant nutrition policy through an intersectional feminist rhetorical lens to make evident how rhetorics of efficiency within public health policy can limit the care made available to caregivers and infants within BFUSA hospitals and facilities. I then turned to the work of the organization Fed is Best to show how an intersectional feminist rhetorical framework of usability that foregrounds the needs of extraordinary users serve as a model for more inclusive and usable policies for patients. In this chapter, I show the versatility of an intersectional feminist rhetorical methodology as I shift from public health policy to voting policy in the U.S. Specifically, I present a case study of Ohio's General Voter Registration Program, Supplemental Process — better known as Ohio's voter purge policy ${ }^{56}$ - that outlines a process for aggressively identifying and removing people from the state's voter rolls. This policy can ultimately prevent Ohioans — particularly those from historically marginalized groups - from exercising their right to vote. As in previous chapters, I understand "users" as those who stand to be directly impacted by policy mandates. Thus, the users of Ohio's purge policy are all registered voters in that state, as the policy can inform their current and/or future status as a registered voter.

Guided by an intersectional feminist rhetorical commitment to challenge rhetorics of efficiency that further normative constructs that homogenize bodies and flatten diverse user experience, my case study examines the documents and discourses that shape Ohio'spurge

\footnotetext{
${ }^{56}$ Reports by many of the largest newspapers and news outlets (Reuters, Wall Street Journal, New York Time, NPR, The Atlantic, Fox News, among others) regularly refer to the Ohio voter purge policy - many never mentioning the official title (Chung; Bravin and Kendall; Liptak; Totenberg; Epps; Mears and Singman).
} 
policy in order to show how certain rhetorics lend credence to a policy that presents insurmountable hurdles and disproportionate burdens on multiply marginalized users.

Ultimately, I argue that rheotrics of efficiency shift responsibility for the policies' usability away from the institutions and administrators charged with overseeing free and fair elections, and onto implicated users: a rhetorical maneuvering that allows discriminatory policies to be masked as efficient governance.

To organize this chapter, I first describe my exigency for using voting rights policy as a site for an intersectional feminist rhetorical analysis, and my rationale for focusing specifically on Ohio's voter purge policy. Next, I contextualize the traditional voter purge process in the U.S. and explain how Ohio's voter purge policy aggressively shifts this process in a way that disproportionately impacts already vulnerable voters. I then engage an intersectional feminist rhetorical critique of the technical documents, regulatory writing, and political discourses that construct, effectuate, and uphold Ohio's purge policy and its mandates. These documents include:

- Ohio's Confirmation Notice—a re-registration notice sent to "flagged" users (a document and process I will describe) —as well as the online registration system,

- Ohio Code 3501.35 — official legal code that authorizes the Secretary of State to oversee the voter registration process purge process, and

- Directive 2018-20 - official directive from Ohio's Secretary of State outlining the current purge process.

Then, I briefly trace the link between Ohio's purge policy and two foundational voting rights acts - the Voting Rights Act (VRA) and the National Voting Rights Act (NVRA) in order to show how Ohio's purge policy selectively takes up sections of these Acts to justify a policy that 
is antithetical to the original documents' goal to promote and protect the right of historically marginalized groups to participate in U.S. elections. Tracing Ohio's purge policy to these foundational documents mirrors the work done in Chapter III and reflects an intersectional feminist rhetorical understanding of public policy arguments as inseparable from the histories that shape them and the relationships of power that allow policy to be "reinterpreted and rewritten" (Dingo 20). Finally, contextualization of the VRA and NVRA is important for the final portion of my critique that centers on the Supreme Court decision upholding the legality of Ohio's purge policy and the Ohio Secretary of State's defense of the policy to the public.

Attending to an intersectional feminist rhetorical methodology that aims to move beyond critique, the latter portion of this chapter engages with the work of Stacy Abram's organization Fair Fight Action to propose how teacher-scholars can learn from, and align with, the work of individuals and organizations fighting against policies that result in voter suppression. Specifically, I highlight Fair Fight Action as a model for intersectional feminist rhetorical scholar-teachers to learn from as it exemplifies the ways in which the foregrounding of embodied experience can construct collective sites of resistance for those whom policies seek to exclude. Centering my analysis on Fair Fight Action's "Hear From Voters Like You" section of the organization's website, I outline how this group rejects homogenized, normative fabrications of users and their experiences by gathering and magnifying diverse embodied narratives that directly contradict dominant constructs of users, and the efficiency and neutrality of purge policies. These individual narratives - gathered in a collective space of resistance and supportcall attention to the aggressions that restrictive voter policies can enact on already vulnerable users. To conclude, I argue that technical and professional communication, alongside rhetoric 
and composition, teacher scholars are uniquely situated to engage with voting policy as a site for social justice analysis and intervention.

In the following section, I explain the exigency for my engagement with voting rights as a site for an intersectional feminist rhetorical analysis and my rationale for focusing on Ohio's purge policy.

\section{Establishing an Exigence}

Ohio's policy is one of a myriad of voting policies introduced in the past decade that restrict access to the voting booth - particularly for people of color, those in urban areas, and the poor. Since the swearing-in of President Obama in 2009, these policies have surgedparticularly in states that experienced higher than average voting participation by African American residents in 2008 and/or are experiencing growth in their "Hispanic/non-white" demographic ("Election 2016"). ${ }^{57}$ Constructed and supported through technical and professional writing and communication, restrictive voter policies have been identified as a growing threat to rights of marginalized populations in the U.S. ${ }^{58}$ This case study contributes to TPC work that "attune[s] practioners and scholars alike to policy-based exclusionary practices, revealing the ways that technical communication genres like regulations and policies instantiate marginalization" (Walton, Moore, and Jones 20). My analysis of the documents and discourses that together give effect to Ohio's purge policy show how "domains of power intersect" to

\footnotetext{
${ }^{57}$ Breakdowns of voter turnout for the 2008 were widely covered, but Sam Robert's New York Times article "2008 Surge in Black Voters Nearly Erased Racial Gap" provides useful context and visual overviews of this information.

58 The Brennan Center for Justice's 2008 report Voter Purges and more recent 2018 Purges: A Growing Threat to the Right to Vote detail both the history and immediate threat of voter purge policies in the U.S. (Pérez; Brater, Morris, Pérez, and Deluzio).
} 
construct and forward hegemonic norms that allow for structural and persistent discrimination to proliferate - a practice foundational to intersectional, social justice TPC research (Walton, Moore, and Jones 118) .

My decision to focus on Ohio's purge policy specifically is informed by three central concerns: First, similar to the BFUSA policy and discourse analyzed in Chapter III, Ohio's purge policy is shaped by rhetorics of efficiency that ignore, deny, and/or dismiss the embodied experiences of individuals who diverge from the policy's normative construct of a white, ablebodied, educated, economically secure, male voter. Second, following the Supreme Court ruling upholding the legality of Ohio's uniquely aggressive purge process, it may now serve as a model for other states - a reality that voting rights advocates note should be of urgent concern for all opposed to voter suppression (Pérez and Brater; Levy). Finally, Ohio's purge policy highlights the importance of the U.S. public remaining vigilant. The election of President Barack Obama in 2008 seems to have lulled many, particularly white, voters into complacency—convinced that the election of a Black man to the highest office in the U.S. was evidence that the electoral system has been purged of its discriminatory past and the country finally evolved into a "postracial" state. ${ }^{59}$ Yet, as numerous studies (and the current political climate) show, there has been significant backlash to the progress represented by Obama's election - a regression made evident through the growth in voting policies that target non-white, low-income voters. ${ }^{60} \mathrm{TPC}$ teacher scholars can play an essential role in bringing increased attention to this trend.

\footnotetext{
${ }^{59}$ This complacency has been widely written about since the 2008 election (See, for instance, Steele or Muwakkil).

${ }^{60}$ Indeed, "[t]he more a state saw increases in minority and low-income voter turnout [since 2008], the more likely it was to push laws cutting back on voting rights" (Weiser; Bentele and O’Brien; Weiser and Opsal).
} 
The increasingly regressive movement of voting policies is both alarming and of grave consequence as it undermines equity and equality in the U.S. by systematically removing the rights of marginalized groups to contribute to laws and governance of their communities. ${ }^{61}$ Central to combatting these discriminatory policies is identification and problematization of the rhetorical maneuvering that allows for oppressive policies to be presented as normal—even good and desirable — and in the public interest, a task for which TPC scholars are particularly wellsuited. In the remainder of this chapter, I model how TPC, rhetoric, and composition scholars invested in issues of social justice and public policy can engage an intersectional feminist rhetorical lens to identify and challenge technical communication practices that result in voter suppression, and how our disciplines might support the efforts of those already actively fighting against these policies by engaging with and amplifying their work.

In the next section, I explain the history of the purge process in the U.S. before entering into my intersectional feminist rhetorical analysis of the documents and discourses that construct, give meaning to, and provide direction for Ohio's purge policy.

\section{Voter Purge Policies and Ohio's Aggressive Interpretation}

Purge Process: Voter purges in the U.S. are ostensibly designed to remove the names of voters who are no longer eligible to vote in a particular state because, among other reasons, they

\footnotetext{
${ }^{61}$ My own multiply privileged status as a white, able bodied, educated, middle-class citizen of the U.S. makes it unlikely that current voter suppression policies such as Ohio's purge policy will present more than an inconvenience for my own access to vote. Thus I enter this project to support and amplify those whose multiply marginalized status makes them particularly vulnerable to this law.
} 
have moved out of state. ${ }^{62}$ These policies outline a system by which the Secretary of State compares change of address info from the U.S. Postal Service (USPS) with the state's voter registration list to identify and "flag" registered voters who may have moved but have not yet updated their address on their voter registration. Usually, those voters whose address with the postal service does not mirror their voter registration information are sent a notice by election officials to update their registration to reflect their current address. Thus voters are typically identified as being potentially ineligible to vote only after records clearly indicate a discrepancy in address.

Although not an inherently discriminatory practice, voter purges in general are concerning as they are often poorly designed, rely on flawed data, and result in eligible voters being purged from rolls and subsequently unable to cast their ballot—-failings that disproportionately impact voters of color, the poor, and women, as well as other marginalized groups (Morris and Pérez). These concerns are exacerbated in Ohio's purge process - currently the most punitive in the nation — as individuals are "flagged" as potentially ineligible to vote as soon as a they do not cast a ballot during a single federal election cycle. This flagging then initiates a process in which the individuals are mailed an official Confirmation Notice (see Figure 3) and required to confirm their Ohio state residence in order to maintain their eligibility to vote. In this way, the policy mandates that eligible voters - voters who have not undergone any change in residency nor any other shift that might necessitate an update to their voter registration—re-confirm their

\footnotetext{
${ }^{62}$ This process also can be used to identify registered voters who have been incarcerated, have passed away, or whose eligibility to vote has changed for other reasons. The central concern for this project, however, is voters whose eligibility has not changed.
} 
continued residency and eligibility to vote in the state of Ohio or risk having their voter registration revoked.

To maintain their voter registration, flagged voters must either: (a) complete and return their Confirmation Notice (Figure 3); (b) update their registration online (Figure $4)$; or (c) cast a vote in their registered precinct within four years of the process being initiated. Any voter who does not confirm their eligibility within the allotted time period, and via one of the mandated steps, is purged from the voter rolls and can be denied their right to vote until they reregister. Unfortunately, voters are often unaware of their flagged status until they arrive to vote and are told that they are ineligible. ${ }^{63}$ Moreover, and central to this particular case study, the actual process required to confirm eligibilityparticularly accessing and completing the paper Confirmation Notice or the online registration process - introduces hurdles that disproportionately impact already vulnerable Ohio residents.

The Confirmation Notice: The Confirmation Notice (Figure 3) is an example of an official government communication that, like many technical and professional documents, is presented by those in power as a neutral and objective artifact. Yet all technical documents are inescapably imbued with the knowledges and values of the individuals and systems that shape them (Haas; Haas and Eble; Jones and Walton; Palmeri; Scott, Longo and Wills; Frost; Katz) and TPC scholarship has a history of challenging the supposedly neutrality of public policies (Grabill), government legislation (Frost), regulatory writing (M. Williams), and legal writing and

${ }^{63}$ In Ohio, voters must be registered at least 30 days prior to election in order to vote. As described later, the plaintiff for the case brought before the Supreme Court challenging the legality of Ohio's purge policy explained that he was not aware of his flagged status until arrived to vote and was denied. 
reasoning (Hannah) among other technical discourses. I engage the Confirmation Notice as a technical document that, although presented by those in power as a neutral artifact, is written, designed, and distributed in a way that both privileges and oppresses.

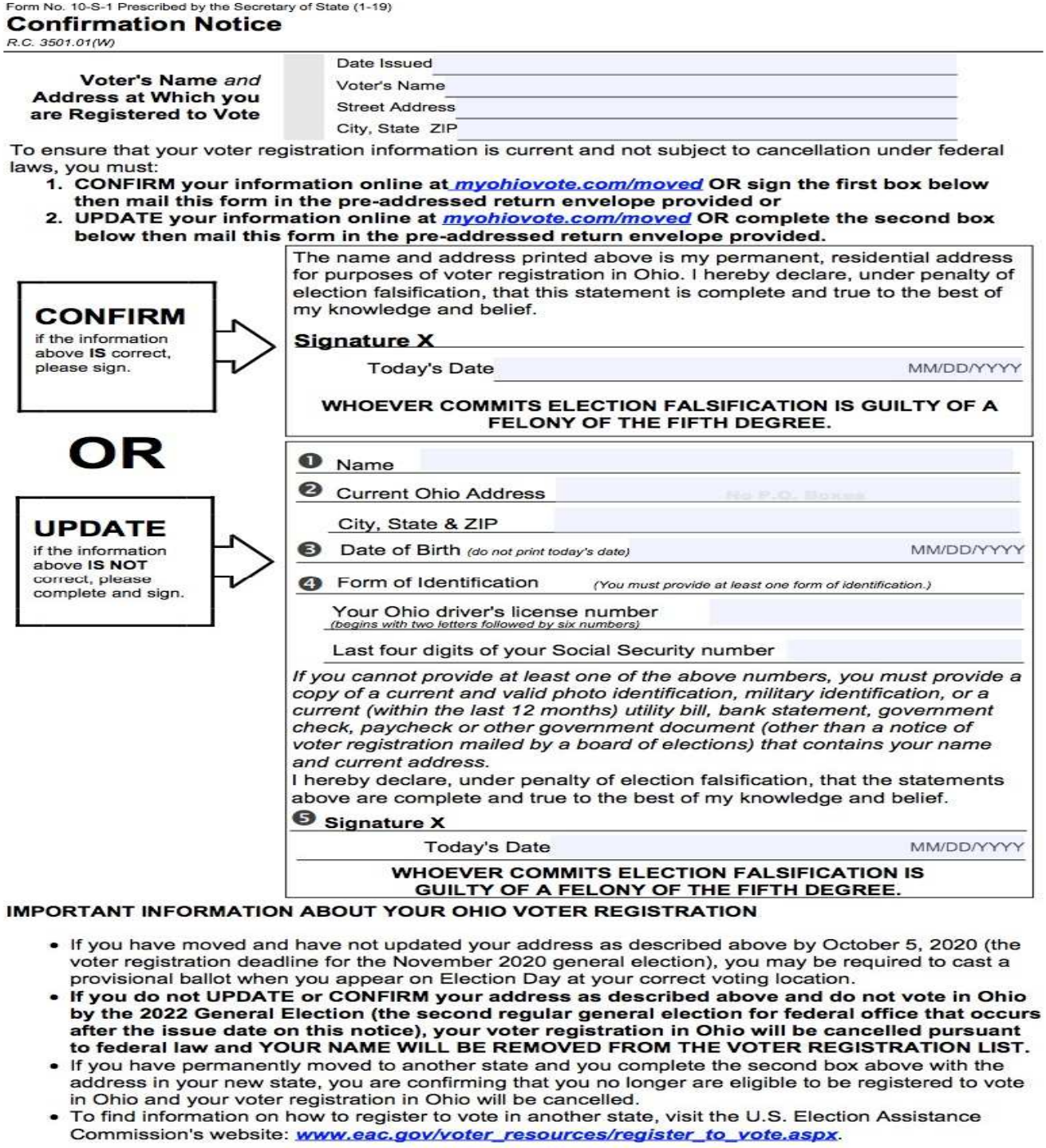

To ensure that your voter registration information is current and not subject to cancellation under federal laws, you must:

1. CONFIRM your information online at myohiovote.com/moved OR sign the first box below then mail this form in the pre-addressed return envelope provided or

2. UPDATE your information online at myohiovote.com/moved OR complete the second box below then mail this form in the pre-addressed return envelope provided.

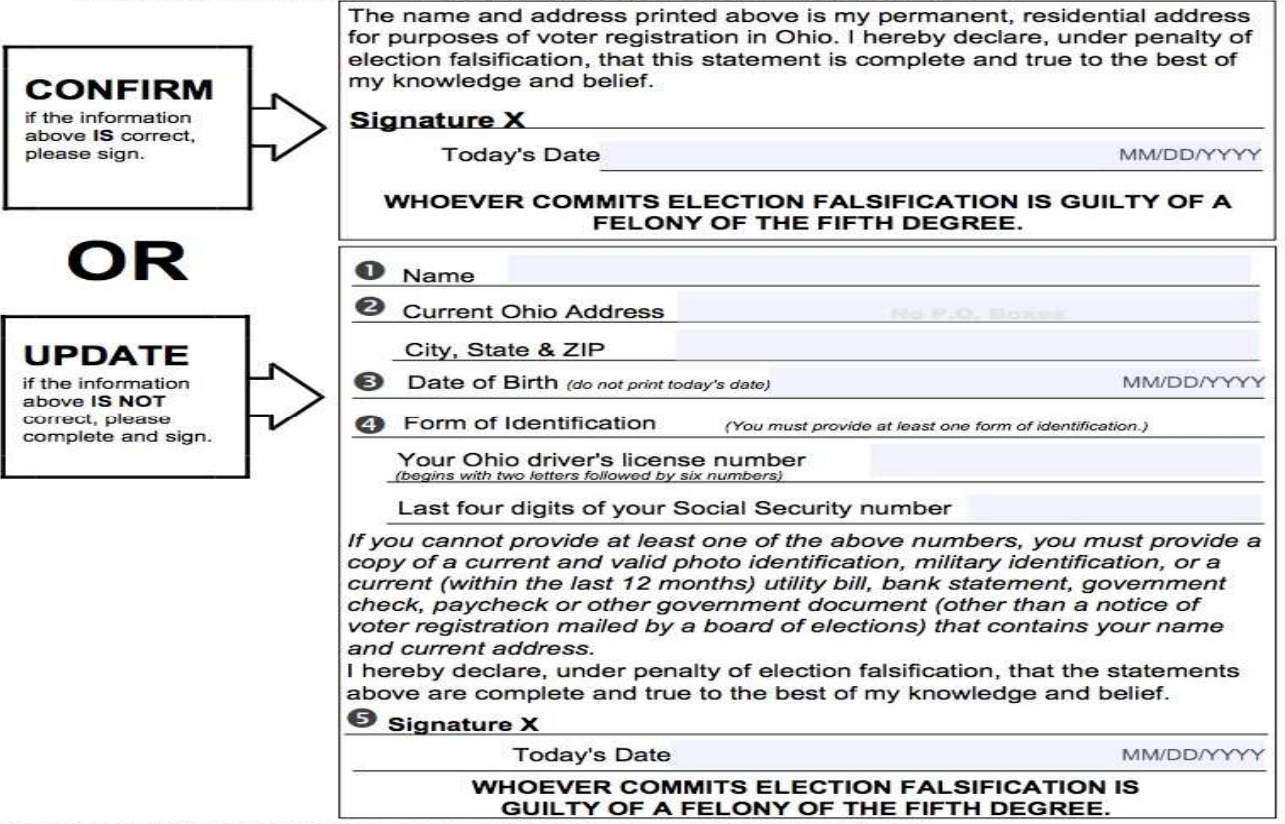
IMPORTANT INFORMATION ABOUT YOUR OHIO VOTER REGISTRATION

- If you have moved and have not updated your address as described above by October 5, 2020 (the voter registration deadline for the November 2020 general election), you may be required to cast a provisional ballot when you appear on Election Day at your correct voting location.

- If you do not UPDATE or CONFIRM your address as described above and do not vote in Ohio by the 2022 General Election (the second regular general election for federal office that occurs after the issue date on this notice), your voter registration in Ohio will be cancelled pursuant

- If you have permanently moved to another state and you complete the second box above with the address in your new state, you are confirming that you no longer are eligible to be registered to vote in Ohio and your voter registration in Ohio will be cancelled.

- To find information on how to register to vote in another state, visit the U.S. Election Assistance Commission's website: www.eac.gov/voter_resources/register_to_vote.aspx.

Figure 3: Confirmation Notice Sent to Ohio Residents

Source: Ohio Secretary of State, www.sos.state.oh.us/globalassets/elections/forms/10-S-1.pdf 
As noted earlier, in Ohio the Confirmation Notice can be sent to any registered voter who did not vote during the previous federal election cycle. The Notice is sent as forwardable mail to the address on file with the board of elections registration record ("Directive 2018-20"). As soon as the mailer is sent, the purge process proceeds as though the Notice has been received by the intended user - no follow-up is required to confirm receipt and/or that the user is aware of their flagged status. This distribution process assumes that the user continues to live at the address on the file with their county election office or has registered a forwarding-address with the post office (and remains in the grace period to continue having their mail forwarded). ${ }^{64}$ This assumption ignores voters who may have moved since registering to vote or voting, who do not have forwarding services, and/or those registered voters who are without a permanent address at which to receive mail.

Even for users who receive the Confirmation Notice, the process assumes that the Notice is not thrown out with the junk mail, misplaced, lost, or forgotten and that users recognize the implications of timely completion. Assuming users do come into possession of the Confirmation Notice and do recognize its official purpose, the directions in the document and the steps required to complete it are not readily accessible to many potential users. To begin, the mailed document appears to be available only in English: The Ohio Secretary of State webpage provides certain forms in both English and Spanish, but no link to a Spanish or any Confirmation Notice other than the one appearing in Figure 4, is available ("Forms and Petitions"). ${ }^{65}$ Even for users fluent in English, the Confirmation Notice assumes a user who has the physical capacity and

${ }^{64}$ USPS policy allows mail to be forwarded for a 12 month period ("Forward"). Federal elections only occur every two years.

${ }^{65}$ As I will explain, those who complete their re-registration online using a separate website have the option to select information in Spanish. This option, however, is not explained on the mailer. 
literacy skills necessary to effectively engage with the document. As the Notice is dense with technical language, overlapping directions, and legal rhetorics, many users may not have access to the necessary literacies to read, understand, and reply to the mailing.

Another key concern — particularly for historically and multiply marginalized users - is the use of language and design elements that highlight the legal repercussions of erroneously completing the form. Repetition, bold fonts, and caps emphasize the legal threats and citations that appear throughout the Confirmation Notice. Although arguably an ethical inclusion that is necessary to warn users of the consequences of knowingly providing false information, there are also constraints in how this warning is presented. For instance, above the signature line in both the "Confirm" box and the "Update" boxes, the form indicates that the signatory is agreeing to the following: "I hereby declare, under penalty of election falsification, that this statement is complete and true to the best of my knowledge and belief" (emphasis is my own). Then immediately following the signature line, in all-caps and bold, users see the follow-up warning: "WHOEVER COMMITS ELECTION FALSIFICATION IS GUILTY OF A FELONY OF

THE FIFTH DEGREE." One could argue that as long as the recipient provides accurate information, they have nothing to fear. But users' perception of this threat may be heavily influenced by a myriad of factors such as their: English proficiency, literacy skills in relation to this type of document, sense of confidence in being able to accurately complete official government forms, criminal record or history, access to identifying paperwork, and cultural historical situatedness as citizens of the U.S., among other concerns. This Confirmation Form, and its accompanying threat, can deter users located within one or more groups long abused, misled, undermined, and/or ignored by government entities—-for instance, Black, Native American, and immigrant populations as well as the poor, homeless, disabled, or otherwise 
marginalized communities. ${ }^{66}$ For many, official government documents elicit caution: The threat of a felony conviction - twice, in bold, and all-caps - is not a universally neutral message.

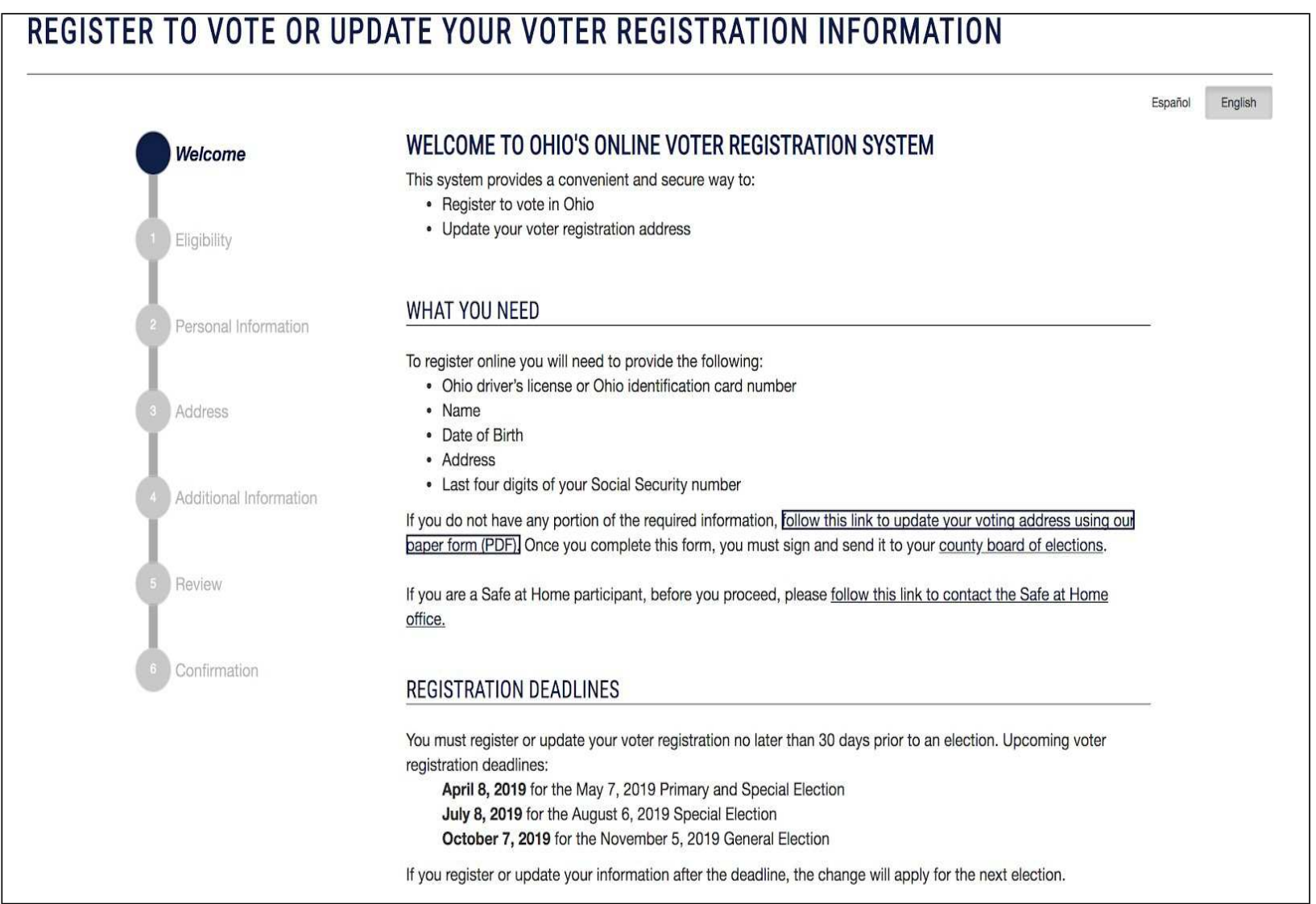

Figure 4: Ohio's Online Voter Registration Homepage

Source: Ohio Secretary of State, https://olvr.sos.state.oh.us/NCOA/NCOA

The Confirmation Notice informs users that they may confirm their status online. Again, access to this process demands many of the same skills and literacies necessary to complete the paper form and requires access to a computer or smart phone as well as reliable internet access and the skills to navigate an online registration system. One laudable aspect of the online system

${ }^{66}$ For instance, Miriam Williams traces how a history of discriminatory regulations, laws, and policies in the U.S. "have so tainted the African American audience's perception of legal discourse, that regulations are perceived, not simply as the traditional style for this genre, but as a style that evokes distrust" (3). 
is that the information can be accessed in English and Spanish, though no other languages or translating capabilities are made available (see top, right corner of Figure 3). And though users are offered the assurance that the website is "convenient and secure," many may be reluctant to share identifying personal information online. ${ }^{67}$

In addition to the myriad and overlapping obstacles that receiving, recognizing the import of, accurately completing, and returning either the paper or digital Confirmation Form poses for users, the requirement to produce and share important, confidential, personal information layers yet another, and arguably insurmountable, deterrent for marginalized voters. Access to the type of "valid" forms of identification required to complete this process—-such as a driver's license, utility bill, bank statement, or paycheck — are lower for women, people of color, the poor, and those living in cities (where car ownership is lower). ${ }^{68}$ Thus, the requirement to produce these documents is grounded in normative assumptions about who votes: users that have a home, car, bank account, and/or job that is part of the "official" economy (and thus distributes official paychecks). By requiring these forms of identification, the ability of large sects of the voting population to comply become difficult and is particularly overwhelming for those located at the

${ }^{67}$ The very information being requested is the same information that government organizations encourage individuals to share sparingly Just two examples include the Veterans Affair website that cautions veterans about sharing their personal information as "[e]very piece of personally identifiable information, whether it's a Social Security number, date of birth, home address, etc., is more than just a number. It represents a person's identity, livelihood, and personal or financial well-being" ("Veterans"); and the IRS website which warns users against scams in which criminals posing as IRS agents solicit identifying information ("Phone Scams".)

${ }^{68}$ A 2006 national survey conducted by the Brennan Center for Justice "reveals that millions of American citizens do not have readily available documentary proof of citizenship" "CCitizens" p. 1) and that significant discrepancies exist for certain segments of the population in terms of access to proof of citizenship and photo I.D. For instance, "only $48 \%$ of voting-age women with ready access to their U.S.birth certificates have a birth certificate with current legal name - and only $66 \%$ of voting-age women with ready access to any proof of citizenship have a document with current legal name ("Citizens" 2). 
intersections of multiple sites of oppression (Lapowski; “Citizens"). Finally, even for those in possession of the necessary documentation, literacies, and skills to complete the form, access to a copy machine or the money, transportation, and proximity to copying services may be required as both the mailed and printable online version require some voters to provide a copy of their identification documents in order to update or reinstate their registration.

As this analysis shows, for many residents of Ohio, their intersecting positionalities situate them as both the target for voter purges and the most burdened in terms of justifying to those in power- through the production and completion of technical and identifying documents - their continued right to access the privileges of citizenship. Thus rather than working in service of users, the Confirmation Notice introduces an unnecessary hurdle and disproportionate burden for already marginalized populations. Despite this, the Confirmation Notice form is, as noted earlier, presented and defended as an objective and neutral technical artifact.

In the following section, I briefly turn to the documents and discourses that shape the authority of the Secretary of State and election officials to enact the purge policy and identify how rhetorics of efficiency are used to interpret and justify the purge policy.

\section{Technical and Professional Communications that Authorize Ohio's Purge Policy}

As with much regulatory action, technical and professional communications are integral to how Ohio's purge policy is composed, enacted, and justified. To further contextualize Ohio's purge policy, I now briefly describe two technical and professional documents that authorize Ohio's Secretary of State to shape voting policy and direct how that policy is to be carried out by election officials. Specifically, I highlight relevant portions of (1) Ohio Revised Code, Title 35- 
a section of Ohio's Administrative Code that establishes rules for maintaining voter registration records, and (2) Directive 2018-20: General Voter Records Maintenance Program, Supplemental Process - a memo directive sent to election officials from Ohio Secretary of State Jon Husted that provides official instructions for how the purge policy is to be carried out.

Ohio Revised Code, Title 35: Ohio Revised Code, Title 35, outlines how elections are conducted, who is considered an eligible voter, what qualifications render one eligible (or ineligible) to vote, how this eligibility is established (or revoked), and who is charged with overseeing and interpreting these laws in the state of Ohio. Part of Ohio's Revised Code, Title 35, establishes that Ohio's Secretary of State "shall prescribe procedures to identify and cancel the registration... of any registrant who changes the registrant's voting residence to a location outside the registrant's current county of registration" (Code 3501.21, line B1). In other words, the Secretary of State is responsible for establishing a system for maintain accurate voter records, including the removal of ineligible voters. And though the code details a specific process for users (flagged voters must confirm their registration by responding to Confirmation, updating their registration with the election office, or voting), it provides ample space for the Secretary of State to design the process by which voters are identified as potentially ineligible to vote. Noting only that " $[\mathrm{t}]$ he secretary of state may prescribe procedures [using] the national change of address service provided by the United States postal system," Code 3501 does not limit the Secretary of State to this traditional method for identifying potentially ineligible voters (Code 3501.21, line B1, emphasis my own). This portion of the code provided the legal opening for Ohio's Secretary of State to outline Ohio's current purge policy mandates flagging voters based on their voting record. 
Directive 2018-20: Directive 2018-20 is a memo directive sent by former Secretary of State Jon Husted to the county boards of elections directors, deputy directors, and election board members. Citing the privileges bestowed on him by Ohio Code 3501.21, Husted outlines the procedures for enacting "Supplemental" voter purges in Ohio. This directive details Husted's vision for "procedures to identify and cancel the registration" of potentially ineligible votersexplaining that in addition to previous purge policies that only flagged voters based on record cross checks with USPS, the new policy requires the flagging of voters based on their voting record. ${ }^{69}$ The Supplemental Process Directive charges election officials "to identify those electors whose lack of voter activity indicates that they might have moved and need to update their voter registration information" (Husted, "Directive" 1), and thus redefined Ohio's voter purge policy. ${ }^{70}$

Having outlined the technical and professional documents that structure Ohio's purge policy, I now provide a brief overview of the Voting Rights Act (VRA) and the National Voting Rights Act (NVRA) as these foundational documents inform the way in which both the public and the legal community understand Ohio's voter purge policy. I then engage an intersectional feminist rhetorical analysis to argue that proponents of Ohio's purge policy have reductively taken up and interpreted these federal voting laws in order to defend a state policy that is antithetical to the spirit of these original documents.

\footnotetext{
${ }^{69}$ The Columbus Dispatch article "Ohio Voter Roll Purges Beginning Again After Husted Directive" provides further detail on this document (Rowland).

${ }^{70}$ The Directive cited here is not the only Directive detailing Ohio's purge policy but it is the most recent directive at this time and thus informs current interpretation and actions related to the purge process.
} 


\section{Increasing Access: VRA and NVRA}

The Voting Rights Act (VRA) of 1965 was designed "to ensure that no federal, state or local government may in any way impede people from registering to vote or voting because of their race or ethnicity" ("Voting Rights Act"). The VRA was not a law guaranteeing the right of non-white citizens to vote; those laws were passed nearly a century earlier. Rather, the VRA was a public acknowledgement of, and response to, local election officials and governments, particularly in the Jim Crow South, who continued to flout established laws, making voting dangerous or impossible for voters of color. The effectiveness of the VRA was immediate and significant, particularly in regions with the most egregious histories of suppressing minority votes. ${ }^{71}$ The VRA, then, reflected an understanding that federal oversight is needed to protect the rights of marginalized citizens to vote in the U.S. Building from the VRA, but acknowledging its limitations, the National Voter Registration Act was signed into law on May 20, 1993.

The NVRA requires states to outline procedures that make it easier for eligible citizens to register to vote in federal elections in the following ways: “(1) simultaneously while applying for a driver's license, (2) by mail, and (3) at selected state and local offices that serve the public" (Crocker 1). Supporters of the NVRA hail it as another step toward increasing access for those whose race, ethnicity, gender, able-bodiedness, or age made them targets for discrimination and ensuring more eligible voters the freedom to "shape their own destiny" and that of U.S. society (Lawson; McNamara). By requiring more uniform standards across all states, the NVRA expands and broadens the pool of active voters (MacNamara). ${ }^{72}$ Central to Ohio's Purge Policy

\footnotetext{
${ }^{71}$ As an example, "[b]etween the 1964 and 1968 presidential elections, black voter registration rates increased 67 percent among Southern states" (Ang).

${ }^{72}$ Flanked by members of the National Association for the Advancement of Colored People (NAACP) and the League of Women Voters in the United States (LWVUS), President Clinton
} 
is the NVRA's stated "Purposes" (see Table 3). As I aim to make apparent, Ohio's purge policy, its proponents, and the Supreme Court judges who ruled in favor of upholding the policy allow for the requirement to "ensure that accurate and current voter registration rolls are maintained" to supersede the purpose that election officials "establish procedures that will increase the number of eligible citizens who register to vote" (NVRA, Sec. 2. Findings and Purposes). Moreover, they call upon rhetorics of efficiency and normative constructs of users to justify a system that results in the exclusion of multiply marginalized voters - the very voters that the VRA and NVRA sought to include.

Table 3

NVRA, Sec. 2. Findings and Purposes

NVRA, Sec. 2.b, Purposes

(b) PURPOSES.-The purposes of this Act are-

(1) to establish procedures that will increase the number of eligible citizens who register to vote in elections for Federal office;

(2) to make it possible for Federal, State, and local governments to implement this Act in a manner that enhances the participation of eligible citizens as voters in elections for Federal office;

(3) to protect the integrity of the electoral process; and

(4) to ensure that accurate and current voter registration rolls are maintained

Source: The United States Department of Justice, https://www.justice.gov/crt/title-42-publichealth-and-welfare-chapter-20-elective-franchise-subchapter-i-h-national-voter\#anchor_1973gg

Access to voting was certainly not solved with the VRA and NVRA, but these pieces of legislation signaled that those in positions of power both acknowledged and sought to address historical and contemporary discriminatory voting policies and practices in the United States.

presented the NVRA as a bill "dedicated to widening the circle of liberty to encompass more and more of our fellow citizens" (Clinton). 
Ohio's purge policy is a clear indication, however, that public policy is now functioning to erode, rather than ensure rights.

I now turn to the Supreme Court's ruling on the legality of Ohio's policy, applying an intersectional feminist rhetorical lens to both the majority and dissenting opinions of the Justices - particularly as these opinions reflect differing interpretations regarding who is responsible for the usability of public policy. An intersectional feminist rhetorical analysis of the court ruling reveals an understanding of usability that fails to acknowledge the embodied and bodily realities of many marginalized groups. Specifically, the decision fails to account for the: (1) physical, time and space barriers that many individuals must overcome in order to access polls (reliable, affordable, accessible transportation; work release; child or eldercare), and the (2) disproportionate impact that this policy has on individuals and groups whose race, socioeconomic status, language, or identity expression, among other factors impact their access to, or experience at, polling stations throughout the country.

\section{Supreme Court Ruling}

Ohio’s purge policy came to national attention following a 2015 incident in which Ohio resident Larry Harmon, a software engineer and Navy veteran living outside of Akron, Ohio, was denied the right to vote when he attempted to cast a ballot on a local initiative. Harmon had voted in the 2004 and 2008 presidential elections but had not voted in the 2012 presidential election nor in the 2010 or 2014 midterm elections. At the time, election officials explained that according to Ohio's purge policy, Harmon had lost eligibility to vote after failing to return the Confirmation Notice sent to him in 2011. Citing the 1993 National Voting Rights Act that "prohibits removing registrants from the voter registration list solely because of a failure to vote" 
and the Help America Vote Act of 2002, ${ }^{73}$ Larry Harmon and the Northeast Ohio Coalition for the Homeless (NEOCH) sued Ohio's Secretary of State Jon Husted (NVRA, Section 8.30). After Ohio's Sixth Circuit Court sided with Harmon and NEOCH, the case was taken to the Supreme Court. In June 2018, the Supreme court ruled in favor of Husted and solidified the right of Ohio's Secretary of State to proactively flag voters as potentially ineligible based solely on their voting record.

Delivering the majority opinion that may now set the bar for future purge laws in the U.S., Supreme Court Justice Samuel Alito justifies the purging of voters by citing the usability of the policy for voters as well as the documents that are used to carry out this process. Using terms like easy, simple, and reasonable, the majority opinion fails to acknowledge bodies and embodiments whose experience of the voting process is outside what the justices deem normal. Alito defended the decision to uphold the legality of the purge policy based on the premise that Ohio's system is easy and accessible for all users, and that any reasonable user will be spared hardship:

The notice in question here ${ }^{74}$ warns recipients that unless they take the simple and easy step of mailing back the pre-addressed, postage prepaid card—or take the equally easy step of updating their information online- their names may be removed from the voting rolls if they do not vote during the next four years ...

\footnotetext{
${ }^{73}$ Passed in response to the infrastructure issues evidenced by the contentious 2000 presidential election, the Help America Vote Act (HAVA) established the Election Assistance Commission to assist in the administration of elections and to establish minimum standards by which state and local governments must conduct elections ("Help America"; Sozan; Zetter). Central to this case, HAVA mandates that state election officials implement "[s]afeguards to ensure that eligible voters are not removed in error from the official list of eligible voters" (HAVA, Section 303B). ${ }^{74}$ Referring to the Confirmation Notice (see Figure 3).
} 
It was Congress's judgment that a reasonable person with an interest in voting is not likely to ignore a notice of this sort. (Alito, emphasis mine)

This interpretation of the users and usability of the Confirmation Notice reveal numerous assumptions about which bodies vote, as well a clear indication of the efficiencies for whom this policy works best.

The opinion outlines the Court's understanding of what is means to be a reasonable citizen: one who has access to a permanent, long-term home address at which they reside and reliably receives mail and/or has a computer and the internet, and the technical know-how to access, comprehend, and complete an online voter registration system. A reasonable citizen can see, read, comprehend, and accurately complete the registration either online or via mail — a construct that again ignores and excludes innumerable bodies. A reasonable citizen, according to Alito, does not question the motives of their government and accepts government communications as benign and apolitical. In short, Justice Alito's statement constructs a normative user-one who is home secure, financially secure, has access to technology, and is able to, comfortable with, and confident in completing government forms. In this way, the justices go beyond arguing that it is possible for individuals to maintain their registration in light of the purge policy; instead they argue that the process is simple and easy for any reasonable person. In this framing, all experiences, all bodies, all histories, are flattened and homogenized: there are the reasonable and, one can infer, the unreasonable. In the majority opinion, only the latter stand to be impacted.

For the dissenting justices, a central argument against the legality of Ohio's voter purge is evidence that it is not usable for many potential users and disproportionately deters participation 
among certain populations. In her dissenting opinion for the minority Justices in Husted $v$.

Randolph, Judge Sonya Sotomayor points to the following evidence:

Amici [the impartial advisor] also explained at length how low voter turnout rates, language-access problems, mail delivery issues, inflexible work schedules, and transportation issues, among other obstacles, make it more difficult for minority, low-income, disabled, homeless, and veteran voters to cast a ballot or return a notice, rendering them particularly vulnerable to unwarranted removal under the Supplemental Process. (Sotomayor 4).

Sotomayor stresses that the "history of such purge programs" provides ample evidence showing that the Supplemental Process "has disproportionately affected minority, lowincome, disabled, veteran voters" (4).

These voters - ignored or constructed as non-normative in the policy, discourse, and majority ruling of the Supreme Court - in fact comprise much of the voting population in Ohio. According to the U.S. Census Bureau 2018 estimates, the Ohio population includes the following "non-normative" citizens: fourteen percent of Ohioans live in poverty; twenty-three percent live in a home without a broadband internet subscription and nearly fifteen percent have no computer in the home; twenty-one percent identify as a race other than "White-alone"; slightly over half identify as female; nearly seventeen percent are over the age of sixty-five; slightly over six percent are veterans; and almost seven percent speak a language other than English in the home ("Quick"). For these voters, evidence shows that the easy, simple steps promised by purge proponents do not resonate with their lived realities. Yet the system continues to prioritize efficiency over usability. 
The limited scope of embodied realities and experiences recognized within the majority ruling fosters the idea that the only individuals who are purged are those who have brought such an action upon themselves and thus have only themselves to blame. Through this lens, reasonable citizens are protected, while only those who fail to comply, who refuse to perform in normalized, "good" ways are excluded. Purged voters are constructed as either disinterested, unreasonable, or lazy—not victims of a system that fails to recognize a diversity of complex, intersecting experiences, realities, and oppressions but rather autonomous beings who refuse to work within a normal, reasonable system. As I show in the next section, the narrative of efficiency presented to the public is one in which users, rather than policy makers and officials, are blamed for inequitable outcomes.

\section{Defenders of Ohio's Purge Policy: Policy Failure as User Failure- Efficiency versus Usability}

In Directive 2018-20, Husted frames Ohio's purge policy as “conducted for the purpose of ensuring the accuracy and currency of voter registration lists" (Husted, "Directive" 2). This argument - that Ohio's purge policy is a necessary efficiency to ensure that voter rolls are kept up-to-date and proactively safeguard against voter fraud—is widely dispersed to the public. In a news release defending Ohio's purge policy, then-Ohio Secretary of State Jon Husted calls upon these efficiencies in his justification of the policy:

Maintaining our voter rolls is a legal requirement and essential part of ensuring

Ohio is a place where it is easy to vote and hard to cheat. We want every eligible Ohioan to participate in our elections, and we must also preserve the integrity of 
our elections...[T]he supplemental process and other tools make sure the state's voter rolls are not bloated with names of people ineligible to vote." (Rowland). Husted's framing of Ohio's voter purge policy as a necessary step to protect the system against fraud counters research that shows little evidence that individual voter fraud is an actual threat to the system and ample evidence that restrictive voter laws impinge of the rights of eligible voters. But by normalizing this myth, Husted employs a strategy that has proven effective in distracting voters from discriminatory election practices:

Today, voter-suppression strategies are pursued through subtle forms of intimidation and obstruction that take on the mantle of law and order. The strategy involves exaggerating the fraud threat to justify the complexity of the electoral system, a complexity created and compounded by the layering of more and more rules to deter fraud. . . Administrative complexities justified as race-neutral necessities for deterring voter fraud are also opportunities for administrative error that have come to replace opportunities for vote suppression by other means. This is the context for the proliferation of unsupported fraud allegations today. The allegations shrewdly veil a political strategy for winning elections by tamping down turnout amongst socially subordinate groups" (Minnite, The Myth 88-89). ${ }^{75}$ Alongside arguments that the purge policy is a necessary protection against voter fraud, proponents present the policy as necessary for efficient governance and assure the public that the

\footnotetext{
${ }^{75}$ For an example of this myth being uncovered, read Minnete's expert testimony in the One Wisconsin Institute Inc., et al v. Gerald Nichol, et al. which informed the court's eventual conclusion that the "voter protection" laws enacted by then-Wisconsin governor Scott Walker " "intentionally discriminates on the basis of race... [and] suppress the reliably Democratic vote of Milwaukee's African Americans." ("Judge"; Levine).
} 
policy will be equally efficient for all users - repeatedly noting that compliance is simple, easy, and readily accessible to all. Inconvenience, inaccurate purging, and voter suppression are dismissed as rare, self-inflicted, and easily corrected. But the policy is designed for a certain user-one whose cultural history and current privileges establish them as a normative user imagined by the policy's proponents. Those users outside the policies' normative constructs of idealized citizenship are faced with sometimes insurmountable challenges even as the policy, and the documents that allow for the enactment and enforcement of it, are touted as objective and neutral. This myth of neutrality allows proponents to defend practices that ignore the embodied circumstances of, and effects on, users as both necessary and legitimate.

Neutrality allows for rhetorical coverage, transforming concerns about discriminatory practices and inaccessibility into conversations about efficiency, and focusing attention away from the usability of the policy and instead on the need to better manage users. Rather than expanding understandings of users and their needs in order to make the policy more accessible to a wider audience, proponents focus public attention, and blame problems, on user compliance- $-\mathrm{a}$ rhetorical maneuver that allows for exclusionary and repressive practices to be framed in terms of users' unwillingness to conform rather than revealed as discriminatory actions imbricated throughout policy documentation and practices. Rhetorics of efficiency mask discriminatory practices, allowing policy writers and proponents to frame marginalized individuals and groups not as victims of an unjust policy but rather as lazy, disinterested, or unreliable citizens. By establishing a limited scope of acceptable, normal practices and a narrow understanding of who votes, rhetorics of efficiency serve to justify unnecessary interference and oversight that disadvantage certain bodies and ways of being. 
Pushing back against critics of the policy, Jon Husted argued that being purged is not an outcome of the policy itself, but rather the consequence of an individual choice: "If this is really important thing to you in your life, voting, you probably would have done so within a six-year period" (Husted qtd. in Graham). Husted frames individual will, reflected through the "choice" to vote or not vote, as the singular, deciding factor informing a voter's maintenance of their voter registration. Defenders of Ohio's purge policy argue that purges only impact those who "fail" to comply. The policy and surrounding discourses establish certain acts as indicative of normal, appropriate behavior: the act of consistent regular voting, the timely completion of the Confirmation Form, and so on. In so doing, a no-vote, lapsed registration, or missed notice are rhetorically constructed as signs of personal failure, disinterest, laziness, or apathy.

The idea that users need only comply with the requirements outlined in Ohio's purge process in order to benefit from the policy, is, as Catherine Gouge describes it, "an exclusionary fantasy that presupposes an oversimplified account of agency" (124). Gouge's work highlights the problem with policies whose efficiency and success are dependent on normative constructs of users, and their ability and willingness to comply. Efficiency via compliance seeks to correct flawed individuals and their behavior rather than recognize the potential weaknesses of the system itself. Currently, voter-purge policies connect the loss of voting rights to issues of compliance/self-discipline. Husted's suggestion that if "voting was really important" to an individual, then they would simply do it, directly parallels voter choice with voter purgesexempting the purge policy and its impact entirely.

When compliance becomes the norm for producing efficient outcomes, it can distract policy makers from gauging the usability of a policy—particularly from understanding how myriad, intersecting experiences inform an individual's capacity to comply with policy strictures. 
Compliance-focused approaches allow for policy failures to be blamed on users lack of selfdiscipline or will. Compliance ignores the cultural, historical, and contextual situatedness of users that informs how they engage with and act on policy mandates. Shifting measures of success from compliance to usability redirects attention to the unique, intersectional, embodied realities of diverse users and their experiences. In the case of Ohio's purge policy, administrators might consider how a failure to vote is not simply a matter of individual character flaws, but rather informed by "the dynamic and kairotic convergence of many phenomena" (Barad 127).

Efficiency via compliance allows politicians and policy writers to gloss over the ways in which policies can privilege and oppress. Employing rhetorics of efficiency that justify voter purges as a logical response to an individual choice is a gross oversimplification grounded in the assumption that the good - in this case access to, and equal authority to help shape and enjoy, the benefits of what it means to be a citizen in the U.S. — is equally accessible to all members of the public. By placing responsibility solely on the individual, Ohio's purge policy absolves its creators of liability for any unjust outcomes that may result from the policy's enactment: removal is framed as the result of individual failure; blame is shifted away from those charged with designing, implementing, and maintaining free and fair elections, and onto the individuals whose "choices" have ostensibly disallowed them from partaking in the good.

The Secretary of State and the Supreme Court ruling highlight a foundational problem in combating discriminatory voting policies: They are too often designed by and for, upheld, carried out, and defended by, those who continue to occupy positions of privilege—namely affluent, heteronormative, able-bodied, white men. The normative rhetorics of efficiency and compliance that structure Ohio's policy and the legal decision maintaining its legality obscure the disproportionate material impacts that this policy has on multiply marginalized users. The 
VRA and NVRA functioned as a wake-up call—making apparent the continued legacy of discriminatory voting practices in the U.S. - but rulings such as that handed down in the case of Ohio's purge laws weaken the power to enact the foundational purposes of these Acts. Justice Sonia Sotomayor concludes the Court's dissenting opinion with the following statement:

Communities that are disproportionately affected by unnecessarily harsh registration laws should not tolerate efforts to marginalize their influence in the political process, nor should allies who recognize blatant unfairness stand idly by. Today's decision forces these communities and their allies to be even more proactive and vigilant in holding their States accountable and working to dismantle the obstacles they face in exercising the fundamental right to vote. (Sotomayor 5)

Sotomayor's dissenting opinion is an example of social justice work in action. Haas and Eble explain that social justice via technical communication "explicitly seek[s] to redistribute and reassemble —or otherwise redress—power imbalances that systematically and systemically disenfranchise some stakeholders while privileging others" (Haas and Eble 4). Justice Sotomayor's dissenting opinion does this work as it explicitly frames the Court's decision as one that will disproportionately impact already marginalized communities, directly undermines the argument that Ohio's policy is neutral and fair, and clearly identifies purge policies as obstacles to individuals wishing to exercise their fundamental right to vote. Justice Sotomayor and the other dissenting justices used their platform and rhetorical skill to relate the effects of purge policies and to express their support for those marginalized by the policy and the Court's ruling. Sotomayor's opinion is an amplification of the embodied experiences of marginalized voters and 
a call to action not only for those who stand to be further marginalized by the ruling, but to all who "recognize the blatant unfairness" of Ohio's policy. Sotomayor reminds us that supporters must not support only in spirit, but also in action.

Modeling the ways in which Justice Sotomayor's call is being answered, I next present the work of Fair Fight Action — an organization that seeks to make apparent and counter the policies and systems of power that deny vulnerable communities from accessing their right to vote. I do so not as a member of these communities, but as an intersectional feminist who recognizes the danger of voter suppression and seeks to amplify the work of marginalized groups fighting back against the "blatant unfairness" of restrictive voting policies.

\section{Intersectional Feminist Rhetorical Response: Stacey Abrams and Fair Fight Action}

As outlined in Chapter II, and illustrated in Chapter III, an intersectional feminist rhetorical methodology works toward a reframing of embodied experience as generative and productive, and recognizes and builds upon individual and collective acts that can serve as models of resistance to policies as discourses that strive to make certain bodies perform in “normalized" ways as framed by dominant standards. Paralleling my Chapter III analysis of Fed is Best as an example of how bodies deemed non-normative are pushing back against rhetorics of efficiency, I now present Fair Fight Action as an organization dedicated to projecting the experiences of those marginalized by discriminatory policies and practices such as those evidenced by Ohio’s voter purge policy.

The mission of Fair Fight Action is not a direct response to Ohio's purge policy, but rather responds to the shared concern of unjust policies and practices that are presented as the 
necessary and normal order of things. I present Fair Fight Action as an example both of what intersectional feminist rhetorical resistance can look like when focused on the goal of making voting policies more user-friendly for all users, and of how everyday users are rejecting rhetorics of efficiency that seek to manage bodies, homogenize user experience, and dictate choice.

As evidenced throughout this chapter, the discriminatory effects of Ohio's voter purge policy are often veiled behind rhetorics of efficiency that reshape narratives such that it is the individual, rather than the system, that is held responsible for policy injustices. Glossing over well-documented instances of unethical practices and unexplainable hurdles played out against marginalized bodies, those charged with ensuring that elections adhere to the tenets of the NVRA undermine or deny the experiences of non-normative users. Secretaries of State, Supreme Court Justices, and election officials attribute the marginalization and discrimination of certain individuals and groups to individual users' refusal to conform or perform in normalized ways. I turn to Fair Fight Action as example of how an intersectional feminist approach that engages with and responds to contextualized, embodied user needs creates a space in which user narratives lay the groundwork for change.

Fair Fight Action is directly connected to Georgia's 2018 gubernatorial elections in which Stacey Abrams - the founder of Fair Fight Action — and Brian Kemp vied for the governorship. As the then-Georgia Secretary of State and thus the chief election official for the state, Kemp was charged with managing the administration and certification of elections, and with ensuring a fair election process. Despite the obvious conflict of interest in being both candidate and election officer, Kemp maintained these dual positions—-never recusing himself from his role as election official, and presiding over an election widely seen as tainted with egregious and extensive acts of voter suppression, including numerous instances of voter 
intimidation, faulty election machines, overly aggressive match-laws, widespread purging of eligible voters, uncounted absentee ballots, and inaccurate counting of votes (Harriot; Anderson; "Georgia's"). ${ }^{76}$ These voter suppression tactics disproportionately impacted Black Georgians and led to what some have argued "may represent the largest mass disenfranchisement in U.S. history" (Judd; Brater and Ayala; Durkin). ${ }^{77}$

Despite widely documented instances of systemic and targeted discriminatory practices and negligence - particularly against Georgians of color — Kemp was eventually declared the victor. On November 16, 2018, Stacey Abrams stood before a crowd of supporters to acknowledge that Brian Kemp would be certified as governor, but that the she was not conceding defeat:

Let's be clear, this is not a speech of concession. Because concession means to acknowledge an action is right, true or proper. As a woman of conscience and faith I cannot concede that. But my assessment is the law currently allows no further viable remedy... Pundits and hyperpartisans will hear my words as a rejection of the normal order. You see, I'm supposed to say nice things and accept my fate...be stoic in my outrage and silent in my rebuke. But stoicism is a luxury

\footnotetext{
${ }^{76}$ Georgia's "exact match" law can place in limbo those voters whose personal information on their voter application do not exactly match information in the state's database. Individuals who leave out a middle name or even a hyphen can have their registration flagged as "pending" and enter into a lengthy, burdensome process to have their status restores (Fausset, "How"; Reid and Smith).

${ }^{77}$ The U.S. House and Oversight Reform Committee has opened an investigation into allegations of voter suppression against Brian Kemp while he served as Georgia Secretary of State (United States, Letter; Astor; Lockhart).
} 
and silence is a weapon for those who would quiet the voices of the people. And I

will not concede because the erosion of our democracy is not right. ${ }^{78}$

Abrams disrupts hegemonic notions of the "normal order" of politics. She acknowledges that while her speech may be read as rejecting the "normal order," the normal order is one that she and her supporters do not accept. The normal order, Abrams makes evident, is one in which Black voters in Georgia continue to be denied their right to vote.

Had Abrams complied with the normal order of things, the blatantly unfair, discriminatory practices that had preceded may have been allowed to go unchecked. But by defying these norms and refusing to comply with dominant expectations-by making apparent the injustices that have and continue to be enacted on certain individuals and groups-Abrams creates a space in which marginalized bodies can push back. In this same speech, Abrams described her plans for Fair Fight Action.

The goal of Fair Fight Action is a system that allows for and counts all votes. Central to the organization is the mission "to advocate for election reform and engage in voter education and turnout to secure the voting rights of Georgians" (Fair). As part of this mission, the organization creates an online space for those individuals whose experiences and bodies do not conform to normative standards to have their realities acknowledged and reaffirmed; a space in which individual narratives coalesce to reject oppressive systems. ${ }^{79}$ The collection and

\footnotetext{
${ }^{78}$ Although the space of this chapter does not allow for inclusion of Abrams speech in its entirety, a printed version if available through the $A J C$ (Galloway) and an audio version on YouTube ("Full Speech").

${ }^{79}$ Fair Fight Actions website provides a physical address for the organization, but it is not clear if testimonials can also be submitted in person, by mail, or over the phone. As noted earlier, communication that is limited to online discourse may present issues for potential users who lack access to, or know-how with, digital technologies.
} 
recognition of diverse lived experiences explicitly challenge the "simple and easy" narrative trafficked in policies such as Ohio's and Georgia's voter purges. By capturing these instances of oppression in a single space, Fair Fight Action equips itself as an organization, as well as those individuals who participate in or come in contact with the organization's website and/or literature, to speak back to those who would homogenize, minimize, or ignore the experiences and realities of marginalized voters.

Immediately under a picture of Stacey Abrams and a side panel titled "About Our Fight," visitors to the Fair Fight Action website are prompted to share their own stories and to learn the stories of others. This section, titled "Our Voices Matter," creates a space in which "non-expert" users participate in reshaping the system. Accessible in both English and Spanish, visitors who click on "Share Your Story" are met with the following message:

Your vote matters and Fair Fight Action is standing up for voters like you.

Please complete this form as fully as possible to help us better understand the issues you experienced while voting. Thank you for your willingness to share your experience so that we can work toward a Georgia where all votes are counted and every voice is heard.

The Fair Fight administrators - individuals with formal public policy, election, and/or law experience and education — situate these stories as an act of resistance ("standing up") and essential to improving the electoral system in Georgia ("share your experience so that we can work toward...”). Immediately following this header is a short fillable form that requests information such as name, date of birth, email, and address proceeded by a prompt asking users to: 
Please describe the voting irregularity or issue(s) you experienced while voting.

Provide as much detail as you can recall. If applicable, please do your best to include the name of your polling location, a clear description of the issue you experienced, and the outcome of your issue.

By requesting that users "describe [what they] experienced," the prompt immediately establishes the writer, and their story, as valid. By requesting polling location, a description of "the issue," and description of the outcomes - the sense is not that the user is abnormal, but rather that the experience, the outcome, that took place are outside acceptable norms. In this way, Georgia's discriminatory voting policies, not the individual user, are framed as the problem.

Rather than inefficient, or burdensome, the experiences of those marginalized by the dominant system are foregrounded as essential to progress. Instead of being chastised as lazy, unmotivated, or incompetent, users are framed as essential contributors and thanked for actively engaging. In the Fair Fight Action model, user participation is essential and bridges the expert knowledge with everyday users' experiences. The narratives being gathered through Fair Fight Action show not only a flawed system but also the disconnect between the rhetorics of efficiency that would have us believe that these systems work the same for all: that registering and voting is simple and easy, that only those who are not adequately invested or compliant are impacted, or that the restrictive policies keep the system running efficiently by "cleaning" unnecessary names from rolls.

The following chart provides a glimpse into the juxtaposition between the narratives being espoused by proponents of purge policies and those of the actual users being impacted by these policies: 
Table 4

Standard versus Embodied Narratives

\begin{tabular}{|c|c|}
\hline Standard Narrative & Embodied Narrative \\
\hline Simple & $\begin{array}{l}\text { "I was shocked and I didn't even know where to begin to fix this to } \\
\text { prove that I'm a citizen. I was not able to vote. Nobody offered me a } \\
\text { provisional ballot and I do not know anything about provisional } \\
\text { ballots." (Kia) }\end{array}$ \\
\hline Easy & $\begin{array}{l}\text { I planned to vote before work on November } 6,2018 \text { at the Webster } \\
\text { County EMS Building. I gave my ID to poll worker to scan an she } \\
\text { informed me that I was Registered in Muskogee County and was } \\
\text { supposed to be voting in Columbus. I have never lived in Muskogee } \\
\text { County or Columbus. The address that the poll worker said was } \\
\text { coming up in her system for me was incorrect. I was told that I could } \\
\text { not vote in Webster County and I was not offered a Provisional } \\
\text { Ballot. Columbus is a } 45 \text { minute drive and I had to report to work so } \\
\text { I was unable to drive there to vote at that time and I didn't finish } \\
\text { working on November } 6,2018 \text { until 10:00pm (Dasia). }\end{array}$ \\
\hline $\begin{array}{l}\text { Necessary to keep } \\
\text { voter rolls clean }\end{array}$ & $\begin{array}{l}\text { wouldn't be able to vote at all because I wasn't on the rolls. I waited } \\
\text { at my polling location for two hours trying to determine if I could } \\
\text { cast a provisional ballot. At times, poll workers made phone calls } \\
\text { and waited on hold for up to } 30 \text { minutes to inquire about my voter } \\
\text { registration, and I felt as though the poll workers doubted my story } \\
\text { from their repeated questions. Ultimately, I had to leave in order to } \\
\text { go to class. So I left without being able to cast a ballot, provisional or } \\
\text { otherwise. When I got home later, I looked up the information on the } \\
\text { Secretary of State's My Voter Page website. . On that page, I saw } \\
\text { that [another Alexus Clark] had registered on April 4, 2018. So it } \\
\text { seemed like the Secretary of State had mixed me up with this other } \\
\text { Alexus Clark and somehow written over or deleted my voter } \\
\text { registration. . My right to vote was taken away from me. (Alexus) }\end{array}$ \\
\hline $\begin{array}{l}\text { Invested voters will not } \\
\text { be impacted } \\
\text { (Table Continues) }\end{array}$ & $\begin{array}{l}\text { I registered to vote online in early October } 2018 \text {. When I registered } \\
\text { to vote, I was given a reference identification number. I took a } \\
\text { screenshot of the confirmation page after I registered to vote. On } \\
\text { Election Day, I went to my local polling place in Gwinnett County to } \\
\text { vote. When I got there, the poll workers told me that I was not } \\
\text { registered to vote and that they could not even give me a provisional } \\
\text { ballot... }\end{array}$ \\
\hline
\end{tabular}




\begin{tabular}{|c|c|}
\hline Standard Narrative & Embodied Narrative \\
\hline & $\begin{array}{l}\text { They told me to have a seat while they checked on the status of my } \\
\text { registration over the phone. When they told me again I was not } \\
\text { registered, I asked to call and speak to someone myself. I really did } \\
\text { not want to leave without voting. I spoke to a lady on the phone who } \\
\text { said that she was not sure why my registration had not showed up, } \\
\text { and that maybe the system had not been updated just yet. She told } \\
\text { me to check with the registrar's office. I told her that I wanted to file } \\
\text { a formal complaint because I was not able to vote and because no } \\
\text { one would even provide me with a provisional ballot. Altogether, I } \\
\text { was at the polling place for over an hour. } \\
\ldots \text { I filed a complaint with the Secretary of State to allege that my } \\
\text { rights had been violated as an African-American woman. Being able } \\
\text { to vote in the midterm elections, including voting for governor, was } \\
\text { very important to me. I was really upset that I could not vote even } \\
\text { after registering online and having what appeared to me to be a } \\
\text { confirmation number to show that I was registered...I am still upset } \\
\text { that I was not able to cast my vote in this election (Tyra). }\end{array}$ \\
\hline
\end{tabular}

Source: "Hear from Voters Like You." Fair Fight Action, www.fairfightaction.com.

The story of Christine Jordan, a 92-year old Black female shared on Fair Fight Action highlights the disproportionate burden that voter purges and other system "efficiencies" can impose on residents. Jordan's story illustrates the layered flaws in the current system and makes evident that while certain efficiencies may cater to system administrators, they certainly do not serve voters. In 2018, Jordan arrived at her polling place to cast her ballot, just as she had done in every election since 1968. Yet when Jordan stepped up to receive her ballot, she was told that she would not be allowed to vote as her name appeared nowhere on the roles. On the Fair Fight Action website, Christine's granddaughter who accompanied her to the polls relates the story ${ }^{80}$ :

On November 6, 2018, I took my 92-year-old grandmother, Christine, to vote at her regular polling place in Fulton County. My grandmother has lived in the

${ }^{80}$ An audio/video interview from Election Day, as well as a more extensive interview with Jordan and her granddaughter Jessica provide additional context (Palast; "92 Year Old" ). 
Historic West End of Atlanta since 1968 and voted at the same polling place for the past 25 years. This year is the fiftieth anniversary of her voting from the Historic West End. On the morning of election day, my mother and I went to my grandmother's home to pick her up and to go vote...Though she is an active voter who cast her ballot in 2016 and in this year's primary, her registration could not be found in the database on Election Day this November. When the poll worker was unable to find her registration, we were initially told she would not be allowed to vote - even with a provisional ballot. The poll workers seemed confused about the process, so I turned to the Democratic Party of Georgia's Voter Protection Hotline on my grandmother's behalf. After nearly 2.5 hours, my grandmother was finally given a provisional ballot, yet we were never told about the necessary steps we might need to take in order to "cure" the provisional ballot and see her vote counted. Instead, the poll workers just thanked her and gave her a sticker. ("Jessica")

Like so many of those voiced through the Fair Fight Action "Share Your Story," Christine's experience serves as a powerful, collective counterstory to the ones pushed by individuals such as Husted, Kemp, and Alito. By providing a space in which users can share their stories, and a platform for projecting these stories, Fair Fight Action represents a framework in which the experiences of voters - the users of the voting system — are pushing back against purge systems that function to include and exclude, privilege and oppress, manage and control bodies. The organization's "Our Voices Matter" foregrounds the importance of everyday experiences being recognized as tangible, primary source evidence that can complicate the dominant narratives that present voter purge laws as efficient and fair, the system as simple and easy, and the impacted users as unreasonable and disinterested.

\section{Implications for Teacher Scholars}

Fair Fight Action serves as an example of how diverse, embodied knowledges and experiences must inform how we understand the material impacts of public policy.

Acknowledging, sharing, and learning from the work of the individual contributors to, and 
collective action of, organizations such as Fair Fight Action opens a pathway for rethinking usability in terms of what it means for public policy to be "usable." My own critique focused on the ways in which Ohio's purge policy assumes a normative user-one who has a permanent address, access to the internet, reliable transportation and other privileges - and thus mandates that users perform in "normal" ways based on these assumptions. Through this critique, I aimed to show how technical documents shape public policy, and thus are complicit in the material impacts of these policies. These documents, then, are never neutral as they are written, interpreted and enacted by individuals with their own cultural, historical, and personal frameworks.

When considered through an intersectional feminist rhetorical lens, it becomes apparent how rhetorics of efficiency that defend the policy as neutral can do damage to bodies. Ohio's purge policy relies on homogenizing and universalizing varied and complex user experiences in the name of efficiency. Moreover, the discourse surrounding the policy projects policy failures on users rather than those charged with designing and enforcing the policy itself. Reinforcing the idea that the process is not only neutral and fair, but also easy and simple, proponents defend the policy by arguing that any reasonable, motivated, "good" citizen will certainly not be impacted.

Returning to the concept I introduced at the end of Chapter III, I want to employ Rosemarie Garland-Thomson's idea of the extraordinary user in order to consider how altering assumptions about potential end-users and their experiences might allow a space in which our assessment of voting policies more accurately represent reality. The experiences described by users in the Fair Fight Action "Our Voices Matter" section make clear that there is a disconnect between the imagined, normed publics constructed throughout Ohio's purge policy and surrounding discourse, and the actual, embodied users impacted by the policy. Thus, in order to 
become more usable, we need to consider potential user embodiments and experiences beyond the current dominant framework. When we expand assumptions about who users are and how efficiencies materialize for various users, it allows us to identify ways in which policies are currently not usable — particularly for marginalized groups. Listening to the embodied experiences of impacted users can provide directions for how policies might become more user friendly. Drawing on and learning from the work of individuals and organizations such as those contributing to Fair Fight Action, can point teacher-scholars toward usability discussions that shift away from a traditional measures of efficiency. In the case of voting policy, this might move usability measures from efficiencies such as expenditure of time, reductions in paperwork, and/or the "cleanliness" of voter rolls, and back to the original usability goals outlined in the VRA and NVRA: a voting system whose usability is measured according to its success at providing free, fair, and robust voter participation.

Applied to voting policy, an intersectional feminist rhetorical methodology has potential for contributing to and forwarding socially-just scholarly and pedagogical work in TPC as it pushes against practices that ignore, undermine, or deny access to multiply marginalized users and instead engages a more human-centered understanding of usability that foregrounds diverse users and their needs. This case study modeled how intersectional feminist rhetorical work might contribute to feminist, rhetorical, and technical and professional communication scholarship that seeks to "remove the veil" from technical writing and rhetorics that contribute to, and help to construct, oppressive practices that include and exclude certain bodies from participating in, and enjoying the benefits of, the public good (M. Williams 13). Voting rights—particularly for multiply marginalized groups - is under attack in the U.S. and technical and professional communication and rhetoric scholars are uniquely situated to make apparent the discriminatory 
effects of policy language, and contribute their technical and rhetorical skills in service of pushing back against hegemonic policies that oppress and supporting the work of those already engaged in this resistance. 


\section{CHAPTER V: AN INTERSECTIONAL FEMINIST RHETORICAL PEDAGOGY:}

\section{REFRAMING USABILITY IN THE TPC CLASSROOM}

In Chapters III and IV, I applied an intersectional feminist rhetorical methodology to two specific case studies: Baby Friendly USA, a public health policy, and Ohio's Supplemental Process, a voter purge policy, to illustrate how seemingly neutral rhetorics of efficiency can promote the management, oversight, and norming of vulnerable people — women, people of color, and the poor, among others. Reimagining public bodies as "users" of public policies, I then highlighted examples of how everyday users are already pushing back against these normative rhetorics and their effects. In previous chapters I engaged an intersectional feminist rhetorical framework of usability to draw attention to the disproportionate impacts and discriminatory effects of rhetorics of efficiency on multiply marginalized users. In this chapter, I focus exclusively on the pedagogical potential of this methodology. Specifically, I offer an intersectional feminist rhetorical pedagogy that engages usability as a tool to help students to see users more complexly and respectfully. This approach (1) explicitly foregrounds extraordinary ${ }^{81}$ users and marginalized perspectives, (2) rejects the non-expert/expert dichotomy, and (3) frames TPC as a field capable of furthering (or hindering) social justice. Seeking to scaffold these goals, I first introduce students to the idea that technical and professional communications and artifacts are never neutral but rather reflect the values and norms of the creators and cultures that shape them. Second, I foster an understanding of technical and professional discourse as having

\footnotetext{
${ }^{81}$ As noted in Chapter I, my use of the term extraordinary is contextual and emerges from Rosemarie Garland-Thomson's articulation of the concept as one used to "denaturalize the cultural encoding" of certain bodies and identities that "support the privileged norm" (5). I use this term as it rejects homogenized, standardized constructs of individuals and instead invites recognition of "the complexity of everyone's needs and knowledges" (Dolmage 170).
} 
material impacts that can both marginalize and privilege. Third, I engage students with usability as a tool to destabilize hegemonic notions of marginalized users and technical and professional practices. Finally, an intersectional feminist rhetorical pedagogy presents students with opportunities to interrogate their own privilege and complicity in furthering hegemonic norms through their academic and professional practices and their technical and professional work.

This pedagogy contributes to the social justice turn in technical communication pedagogy over the past decade and responds to calls within various areas of technical and professional communication for scholars to engage in new theories or applications for usability (Meloncon; Simmons and Zoetewey; Rivers and Söderlund). In this framework, TPC students' engagement with usability explicitly prompts identification of normalizing assumptions about users of, access to, and uses for technical and professional communication, and highlights the imperative of recognizing and engaging with users who occupy complex and marginalized positionalities. In this way, students are asked to purposefully attend to diverse and complex user embodiments and work toward discourses that are responsive to, and useful for, underrepresented groups.

As described more fully in Chapter I, my understanding of usability is shaped by TPC scholars who forward user- and human-centered design and cultural usability models that begin with consideration of which users are being included and excluded, and what experiences and contexts are being acknowledged or ignored when gauging the usability of an artifact (Rose; Simmons and Zoetewey; Shivers-McNair and San Diego). In particular, an intersectional feminist rhetorical pedagogy reflects the arguments of other TPC scholars regarding the social justice potential of usability methods that foregrounds "overlooked, vulnerable, or marginalized audiences [as this] leads to different design considerations, methods, practices and resulting designs" (Rose, Gonzales, Jones, Edenfield, Shivers McNair, Garcia de Mueller, Walton, 
Zhvotovska, and Moore). Adding to these human centered approaches, an intersectional feminist rhetorical pedagogy prompts students to continually problematize their own sense of objectivity and neutrality, recognize the privileging of hegemonic norms in seemingly neutral discourses, understand the damaging material impacts of these discourses on vulnerable bodies, and identify TPC work as both complicit in and a potential solution for these problems. Ultimately, this pedagogical approach engages usability as a pedagogical framework that asks students to consistently gauge the usability of their documents, discourses, and professional practices in terms of its capacity to reflect and respond to diverse, complex, and contextualized user needs.

In this chapter, I present a case study of an intersectional feminist rhetorical pedagogy that seeks to "reframe the field" of TPC for introductory TPC students—-shifting their view of the field from one focused solely on efficiency and consistency to one both invested in, and working toward, socially just practices (Walton, Moore, and Jones). An intersectional feminist rhetorical pedagogy reflects (1) an understanding of TPC as a field that is deeply invested in social justice pedagogy, (2) a desire to contribute to the robust and growing presence of social justice pedagogies in technical and professional communication (TPC), ${ }^{82}$ and (3) a commitment to sustained engagement with usability as a means for expanding students' capacity to identify problematic norms in TPC and to imagine how their future work can positively impact users.

Through these pedagogical practices, students are introduced to critical thinking skills and practices that "seek to counteract the ethic of expediency associated with the engineering

\footnotetext{
${ }^{82}$ As noted in Chapter I, I draw from Jones and Walton's definition of social justice work in TPC as work that can "amplify the agency of oppressed people - those who are materially, socially, politically, and/or economically under-resourced" ("Using" 242) and Gerald Savage's point that social justice "works to transform the social and cultural structures that have permitted injustice to exist, that have in fact made injustice invisible, or worse, have denied its existence" (x).
} 
model of usability," instead focusing on increased user involvement, the elevation of users' status and knowledges, and the reframing of users as participants in—rather than subjects ofthe usability process (Sun 36-37). Usability provides a grounding concept and practice from which to complicate the role both of users and of technical and professional communicators. Specifically, this pedagogical approach explicitly foregrounds extraordinary users- - those marginalized by normative constructs of who constitutes a user and/or how users engage with a discourse - as integral to any measurement of usability. By foregrounding extraordinary users, an intersectional feminist rhetorical pedagogy recognizes bodies and embodiments as always intersectional and further disrupts the expert/non-expert binary. Inspired by other TPC scholars who promote usability approaches that center and respond to marginalized users and their experiences and, in this way, contribute to more inclusive technical and professional design (Peterson; Grabill; Scott; Schneider; Palmeri; Sun; Simmons and Zoetewey), this particular framework prompts students to measure the usability of any technical and professional artifact or discourse by beginning with its capacity to respond to and reflect needs of users whose bodies and experiences are not represented in dominant constructs of an "ordinary" users. Ultimately, an explicitly intersectional feminist rhetorical approach to usability adds to other progressive approaches to usability thereby insuring that diversity and complexity are central to our work.

My pedagogical approach is informed by a desire to teach students that "injustice is not just a problem in technical communication but also one that we can solve with technical communication" (Haas and Eble 8). Drawing on social justice pedagogical scholarship (Agboka \& Matveeva; Blyler; Grabill; Haas, "Race"; Haas \& Eble; Jones; Jones, Moore \& Walton; Palmeri; Savage; Williams \& Pimentel); extended concepts of efficiency (Frost; Katz); and reimagined approaches to usability in technical communication (Rivers and Söderlund; Simmons 
and Zoetewey; Sun), rhetoric and composition (Miller-Cochran and Rodrigo), and Rhetoric of Health and Medicine (Gouge; Meloncon; Segal), I next present a case study of an introductory level technical and professional writing course in which I was practicing, developing, and revising this pedagogical approach. In the limitations section of this chapter, I will expand on this pedagogical approach which was, and still is, developing. Following a contextualization of my own positionality in relation to this work, I provide an overview of the institutional context followed by the course goals. The remainder of the chapter is then divided into the following sections: course readings and discussions, course projects, and student learning. I conclude by discussing the limitations of this approach as well as suggestions for how I, and other scholars, might move forward with this pedagogy in order to increase the social justice potential of our teaching. ${ }^{83}$

\section{Personal and Institutional Context}

Personal Context: Attention to bodies and embodiment is integral to an intersectional feminist rhetorical pedagogy, and important to the ways in which both instructors and students engage with it. Thus, seeking to enact the values of an intersectional feminist rhetorical practice, I want to briefly situate my own positionality and what this signifies in the space of the classroom and in relation to this pedagogy ${ }^{84}$ Among other elements of my person, my whiteness, able-bodiedness, age, heterosexuality, and Midwestern accent allow me to move through the

\footnotetext{
${ }^{83}$ Chapter VI provides a fuller examination of potential implications for this pedagogical approach.

${ }^{84}$ Numerous feminist scholars in rhetoric, composition and technical communication stress the importance of acknowledging the bodies that share and move through spaces of academia, and their disparate experiences of powers (Anzaldúa; Dolmage; Haas; hooks; Wray; Bates, Macarthy, and Warren-Riley).
} 
space of the university and the classroom relatively unmarked. My economic security, access to transportation, on-campus office, and supportive relationship with those in authority provide me with privileges that make my movement to, from, and within university fairly easy. As a graduate student, however, I also am aware of the tenuous nature of my authority in the classroom, and as a teacher to predominately male undergraduate students from the IT field, my status as a woman, a mother to young children, and an English major often requires me to convince students of my expertise and capacity to teach them technical and professional content and skills. These affordances and constraints inform my experience of the classroom and university and influence students' responses to me. Although I return to this subject again at the end of this chapter, it is important to acknowledge at the start as my experience enacting a progressive pedagogy will be different than for those whose actual or perceived race, ethnicity, sexuality, able-bodiedness, socioeconomics, or language, among other factors, make their access to and relationships with power different than my own. Thus I want to acknowledge that implementing this, and any, pedagogical practice that explicitly challenges or invites disruption of hegemonic norms can involve considerable risks for those located at multiple positions of marginality.

Institutional Context: This case study reflects my experience with developing and enacting the values of an intersectional feminist rhetorical pedagogy over the course of five semesters (from Spring 2017 to Spring 2019) teaching an introductory technical and professional writing course (ENG 249) at Illinois State University. To begin, I want to first provide institutional context and an overview of the course goals that give shape to this study. ENG 249: Technical \& Professional Writing I is a course offered by the English Department that is enrolled with undergraduate students majoring predominantly in English, Computer Science, 
Cybersecurity, and Information Systems. As a teacher of the non-majors sections, students in my classes are predominantly from the Applied Science and Technology department at the university. ${ }^{85}$ The course catalog description for ENG 249 includes: "Introduction to technical and professional writing. Includes study of manuals, reports, proposals, audience analysis, formatting, and style" ("ENG 249"). Many students enter the class anticipating the composition of "objective" professional documents. Instruction and practice in composing and revising widely used genres of professional writing — such as memos, emails, proposals, reports, and test plans - are central to the work of our class, but students are asked to encounter these technical and professional discourses as complicit in systems that function to marginalize some while privileging others. In particular, they are asked to consider how their work, and that of others, might more fully acknowledge and be made useable for multiply marginalized users.

In this way, an introductory TPC class can serve as a site for students to gain experience with rhetorical critique. An intersectional feminist rhetorical approach, however, asks students not only to critique but also to grapple with "the much larger project of trying to understand how change happens" and their own capacity to help realize change (Booher and Jung 32).

Specifically, students are asked how their own knowledges, practices, and work might contribute to more inclusive, socially just practices. In this way, students engage in critique but also propose ways in which their work, and thus its effects, might be different. An intersectional feminist rhetorical pedagogy makes these critiques and openness to possibilities central to course

\footnotetext{
${ }^{85}$ Of the 80 students enrolled in my sections of ENG 249 over the past five semesters, only 12 declared a major outside of Applied Science and Technology. Most English majors enroll in majors-only sections of ENG 249, which I didn't teach.
} 
readings, discussions, projects, and assessments - foregrounding considerations of usability as integral to all the work that we do in the class.

As noted earlier, an intersectional feminist rhetorical pedagogy takes seriously the need for social justice pedagogies to be sustained and central to the work of the course, and is attentive to Godwin Agboka's warning that presenting issues of human rights as individual units or courses can prompt "students [to] think that human rights issues are separate from the technical communication issues that they will undertake in the "real" world" (131). Moreover, an intersectional feminist rhetorical pedagogy honors the call to foreground rhetorics and theories of people of color in our core courses as a means of enacting social justice pedagogy (Martinez, "Core-Coursing Counterstory"). As the course draws from a wide range of majors and is a required course for many students, it is an ideal space for introducing students to underrepresented scholars and ideas, and provides them with foundational critical thinking skills that can ready them to attend to social justice in a wide range of academic and professional work.

\section{Course Goals}

The gap between what I understand to be an obligation of, and opportunity for, technical and professional communicators to engage in social justice work and my students' understanding of their own agency for impacting social justice issues is significant and has helped lay the foundation for my intersectional feminist rhetorical pedagogy. My course goals are prompted by a concern that despite preparing for professions that have enormous social justice implications (for example, systems technology, cybersecurity, or web development), many technical and professional writing students enter my course with an understanding of technologies, professional discourses, and their role as future technical communicators, designers, and 
programmers as being fairly neutral and often disconnected from issues of social justice. The social justice implications of TPC work, and thus pedagogy, has been theorized by numerous scholars who acknowledge that "[p]rofessional and technical communication courses that emphasize only skill-sets, software, and specific documents fail to consider broader literaciesespecially ethical literacies, which potentially can help students become not only effective writers but also engaged citizens who effect change in their communities" (Eble and Gaillet 341). This approach to TPC pedagogy seeks not only to equip students with the skills necessary to be effective employees, but also to recognize their potential to effect change at local and global levels (Sun; Agboka).

Incorporating theoretical lenses such as apparent feminism (Frost), decoloniality (Haas, "Race"), feminist disability (Smyser-Fauble), critical geography theory (Verzosa Hurley), and pedagogical methods such as community action research (Grabill); service learning (KramerSimpson and Simpson), narrative, antenarrative, and counternarrative (Blyer; Moore; Jones and Walton) among many others, TPC scholars have shown a commitment to helping students recognize the potential of TPC expertise to enhance their professional acumen but also to positively influence civic life. ${ }^{86}$ Yet despite the growing recognition of its import, the merging of professional skills and civic responsibility is frequently a new approach for many students who enter into introductory technical and professional communication course. Thus, even for students familiar with the concept of usability as a TPC tool, engagement with usability framed through a lens of social justice is unfamiliar.

\footnotetext{
${ }^{86}$ As noted elsewhere in the chapter, Haas and Eble's recent collection contains numerous examples of theoretical approaches for social justice work in the TPC classroom, and Agboka's and Matveeva's Citizenship and Advocacy in Technical Communication is dedicated to the practice of social justice in the classroom.
} 
Although necessarily limited, I focus this chapter on four of the central course learning goals that I provide students and how these goals reflect the values of an intersectional feminist rhetorical pedagogy. Alongside the course goals listed in Table 5, I include the manner by which an intersectional feminist rhetorical framework helps to support these goals. ${ }^{87}$

Table 5

Course Goals and Pedagogical Supports

\begin{tabular}{|l|l|}
\hline Course Goals & $\begin{array}{l}\text { An Intersectional Feminist Rhetorical } \\
\text { Framework helps to support these goals by: }\end{array}$ \\
\hline $\begin{array}{l}\text { Students will understand the work of } \\
\text { technical and professional communicators as } \\
\text { inherently ethical work. }\end{array}$ & $\begin{array}{l}\text { recognizing that technical and professional } \\
\text { design and discourse can either further (or } \\
\text { hinder) access and inclusivity for } \\
\text { marginalized users }\end{array}$ \\
\hline $\begin{array}{l}\text { Students will develop critical thinking and } \\
\text { communicative skills that account for } \\
\text { rhetorical situation, context, cultural } \\
\text { considerations, and audience needs. }\end{array}$ & $\begin{array}{l}\text { cultivating an understanding of users and } \\
\text { discourses that attends to power dynamics } \\
\text { shaped by cultural and historical context. }\end{array}$ \\
\hline $\begin{array}{l}\text { Students will design documents and artifacts } \\
\text { that account for and are responsive to diverse } \\
\text { user needs. }\end{array}$ & $\begin{array}{l}\text { expanding student notions of what it means to } \\
\text { consider diversity; encouraging an } \\
\text { understanding of positionalities as complex } \\
\text { and oppressions as multiple, overlapping, and } \\
\text { systemic. }\end{array}$ \\
\hline $\begin{array}{l}\text { Students will recognize the different expertise } \\
\text { and knowledges that various invested } \\
\text { individuals and groups can contribute to } \\
\text { technical and professional work. }\end{array}$ & $\begin{array}{l}\text { disrupting notions of expert and non-expert } \\
\text { by foregrounding the value or extraordinary } \\
\text { users and their embodied experiences. }\end{array}$ \\
\hline
\end{tabular}

Alongside theories and pedagogies cited earlier in this chapter, these course goals also reflect elements of the "Core Principles" outlined by the Association for the Teachers of Technical

${ }^{87}$ As I expand on in the implications sections, while the goals were provided to students within their syllabus, the connection to intersectional feminist values was not made apparent. This is a gap that I intend to address as I move forward implementing this pedagogical practice. 
Writing ("Code") and the "Ethical Principles" outlined by the Society for Technical Communication ("Ethical”).

\section{Case Study}

I now present a description and analysis of a pedagogical case study of designing and teaching ENG 249 with an intersectional feminist rhetorical framework for five semesters that aimed to support students in achieving the aforementioned course goals. To realize these goals, our classwork constantly returned to discussions and analysis of usability: examining how artifacts, discourses, and spaces can be made more usable for wider audiences. With each reading, discussion, and project, students were challenged to think rhetorically: to consider how location, socioeconomics, race, able-bodiedness, culture, education, or age, among other factors, impact the ways in which users might access or take up certain communications or artifacts — and thus how creators can best address these diverse needs.

To make apparent the power structures and ideological investments present in all artifacts and discourses, students were prompted early on to respond to questions such as: (1) What constitutes a technology?; and (2) What counts as technical and professional writing or communication? The ensuing discussions introduced students to the idea that the work of technical and professional communicators is, in fact, culturally and historically situated. It opened a space to discuss how approaches to usability that are informed by and perpetuate dominant understandings of technical and professional artifacts and practices limit the potential of our work to engage and reflect the needs of diverse users.

Each semester, students' initial responses to these questions tended to focus on 
technology as a digital tool that allows humans to do things better, easier, or faster and technical and professional communication as workplace writing that is formal and objective. Their responses mirrored a form of hyperpragmatism, the goal of which is "conformity, expediency, and success, narrowly defined;" an embrace of the myth of neutrality, objectivity, and efficiency that can lead students to "co-opt as well as foreclose critique...replacing ethical standards with those of economic expediency" (Scott, Longo, and Wills 5; 13). For instance, students always identified computers as a technology because it allows humans and businesses to do things faster, easier, and repetitiously. These identifying aspects of a technology allowed us to backtrack: Is a typewriter then a technology? What about a pencil? What about charcoal or a stick if it is used to write a message from one person to another? These initial discussions then segued into consideration of how time and place, access and socioeconomics, culture and education inform users' knowledges of, and interactions with, certain technologies.

This work continued throughout each semester as our work problematized reductive approaches to users and usability that present technical and professional artifacts, spaces, and discourses as objective and neutral, and/or users as standardized or homogenized. Below are just a few examples of how discussions of usability challenge normative frameworks and invite students to problematize rhetorics of efficiency, neutrality, and objectivity. We examined:

- The space of our classroom — for instance the designated "accessible" desk on the front wall of the classroom, immediately to the right of the projector screen, which holds the only classroom printer. We discussed how the desk — ostensibly intended to make the classroom more accessible—failed to 
make the space and experience of the classroom inclusive and usable.

- Our course syllabus alongside other examples of course syllabi, focusing particularly on grading, communication with instructors, and technology in the classroom. One example frequently discussed is attendance policies and how these can penalize students whose multiple obligations (such as school, family, work) and obstacles (unreliable transport or on-campus housing) present overlapping hurdles for compliance.

- The flyers, student health posters, signs, and bulletin boards within our building and what knowledges, ways of being, languages, physical appearances, among other factors, are highlighted and prioritized and those that are ignored or demeaned.

Through our analysis, we problematized how notions of efficiency, neutrality, and objectivity normalize systems that fail to recognize or respond to underrepresented users as complex, multilayered. In response to traditional observations of technical and professional communications, we asked questions such as: Easy and efficient for whom? Straightforward for which users? Neutral according to what norms? These questions pushed students to consider how positionalities of race, ethnicity, able bodiedness, sexuality, gender, socioeconomic status, or technology access, among other factors, figured into the way individuals and groups experience technical and professional discourse; they made evident that technical and professional communication work always already has material impacts on users and that these impacts are not the same for all users. A central goal of the class, then, was for students to consider the potential for "responsible citizenship and advocacy, selfawareness and consciousness, and critical thinking" in the academic and professional realms 
of TPC (Haas and Eble 17).

\section{Course Readings and Discussions}

Our textbook for the course, Lannon and Gurak's Technical Communication 14th edition, provided students access to overviews and templates of key technical and professional documents and practices - from oral presentations and social media to resumes and memos. ${ }^{88}$ Alongside this textbook, I assigned scholarly and popular articles and artifacts - several of which I discuss in more detail below - that are intended to challenge views of technical writing, including textbooks, as objective and neutral. These readings disrupted students' firm sense of expert/technical and non-expert/non-technical users by prompting discussion about the value of localized, cultural, contextual knowledge. The readings also explicitly problematize Western constructs of progress and efficiency, and clearly situate technical and professional work as having consequential, material impacts.

Seeking to immediately disrupt students notions of "expert" and "nonexpert" users; technical and nontechnical knowledge; and the relationship between technical communicators and users, we began each semester reading Angela M. Haas's "Wampum as Hypertext." Haas's article presents wampum as technical rhetorics, and the practioners, designers, and users of this communicative technology as savvy designers and users — and it makes space for students to reimagine normed constructs of technology and reductive understandings of who possesses technical skills. Haas's decolonial history prompted questions such as: What histories do we assume to be neutral and unbiased? Is any text ever truly unbiased or free from opinion? If not, who is served by this myth? Who constructs "traditional" notions of technology and technological expertise? How does this 
impact our understandings of professionalism and expertise? Is technology only that which makes things faster, easier, and cheaper for humans?

${ }^{88}$ As the cost of textbooks present a hurdle for many students, an additional but important factor informing my choice of Lannon and Gurak's text is that it is accessible for rent as an eTextbook or to purchase used as a paperback. 
Who benefits from these understandings? Who doesn't? ${ }^{89}$ Haas's article provides an opening to discuss how adherence to notions of experts and non-experts supports hegemonic systems in which certain people — women, people of color, indigenous people, the poor, the disabled, among others - are dismissed as lacking valuable literacies and knowledges, and how these demeaning assumptions are exacerbated for those occupying multiple positions of marginality. Similarly, this article introduces students to expanded notions of what counts as technology, and how dominant social constructs privilege Western, digital technologies and frame artifacts and systems designed by, and used within, marginalized groups as somehow inefficient or outside the realm of technical or professional significance. ${ }^{90}$ Finally, in addition to showing the problematic and racialized assumptions about who possesses technical skill and what technologies reflect technical expertise, Haas's article reveals the limitations of technical and professional work that fails to acknowledge, learn from, and respond to the knowledges and skills of marginalized people and practices. For instance, if wampum belts are only viewed through a hegemonic lens as antiquated or decorative artifacts, then they render little information about how to engage with their creators and users as technologically savvy individuals. But, equipped with an intersectional feminist understanding that explicitly foregrounds the knowledges, practices, and feedback of underrepresented users, wampum are understood as communicative technologies consisting of "nodes," "links," and "layered messages" (Haas, "Wampum" 86). In this way, Haas's article

\footnotetext{
${ }^{89}$ As a point for comparison, we frequently read "A Brief History of Technical Communication" by Frederick M. O'Hara, Jr. alongside Haas's article.

${ }^{90}$ Extending this, we analyze recipes and household technologies to debate how understandings of users and uses shape dominant notions of who possesses and create technical and professional knowledge and the artifacts that represent this.
} 
prompted critical thinking about the ways in which context and cultural considerations are essential to ethical, socially responsive, user-centered work.

Further framing technical and professional communication as ethical work, and technical documents as having material impacts, we engaged with a series of readings beginning with Steven Katz's "The Ethic of Expediency: Classical Rhetoric, Technology, and the Holocaust." Katz's description of Nazi Holocaust memos in which expediency was allowed to take precedence over ethics led to discussions concerning ethical standards as socially constructed and technical writing as having material consequences. Yet as Katz notes, the Holocaust, and thus the technical documentation that supported it, is such an extreme example of human depravity that it can seem disconnected to contemporary concerns. Reflecting this potential disconnect, students often reassured themselves that $21^{\text {st }}$-century laws and oversight protect the public from abusive practices by those in power. ${ }^{91}$ In order to make clearer the connection between Katz's ethics of expediency and students' current and future professions, we engaged with two in-class lessons that draw clear parallels between Katz's concerns and $21^{\text {st-century }}$ “efficiencies."

To begin, I assigned in-class reading that prompted recognition that technical and professional discourses impact the bodies and experiences of users beyond the target recipient for a communication and that technical and professional communicators have an obligation to consider the potential material impacts of their rhetorics. For the first lesson, I broke students up into small groups and provided each with a few pages from a 2002 memo that details the

\footnotetext{
${ }^{91}$ Even Katz's examples of more recent examples of industry abuse can feel "historical" for many students who were born in the late 90 s or early 2000 s.
} 
"interrogation" of suspected al Qaeda operatives in U.S. custody (Bybee) ${ }^{92}$ I did not tell students what they were looking at; rather, I asked them to analyze the section that they had, and to specifically look for language that is efficiency-focused, straight-forward, objective, or formal. We then came together and discussed as a class. Students were quick to point out how the writers use language that distances them and the readers from the acts that are being described. They pointed to the use of seemingly "technical" or "neutral" phrases like "attention grasp" or "cramped confinement" that stand in for and mask acts of physical and psychological violence. Students were bothered that the language disconnects the writers and executors of the actions from the abuses being sanctioned and experienced. They noted the exactness and efficiency of the memo: interrogation "techniques" presented as a checklist of tasks; official language that distracts from the torture being described; and qualitative, scientific "data" used to justify inhumane actions. Our rhetorical analysis of the memo — written by the U.S. government in their lifetime - muddied the previously clear lines many students drew between historical and contemporary issues and made apparent the dangers of technical and professional communicators distancing themselves from the human lives that can be impacted by the documents and technologies that they create.

Yet, some students still sought a degree of separation between their future work and the work being represented in both of these government memos - memos, they argued, that were written during periods of conflict and war. Similarly, they found solace in the idea that those involved with the government memos were clearly immoral people and aware that what they were doing was unethical. To further blur these convenient dichotomies, the final reading for this

${ }^{92}$ Thank you to Dr. Elise Verzosa Hurley for sharing the idea and resources that prompted this activity. 
section was intended to complicate the notion that workplace decisions will have clear lines of right and wrong, to make apparent that the seemingly routine decisions made by professional and technical decisions have material consequences, and to stress that professionals have an obligation to understand how users might take up the artifacts that they design (even if in unintended ways). ${ }^{93}$ The reading, Bill Sourer's “The Code I'm Still Ashamed Of” begins: "If you write code for a living, there's a chance that at some point in your career, someone will ask you to code something a little deceitful—if not outright unethical." Sourer traces his story of writing code for online quizzes at pharmaceutical company that were "basically designed to trick young girls" into seeking a specific drug treatment. Noting that the job wasn't technically illegal and paid well, Sourer eventually learns that the drug can could cause severe, sometimes fatal reactions in patients. He argues that "[t]he more software continues to take over every aspect of our lives, the more important it will be for us to take a stand and ensure that our ethics are everpresent in our code." This article helped solidify for students a connection between Katz's ethic of expediency and the work students will be tasked with post-graduation; it made the human implications of technical and professional writing feel real for many students; and it made them uncomfortably aware of how easy it is to make harmful decisions when we fail to think through and prioritize the material effects of our work on users.

Informed by an intersectional feminist rhetorical pedagogy that foregrounds marginalized perspectives and seeks to impress upon students the social justice implications of their future work, our course readings provided students with examples of how technical and professional

\footnotetext{
${ }^{93}$ Alongside these pieces, we read articles on the discriminatory effects of technologies and writing that fail to account for or adequately represent diverse users: For instance, facial recognition algorithms that fail to recognize darker skin tones or textbooks that promote stereotypes based on gender, race, disability and sexuality (Singer; Taylor; Varathan).
} 
discourse has disproportionate material impacts on already marginalized users. These readings reinforced for students that documents and discourses are never neutral and thus technical and professional communicators have a responsibility and opportunity to shape their work in a way that contributes to social justice. A central avenue for pursuing this goal is through the creation of usable, culturally responsive designs. Informing students' understanding of usability, our readings blurred the lines between expert and nonexpert, complicated notions of users as universal or homogenous, and highlighted the import of our work seeking out and attending to user needs.

\section{Course Projects}

Informed by the values of an intersectional feminist rhetorical pedagogy, and building from our readings, course projects provided students the opportunity to research and apply elements of technical and professional practice that enhance users' experience and participation, and to reflect on these moves as an essential aspect of ethical, socially just technical and professional writing and communication practice. In this section, I highlight two projects, the Technology Autobiography and the Technical Instructions and Usability Testing, and two ongoing aspects of our course work, team contracts and assessment practices. Each of these centered on usability and responsiveness to diverse user needs as integral to effective technical and professional practice and to furthering issues of social justice.

Technology Autobiography: I assign a technology literacy narrative autobiography project directed toward meeting the learning goals of complicating hegemonic notions of technologies and technological literacies (as first introduced through Haas's article). Technofeminists have long touted the importance of technology literacy narratives in courses 
that require the use of technology as a way of assessing and reflecting on personal lived experiences as a means of interrogating privilege and intersectional identities in relation to technological access, expertise, accumulated literacies, etc. (Blair; Hawisher, Selfe, Moraski, and Pearson). I build upon this feminist rhetorical tradition by providing an opportunity for students' experiences to serve as a foundation for broader discussions of complex user identities. The autobiographies and interviews that shaped this project uncovered first hand, contextualized examples of the ways in which users' knowledges, needs, and purposes for engaging with technological artifacts and discourses are essential to how issues of usability are measured and the ways in which reductive generalizations can result in stereotypes rather than improved practice. Thus, the project addressed many of the central goals of our course as it prompted students to consider how users' contexts, cultures, and needs must inform how we design, test, and revise technical artifacts and communications.

This Technology Autobiography project is modeled after the Technology Autobiography projects described by Karla Kitalong, Tracy Bridgeford, Michael Moore and Dickie in Teaching Writing with Computers. The authors explain how "[w]riting technology autobiographies encourages [students] to reflect upon their own (and sometimes other people's) experiences with technology, which leads them to think critically about technology. In the process, the invisibles become visible, the implicit can be made explicit" (219). The project also draws on Natasha Jones' valuation of narrative as a technical communication tool that "not only allow other voices and points of view to be heard and understood, but it pushes the researcher and scholar to examine his or her own positionality and enactment of power and agency in a reflexive manner" (“Technical Communicator as Advocate" 351). The Technology Autobiography includes: a technology autobiography, the form of which should reflect the story (for instance, a graphic 
short story, printed essay, resume, digital story, video, poster, audio recording, newspaper article); an intergenerational interview; and a summative memo. Collectively, these components invited students to examine their relationship to technology alongside different user experiences and to consider how cultural, historical, embodied positionalities influence our perceptions of and relationships with technology. The intergenerational interviews in particular, prompted students to complicate the profiles that they had relied on to describe users at the beginning of the semester: categories such as old versus young, Western versus non-Western, technical versus non-technical, or male versus female practitioners and users.

Interviewing a family member, friend, and/or colleague at least ten years their junior or senior, students recognized that "even seemingly mundane lives have almost inevitably been enriched, complicated, or irrevocably changed by technology[- $]$ an insight that broaden[ed] their definition of technology" and complicated the effectiveness of categorizing users into singular domains (Kitalong, et al. 226). For instance, interviews with users from previous generations prompted students to recognize that "old people" aren't necessarily lacking in technical and professional skills, but rather have had their needs and desires ignored by a rapidly changing industry. Similarly, interviews with younger siblings, and reflections on their own technology use, often uncovered experiences with addiction or bullying that generated critical examinations of the personal and social ramifications of technology, and the responsibility of the tech industry — and those employed by it— to incorporate these concerns into their testing of products. Thus, the project highlighted that cultural-historical context and embodied needs are essential to any understanding of usability, and that incorporating diverse users (even within identified categories such as "senior citizens" or "Generation Xers") is pivotal to more fully understanding the usability of an artifact or discourse. 
Finally, I made apparent to students that one of my motives for this project was my desire to learn about and from them both individually and collectively so that I could make our classroom space, projects, and work more usable for them. In this way, the project also modeled the course goal to disrupt notions of expert/non-expert positionalities in order to learn from, and respond to, the knowledges and needs of users. Alongside this aspect of the project, I frequently shared portions of my own intergenerational interview as well as Kristen Arola's Technology Autobiography in which normative assumptions about who holds relevant knowledge and expertise is challenged (Gilson, "Grandma's Letters"; Arola). These pieces reinforced the proposition that users' differential knowledges and experiences hold potential rather than pose a burden, and situated both me and students as teacher/experts and learners.

Students generally emerged from the project with specific, often personal, examples for why simplistic, checklist approaches for categorizing users can be easy but also reductive. In response to the summative memo question: "What did you take away from this project that will be useful to you in your future career?," students frequently explained that the project made them aware of how easy it is to pigeonhole, or simply ignore, certain users and their reasons for engaging (or not engaging) with a technical or professional artifact. Equipped with this recognition, we returned to our textbook's checklists for "Identifying the Audience's Cultural Background," "Anticipating your Audience's Preferences," and "User Profiles" to consider the affordances and constraints of efficiency-focused checklist approaches to understanding users. Students were quick with examples from their projects that illustrated how these standardized lists fail to account for intersecting user identities, experiences, and knowledges. Through this project, students' initial fealty to concepts of objectivity, neutrality, and standardization became less concrete as they recognized that what is most immediately efficient (for instance, a checklist 
or generic user-profile), can ultimately have reductive and potentially damaging impacts on users and their own professional and technical acumen.

Technical Instructions and Usability Testing: A central goal of the Technical Instructions and Usability Testing Project was for students to gain experience designing technical and professional documents that account for and are responsive to user needs. ${ }^{94}$ An essential aspect of the project was usability testing that made apparent the importance of diverse user feedback to effective designs that address complex and unique user needs. The basic outline of the project was for groups to compose technical instructions for a non-technical audience, design and conduct usability testing, and revise instructions based on user feedback. Throughout the project, our readings and classwork considered how something as mundane as instructions can foster social justice goals via inclusion of audio or visual that make the instructions accessible to a wider audience, images and language that reflect the diversity users, and/or the incorporation of materials that minimize environmental impacts. We discussed how defining terms, breaking up steps, and including alternatives for materials or processes can make instructions more inclusive of and usable for a wider and more diverse audience.

To begin their projects, student groups decided on a topic and target audience for their technical instructions. ${ }^{95}$ In addition to learning how to compose and design technical instructions

\footnotetext{
${ }^{94}$ Thank you to Elise Verzosa Hurley and Angela Haas whose Instructables projects form the foundation for my own.

${ }^{95}$ With the exception of one semester, students were asked to complete work within the Instructables website. Although there are constraints to this, it allowed students to immediately begin researching potential audiences and possible delivery methods possible within a specific website. While asking students to research and choose a website definitely had advantages, limiting all students to the same website allowed us to talk in-depth about the affordances and constraints of Instructables and increased the potential for students to work collaboratively across groups to make projects more accessible and usable for diverse audiences.
} 
for a non-technical audience, central goals of this project were for students to recognize user experience as unique, contextual, and intersectional; to design and revise artifacts that are responsive to user feedback; and to gain experience with collaborative work (a goal discussed more fully in the "Team Contracts" section of this chapter). Most projects emerged from interests and concerns that students held based on communities and experiences of which they were a part, and a need or opportunity that they recognized and/or had experienced within these communities. For instance, one group's instructions emerged from a desire to repurpose the growing collection of plastic bottles that they encountered in their dorms: Using recycled plastic bottles, their instructions outlined an easy, inexpensive craft for kids to give to parents or teachers as a gift at the holidays. Another group, prompted by two members' experiences working at dog shelters, created instructions for building a "dog puzzle" from PVC pipe that is designed to reduce the number of dogs "returned" because of having caused damage during hours spent at home alone. One group that struggled to decide on instructions found inspiration from their unrelated conversation about the necessity and cost of maintaining their laptops. A member who had recently damaged a computer in transport was working extra hours in order to save money for a new one. Based on this experience, the group decided on instructions for laptop covers constructed from old bath towels as an affordable way for cash-strapped college students to extend the life of their computers.

Although required testing was limited to in-class peers and feedback from the Instructables community, our readings aimed to extend students' understanding of usability concerns beyond their target audiences. ${ }^{96}$ For instance, as students read articles centered on how

\footnotetext{
${ }^{96}$ I recognize this as a limitation and hope in the future to collaborate with other instructors and or to expand the number and diversity of users providing feedback.
} 
visually impaired users are participating in and improving Twitter $^{97}$, they considered how users outside of an organization's target audience can engage with and grow the potential of technology and discourse beyond its original boundaries. Students reading responses to these articles often described their ignorance of the existence of visually impaired and blind users on Twitter-writing something along the lines of "[i]t never occurred to me that blind people could use Twitter." Beginning with their responses, we deliberated the opportunity and obligation of organizations such as Twitter, and technical and professional communicators more broadly, to proactively expand notions of "normal" users and uses of their technologies. Likewise, the articles and posts from the visually-impaired and blind Twitter users (rather than the "experts" reporting on this shift) focused our attention not just on Twitter's obligation to devise and implement solutions, but on the necessity for users to be an integral part of these redesigns. In this way, we talked not about the role of technical and professional communicator to "help" blind or visually impaired users, but rather the need for the field to transform such that it recognizes the potential for these users to participate in and improve Twitter (Brewer, Selfe, and Yergeau 153-54).

Guided by intersectional feminist rhetorical values, these discussions of usability also examine how multiply marginalized user feedback and participation are essential to inclusive design. Acknowledging how simplistic notions of diversity fail to attend to intersectional users' realities, we examine how, in order for Twitter to be more accessible and inclusive for all visually impaired users, designers must recognize and learn from a range of users who identify as visually impaired. Stressing that users who share a certain identity marker cannot be

\footnotetext{
${ }^{97}$ For example, @Todd; Ellis; Garfield; Sulleyman among others.
} 
homogenized into a monolithic group with standardized needs, students discuss how users who are visually impaired may also experience additional layers of marginalization within, or access to, the Twitter community based on their race, nationality, gender, or socioeconomic status among other factors. These discussions are incorporated into how groups moved forward to improve their Instructables and are foundational for class discussion and analysis related to the limitations of our own in-class user testing.

The next aspect of this project—usability testing — explicitly aimed to develop and foster attentiveness to diverse user needs and “non-expert” feedback. Informed by Huatong Sun's description of integrating action and meaning into cross-cultural design, the usability testing was intentionally designed so that " $[\mathrm{u}]$ sers play a vital role in bringing something to the experience and in co-constructing the experience" (82). Preliminary surveys, interviews, and questionnaires; observations during the testing; and post-test interviews were all tools that testing groups designed so that they could learn from their users. The collection of multiple, and first person, forms of user data proved essential as students' observation notes frequently attributed any usability shortcoming to user error. Notes reflected a tendency to blame users for confusion or inaccuracies - exhibited through descriptions of users not properly following the instructions, lacking experience or an investment in the outcome, or simply not being skilled enough to accurately complete the instructions. These reactions provided an ideal opportunity to reframe the responsibilities of, and relationship between, writers/designers and end users.

Post-test discussions with users and our dissemination of the usability testing as a class prompted a reframing: It shifted focus from user "failure" to potential weaknesses in the instructions writing, design, or presentation. Testing groups were frequently able to identify how an assumption that they had made about users' backgrounds, processes, or motives were 
informed by their own experiences rather than their actual knowledge of their users, and the possibility that these assumptions led to instructions that were simply not user-friendly for many users. The ability to pinpoint specific examples of what, how, when, why, and to what extent these normative assumptions played out during testing, better equipped students to articulate the benefits of a diverse team of designers and an equally diverse pool of users to provide feedback during testing.

In their summative memo, testing groups pointed to aspects of their instructions that they had previously understood to be objective, simple, and straightforward but that had fostered confusion, varied interpretations, and/or misunderstandings when taken up by outside users. They pointed to specific revisions incorporated to make the instructions more user-friendly and accessible to a wider audience. Recognizing that "[i]f meaning and cultural factors are not carefully studied and attended to in design, serious breakdowns will occur," students defined terms, more clearly listed and labelled materials, broke down steps into smaller more coherent groups, incorporated visuals and video, and integrated more extensive explanations and links to alternative approaches (Sun 51). Finally, based on their observation of users engaging with the instructions in ways that were not planned or anticipated, students frequently expanded their descriptions of the potential uses, audiences, and ways to personalize their projects. Ultimately, students embraced the benefits of user testing, almost always noting how much better the testing made their instructions and recognizing how limited the project remained without further testing a more diverse pool of potential users.

For many students, this was their first—and sometimes only—exposure to usability testing. And though our formal usability testing was limited to in-class peers-a limitation we openly examined in class - it highlighted user feedback as essential to basic usability and a rich 
resource for expanding the potential uses of an artifact. Students were often similar in age and major, but they each came with unique cultural and historical situatedness that informed how they engaged with, processed and took up information during testing. Usability testing, then, got students thinking at a very foundational level about how technical expertise and cultural context influences the ways in which designers craft, and users engage with, technical and professional artifacts.

Finally, students were often anxious to share "if only" scenarios when providing feedback on how I might improve the project for future classes - scenarios that called for increased usability testing, more and increasingly diverse users, and additional opportunities for feedback and revision. This feedback suggests to me that students' understanding of usability and the designer/user relationship shifted from one of functional empowerment ${ }^{98}$ toward a more user-friendly, responsive approach that foregrounds diverse user needs. Although certainly on a micro-scale, the gaps between expectations and experience during our in-class testing made students cognizant of the ways in which usability is exponentially enhanced when designers proactively consider the unique needs of diverse users.

Team Contracts: Prior to each of our two collaborative projects, student groups were tasked with composing a team contract that outlined project goals, expectations for collaboration, individual responsibilities, and conflict resolution. We discussed models and theories about team contracts together as a class but project contracts were largely shaped by each group. Central to our course was work that addresses workplace culture and the power dynamics that inform not just what and how we create, but also how we exist and move within an organization. This work

\footnotetext{
${ }^{98}$ Clay Spinuzzi describes the goal of "functional empowerment" as one in which users carry out "tasks in a prescribed manner" (13).
} 
prompted students "to reflect on and critique the discourse that is produced in the workplace and the circumstances within which it is produced" (Blyer 290).${ }^{99}$ There is ample scholarship in feminist and disability rhetorics, technical and professional communication, and composition that point to the macro and micro aggressions enacted on bodies whose race, gender, sexuality, ablebodiedness, ethnicity, or language are deemed non-normative in their space of employment (Anzaldúa; Hill-Collins; hooks; Mohanty; Sandoval; among many others). Committed to a practice that embraces diversity, complexity, and understandings that challenge constructed norms, my goal was that students gained knowledge and skills to advocate for themselves and be allies to others. This knowledge includes recognizing the nuances of workplace culture so that students are able to push back against toxic coworkers and workplace cultures as well as recognize when their own and/or others' embodied realities might make it unsafe to do so. The goal of students developing team contracts was to invite discussions that would highlight the complexity of working with others and the care that is required so that all members, but particularly those marginalized by hegemonic constructs of what it means to be a professional, could fully contribute to, and benefit from, the skills and knowledges of all. Ultimately, the team contracts modelled how students can engage in work that furthers an environment that embraces embodied and bodily differences as an asset rather than a hurdle.

To introduce students to team contracts, they completed a three-part, full class-period, activity that prompted discussion about everything from meeting attendance and labor distribution to micro and macro aggressions within the group (see excerpts of the activity in

\footnotetext{
${ }^{99}$ Although beyond the scope of this chapter, an entire project - the Professional Portfolio-is centered on this goal. As part of their portfolio, students research the values and professional practices of a specific company and synthesize how the company's culture and norms complement or diverge from their own values, skills, and goals.
} 
Table 6, below). The expectation was not that this activity would prevent any or all of these from happening, but rather that students would become aware of their own tendencies to contribute to or passively support unproductive, inequitable distributions of power in the classroom or workplace, and thus would be better equipped with the terminology and skills to advocate for themselves and others in our class and their future professions.

Table 6

Excerpts of Preliminary Exercise for Team Contracts

Step 1: True or False: If you answer False, briefly write a note that will help you explain.

- I work outside of school, have family obligations, or have other commitments that can make group scheduling a challenge for me.

Step 2: Get together with your group and discuss:

- Everyone's answers to questions in Step 1. Where do various members ideas, practices, and plans for group work diverge? How might your individual experiences and situations inform how you work together as a team? How can your team contract best address the needs, wants and concerns of all members?

Step 3: As a group, discuss the following scenarios - all of which have occurred in my class. What could you, as an individual and as a team, do to anticipate, prevent, address, and/or work through these issues?

- Team Member B tends to interrupt or talk over other members of the group and has a habit of explaining other members' ideas to the group as though they need additional clarification in order to be valid. Member B isn't necessarily being intentionally rude or condescending, but these habits aren't helping the productivity or morale of the group.

This activity models intersectional feminist rhetorical values by prompting students to "attune [themselves] to the built-in and historical power relations that oppress individuals and social groups through structures that organize the world and the country" (Walton, Moore, and Jones 116). Instead, we discuss how hegemonic notions of power-who holds it and how it is deployed - are layered in ways to benefit some while providing numerous obstacles for others to 
have their persons, ideas, and contributions acknowledged and valued. As with much of our work, these conversations were sometimes uncomfortable. But the discomfort eventually gave way to earnest recognition of specific instances or general habits in students' own experiences or practices reminiscent of those described in the activity—instances in which they were the recipient of and/or source for devaluing the knowledges, experiences, or practices of a colleague or peer. Similarly—and integral to my intersectional feminist rhetorical pedagogy—this activity prompted discussion around what is accepted as "normal" in the workplace and who these norms privilege and disadvantage.

Assessment: An intersectional feminist rhetorical pedagogy acknowledges students as valuable contributors to the learning of the classroom and my assessment practices reflected this. For project portfolios, each student or student group composed a Summative Memo in which they were asked to "guide" me through how they would like me to engage with—and to a certain degree, assess - their project. Central to each of these memos, and as is demonstrated in Table 7, was the opportunity for students to articulate what and how they learned from their users, and to specifically point to the ways in which this feedback was (or was not) consciously incorporated as a means for improving their final projects. To guide these memos, students referenced the various project handouts that connected project components to our larger course goals. Table 7 provides excerpts from the handouts provided to students as part of their Technical Instructions and Usability Testing Project. As shown, the goals of the project, and thus my assessment of it, are informed by the values that underlie my intersectional feminist rhetorical pedagogy: 


\section{Table 7}

Integrating Intersectional Feminist Rhetorical Commitments into Assessment

\begin{tabular}{|c|c|}
\hline $\begin{array}{l}\text { Intersectional Feminist } \\
\text { Rhetorical Pedagogy }\end{array}$ & Assessment Language ${ }^{100}$ \\
\hline Foregrounds extraordinary users & $\begin{array}{l}\text { Summative Memo: Who is included? Who is excluded? } \\
\text { Consider how users' intersecting experiences of race, } \\
\text { socioeconomics, gender, ethnicity, ablebodiedness, or } \\
\text { technical literacies among other factors, might inform their } \\
\text { experience. Point to specific examples in which your group } \\
\text { employed language, audio or video, images, definitions } \\
\text { and/or other elements in your instructions to explicitly seek } \\
\text { to include diverse users. }\end{array}$ \\
\hline $\begin{array}{l}\text { Recognizes embodiment as } \\
\text { always intersectional }\end{array}$ & $\begin{array}{l}\text { Usability Test Plan and Report: What did you learn about } \\
\text { your users from the preliminary surveys, observations, and } \\
\text { post-testing interviews or questionnaires that helped you to } \\
\text { better understand the different ways that users might read or } \\
\text { understand your technical instructions? What more could } \\
\text { you have researched, asked about, considered in order to } \\
\text { better anticipate and/or respond to the users intersecting } \\
\text { experiences? }\end{array}$ \\
\hline $\begin{array}{l}\text { Values "non-expert" experience } \\
\text { and voice }\end{array}$ & $\begin{array}{l}\text { Summative Memo: Point to specific feedback you received } \\
\text { from users and from the Instructables community. How } \\
\text { were these recommendations incorporated in order to make } \\
\text { the instructions more user-friendly and effective? What } \\
\text { users and user-experiences are not being represented? How } \\
\text { can the Instructables be made more accessible to } \\
\text { marginalized users outside of those within your current } \\
\text { testing groups? }\end{array}$ \\
\hline $\begin{array}{l}\text { Provides space for diverse and } \\
\text { complex user needs to be } \\
\text { realized }\end{array}$ & $\begin{array}{l}\text { Usability Testing: How did users adapt your instructions to } \\
\text { their own experiences, knowledges, needs, and/or interests? } \\
\text { What did these adaptations, revisions, or add-ons teach you } \\
\text { about how your instructions could expand/change to be } \\
\text { more inclusive of diverse and complex users? }\end{array}$ \\
\hline
\end{tabular}

${ }^{100}$ As I describe in later in this chapter, I recognize the need to more explicitly incorporate the language, practices, and values of an intersectional feminist rhetorical methodology in my course documents. For example, future iterations of this project will include assessment language and practices that more directly prompt students to explicitly prioritize multiply-marginalized users as they design, test, and revise their Instructables. 
An intersectional feminist rhetorical pedagogy aims to integrate socially just practice into the very fabric of our coursework. In their projects, rhetorical analyses, reading responses, chapter facilitations, and in-class activities, students were constantly challenged to identify and problematize rhetorics of efficiency that impede user agency; reframe user-difference as an opportunity for expansion rather than an impediment to efficiency; and imagine and practice usability testing as an essential process for learning from and responding to user needs rather than an additional step for managing and norming user experience.

\section{Student Learning and Feminist Transparency}

As can happen when belief systems are challenged, the intersectional feminist rhetorical pedagogy outlined in this chapter was often met with initial, and sometimes sustained, resistance. ${ }^{101}$ Asking students to reconsider what they have embodied as valuable about their current work and future professions can be jarring and unwelcomed. For example, my assigning of Haas's article early in the semester was welcomed by some students but was also the source of confusion or frustration for others. Some students questioned my choice to assign a text from the journal Studies in American Indian Literature, or, as one student put it, "a text that is so obviously biased and opinionated" in a TPC course. Others expressed discomfort or anger at Haas's decolonial approach — alleging that it makes "white guys out to be bad guys." When asked to point to specific passages to support this claim, students are often frustrated by their inability to do so. And while certainly a challenge, these moments presented an opportunity to

${ }^{101}$ Haas's "Race, Rhetoric, and Technology" and Aja Martinez's forthcoming "Core-Coursing Counterstory" offer examples and extended analysis of student resistance to work outside the dominant narrative in the TPC and composition classroom and are foundational to my synthesizing of student reactions to my teaching and course content. 
discuss why it is that Haas's history is read as opinionated and biased while those she challenges are assumed to be factual and objective; to examine why challenges to the neutrality of Western histories makes some so uncomfortable; and to point to the ways in which avoiding these very conversations allows the status quo - one in which certain bodies, histories, and knowledges are privileged and others oppressed — to remain unchanged. By prompting students to explicitly point to the claims and passages that shape their reactions to Haas's article, this discussion provided the foundation for future interrogation into how our own intersectional identities inform the ways in which we read and respond to texts.

And while I did not shy away from challenging students, I was also cognizant of the teacher-student power dynamic. I wanted students to remain open to the possibility that they could learn something from me and the scholars whose work I assigned in the class, even if it was unfamiliar and felt uncomfortable at the start. In pursuit of this goal, and to enact feminist transparency, I shared examples in which my own ignorance of communities outside of my own (and a failure to recognize this gap) led me to make professional and technical mistakes in my work. In doing so, I strove to enact bell hooks's model of engaged pedagogy in which "professors take the first risk, linking confessional narratives to academic discussions so as to show how experience can illuminate and enhance our understanding of academic material" (Teaching 21). In particular, I shared my own experiences to illuminate the feminist values of process, listening, and collaboration—essential skills for technical and professional writers invested in usability as a practice enhanced by the ideas, feedback, and knowledge of "nonexpert" users.

My transparency and shared vulnerability often shifted students' experience of our work 
from one that prompted defensiveness to one that elicited reflection. ${ }^{102}$ The stories I shared not only complicated the expert/non-expert dichotomy but also complicated students previous reactions in which the discriminatory effects of technical and professional artifacts were summarily attributed to villainous designers. I sought to make evident that user-friendly work must be purposeful and requires early, ongoing, and often complex attention to users and their needs. Finally, as the experiences I often shared were shaped by my work outside of the formal technical and communication or academic profession, these narratives also illustrated for my predominantly non-majors students how often professionals in all fields are called upon to engage in technical and professional work that benefits from a user-centered approach.

One example I shared took place when I was working as an AmeriCorps VISTA charged with implementing a volunteer literacy program in a Madison, WI, elementary school. Confident in my knowledge of the community, I outlined an entire program—-from volunteer recruitment materials and scheduling templates to training packets and parent communications-without having ever spoken with the central users of these documents: students, parents, and community volunteers. Within the first week of the program, I realized that the area surrounding the elementary school was very different from the university community in which I had been living — inhabited by young working families and retirees rather than college students and professors. My initial recruitment materials, which highlighted the benefits to volunteers of acquiring job-building skills, completely missed the mark. Likewise, the students enrolled in the literacy program were not the "traditional" Midwestern kids that I had imagined. Instead, the

\footnotetext{
${ }^{102}$ It is important to note that my own embodiment and privilege allowed me to be vulnerable in ways that other instructors cannot without increased risk (a point that I will return to in the implications section of this chapter).
} 
students were predominately first-generation English-speaking children of Hmong immigrants, many with parents who did not speak or understand English and who had a history of oral versus written language. My failure to do my research, to consider the unique, embodied, intersecting needs of my users rendered most of my original documentation either useless or ineffective for my audiences. Rather than moving forward with documents and communicative practices that failed to reflect the experiences, needs, and values of my users, I recognized the need to start over. After talking to, researching, and learning from students, families, and volunteers, I changed the entire system for communication and documentation. For instance, rather than textual communications sent home to parents, I organized in-person meetings with students and families (the elementary-aged kids or siblings often serving as translator between me and/or their tutors and their parents); instead of recruitment posters promoting volunteerism as beneficial for resume building, I highlighted the program as one that provided opportunities for intergenerational and intercultural communication and a strengthened sense of community.

Empowered by my willingness to share my own mistakes and failures, students often reciprocated by relating their experiences navigating complex professional situations. In particular, many were anxious to talk about experiences in which they struggled to balance their sense of obligation to users and employers. For instance, a student who had interned within the environmental health and safety field described a situation in which he was charged with assessing worker compliance with OSHA mandates. While documenting the correct and regular use of respiratory masks designed to protect employees against toxic chemicals in the workplace, his obligation to accurately document employees' use of the masks was challenged by the actual users of the masks who pressured him to "cut them some slack" and not document lack of use. Employees described how the masks were hot, uncomfortable, and slowed down their work. 
These were the people with whom he spent the day and felt a sense of comradery; moreover, employees argued that it was their own health they were risking by not using the respirators, and thus compliance should be their choice. The student described his struggle as he weighed various options, ultimately deciding that he had an obligation to maintain accurate records, but a responsibility to advocate for workers by voicing concerns to his boss about the current respirators' usability.

Such discussions helped to narrow the gap that students perceived between social justice work and technical and professional communication, and between expert designers and nonexpert users. These discussions prompted students to "think critically not only about their own views of the world but to consider and value the views of others" (D. Martinez, 244), illustrated that technical and professional writing and communication have material impacts, and clearly situated the individuals designing and writing these communications as inseparable from the effects of these artifacts on users. Students grappled with the sometimes-conflicting obligations to employer, community, users, and self and the reality that their work may constantly present them with choices to either forward social justice or—by action or inaction—work against a more equitable society. My goal was not to determine or teach the right choices for students, but rather to make them aware that it was indeed a choice, and to equip them with the necessary skills, theoretical groundings, and tools so that they are better able to make informed decisions that they will be comfortable living with.

Students' reactions to the readings and individual projects cited in the previous section, as well as our work with Team Contracts, suggest that the intersectional feminist rhetorical approach to our course resonated with many students and impacted their sense of how seemingly neutral, or at least widely accepted, practices can disproportionately impact certain bodies and 
undermine certain ways of knowing and being. As an example, when our class talked about assumptions regarding group work, one of the most often cited norms was that female students tend to offer, or be volunteered, to take notes during group meetings and projects. Although quick to agree that this isn't fair, many students had never thought much about the material effects of this normed practice. So, I'd challenge them to think rhetorically: Who is this practice most usable and efficient for? When someone is taking notes, how does that influence their ability to listen for content and contribute their own ideas to the group? Over time, what are the professional, financial, and intellectual consequences when one group assumes responsibility for note taking while others are freed up to listen closely and contribute without distraction? Building on these discussions, we examined how certain practices come to be thought of as normal, who these norms privilege, and who they burden. For some students, these discussions provided a space to share the financial, work, or family obligations that presented them with challenges but which they rarely shared with peers for fear of sounding like they were "making excuses." These "confessional narratives...illuminate[d] and enhance[d] our understanding" of coursework and empowered students to further analyze how embodied realities outside the purview of colleagues nonetheless impact individual experiences of academia and the workplace (hooks 21). Equipped with these understandings—-small insights into the intersectional identities of their partners, and the potential material consequences of seemingly benign practicesstudents entered into their work and contracts with an increasing attentiveness to unique, complex experiences, knowledges, and interactions.

Despite years of academic group work being assigned under the rationale that it would be required of them in their future professions (a rationale which I also include in my explanation to students), few students had experience learning about or imagining how group work, or 
workplace dynamics in general, can or should function. Even fewer had experience in a college course that asked them to imagine or practice how they might actively advocate for themselves and others when working in groups. A senior student responded to my request for feedback on the activity by explaining how it was the first time she had ever been asked to think about group work as a process that required preliminary planning and ongoing maintenance. As someone who had "hated" group assignments, she felt like the exercise helped her improve on her own practice as well as to demand better of others with whom she worked in school and her job.

\section{Case Study Limitations}

Although pleased with the course outline and student learning described in this chapter, I am aware of a number of limitations to this case study which I will now briefly describe. ${ }^{103}$ To begin, I did not obtain an IRB for my 249 courses and thus was not able to incorporate verbatim excerpts from student writing and projects or quotes from in-class discussions. Thus the failures and successes of this pedagogy are inescapably filtered through my voice and perspective. Another related limitation is that I have not followed students beyond our course together to gauge how, or if, the work of our class informed their willingness or capacity to engage in socially just practices in their professional practice.

I am grateful to have had the opportunity to teach Introduction to Technical and Professional Writing for the past five semesters at ISU and believe that this experience was integral to my development and articulation of an intersectional feminist rhetorical pedagogy. And though this pedagogy began taking shape long before I had a name by which to call it, and

\footnotetext{
${ }^{103}$ I want to acknowledge, but will not repeat, the individual project limitations that I describe in the earlier sections on course projects.
} 
the values and goals of an intersectional feminist rhetorical pedagogy have been central to my teaching for years, I have yet to announce my approach as an "intersectional feminist rhetorical pedagogy" to my students. A potential advantage is that students come to identify technical and professional writing as writing that is attentive to and engaging of diverse audiences, challenges normative frameworks, aims to address the needs of all users, and works toward the goals of social justice. A drawback is that students are left unaware of how my pedagogical approach is informed by, and furthers, feminist values. As Erin Frost makes evident in her "Apparent Feminism as a Methodology for Technical Communication and Rhetoric," there are significant benefits to students and the field when feminist practitioners make their feminist values known.

Finally, I recognize that the greatest limitation of this case study is that I was still developing and thinking through my intersectional feminist rhetorical methodology as I was teaching the courses described in this chapter. Thus, while my pedagogical practice was shaped by intersectional feminist rhetorical values, I recognize that these values and their purposes were not always fully, or effectively, integrated into the work of our class. In particular, explicitly citing and describing intersectionality and feminism, and how these come together to shape an understanding of, and method for, usability is something that I will more carefully map out for future courses. An intersectional feminist rhetorical framework was integral to our work, but the work of this chapter and project has made apparent how I can more explicitly engage in pedagogical practices that better model these values.

\section{Case Study Implications}

This particular case study is just one example of how an intersectional feminist rhetorical pedagogy in the technical and professional communication classroom prompted students to 
consider the disparate material impacts that certain efficiencies have on bodies-privileging certain ways of being while demanding compliance of others - and the small but concrete actions that they could engage in to disrupt systems that forward such disparity. This is just one possible example of how an intersectional feminist rhetorical pedagogy might be incorporated into the technical and professional communication classroom. Others desiring to engage an intersectional feminist rhetorical pedagogy into their own course may wish to develop new approaches, projects, readings, and outcomes. Similarly, others may use the underlying values of this pedagogy for majors-only, usability-focused, or service-learning courses rather than an introductory, general education course as outlined here. In either model, an intersectional feminist rhetorical pedagogy provides a path for students to examine their role as future professionals and their potential to either consciously contribute to, or passively or actively work against, an increasingly just workplace and society.

Similarly, the students that fill our rosters each semester impact the ways in which we shape and present materials as well as how those materials are received and taken up. As Julie Bates notes in her description of implementing an interventionary rhetoric in the classroom: “What teachers' and students' knowledges are and how they relate to key information and concepts depends on many factors, including their identities, locations, educational backgrounds, and personal goals" (136). Similarly, Elise Verzosa Hurley foregrounds how "space, place, location, [and] embodiment” all impact our pedagogical practice and Angela M. Haas's description of enacting a decolonial pedagogy illustrates the give-and-take instructors must undergo in order to both live their values and meet institutional demands (95; Haas, "Race"). These scholars make evident that social justice pedagogy is not static but rather constantly in- 
flux, responding to and adjusting for the space, place, and time in which it is occurring and the bodies with which it is engaging.

\section{Moving Forward with an Intersectional Feminist Rhetorical Pedagogy}

The advantage of teaching usability through an intersectional feminist rhetorical lens is that it consistently and explicitly centers attention on the ways in which increasing attentiveness and responsiveness to diverse user needs and knowledges can improve our professional practice and work in service of social justice imperatives. This case study highlighted how enacting this pedagogy in an introductory level, non-majors course prompted students to examine their role as future professionals and their potential to contribute to an increasingly just workplace and society.

An intersectional feminist rhetorical pedagogy could provide the foundation for many technical and professional communication courses that have an underlying commitment to students' shifting understanding of usability away from a narrow focus on efficiency and conformity and toward more socially just measures that reflect and respond to diverse users and their needs. This pedagogy might also inform readings, courses, and/or projects outside of the technical and professional communication field. For instance, while teaching a general education, writing-intensive, Interdisciplinary Studies Course, I assigned students to compose multimodal projects aimed at furthering issues of social justice within a community of which they were a part, and/or had connections. ${ }^{104}$ Students engaged with, and learned from,

${ }^{104}$ I recognize that there are limitations to this approach, but given the time constraints of the project, I believe it allowed us to achieve the goals of the project and safeguarded against imposing on outside organizations. 
community members via research and interviews; garnered feedback on the proposed projects; conducted informal usability testing on their deliverables; and worked collaboratively in order to meet individual and collective goals. Samples of projects included a Twitter campaign to increase awareness of, and support for, victims of sexual assault; an informative letter-writing campaign to bring professors' attention to alternative, cost-saving options to print textbooks; and a Facebook group designed to pair incoming nursing students with upper-division nursing students in order to create connections for carpools to off-campus medical facilities, buy and sell textbooks, and grow the sense of community and support amongst nursing majors.

Bringing an intersectional feminist rhetorical pedagogy into the classroom can help frame courses aimed at challenging exclusionary rhetorics of efficiency. By presenting this critique through the lens of usability, students are encouraged to learn from, and propel, the agentive power of diverse, intersectional users and recognize how rhetorics of efficiency can marginalize certain groups by failing to recognize or attend to their unique, intersectional, and embodied realities. By foregrounding rhetorical practices that are responsive to user needs, students gain skills necessary to recognize embodiment as always intersectional, value "non-expert" experience and voice, and embrace diversity and complexity. 


\section{CHAPTER VI: IMPLICATIONS AND FUTURE INTERSECTIONAL FEMINIST}

\section{RHETORICAL PROJECTS}

The injustices of our country are systemic and deeply engrained. Public policies that allow for or result in societal inequities, but are promoted under the guise of being good for all, are pivotal to establishing, maintaining and expanding these injustices and are of urgent concern. ${ }^{105}$ The intersectional feminist rhetorical methodology presented and enacted throughout this dissertation calls on practitioners to identify and challenge the rhetorics of efficiency that shape and support these discriminatory policies, and to engage with and learn from multiply marginalized users in order to push for public policies and practices that better reflect underrepresented user needs and experiences. In this final chapter, I outline implications of this work for scholarship and pedagogical practices within and beyond the discipline of TPC, as well as its potential uses outside of academia. To begin, I reiterate the exigency for TPC frameworks that focus attention on multiply marginalized individuals and communities and the significance of usability in furthering issues of social justice. Next, I discuss how intersectional feminist rhetorical practices might allow those in the fields of TPC, rhetoric, and composition to influence public policy matters through engagement with policy writers, users, students, and the broader public. I conclude by proposing how I plan to extend this intersectional feminist rhetorical approach to usability in, and beyond, my own TPC scholarship and classroom practices.

As discussed in Chapter I, a central exigence of this project is the continued need for intersectional scholarship in technical and professional communication that foregrounds the

\footnotetext{
${ }^{105}$ A glaring example at the time of this writing is the numerous policies that are being proposed under the premise that they will "Make America Great Again," even as they encourage and directly enact violence on the bodies of people of color, women, the LGBTQ community, immigrants, Muslims, and numerous other vulnerable populations.
} 
experiences, oppressions, and knowledges of multiply marginalized individuals and communities (Haas and Medina, "Intersectionality) and that highlights the material effects of unproblematized rhetorics and notions of efficiency on vulnerable populations (Frost, "Apparent Feminism as a Methodology"). Reading public policy through an intersectional feminist rhetorical lens can encourage scholars to consistently and continuously gauge the effectiveness of a public policy in terms of its usability for "extraordinary" individuals and communities - users whose bodies and/or embodiments defy or refuse to comply with hegemonic norms. Despite increasing scholarship and pedagogical practices in TPC, rhetoric, and composition that trace how power moves through language, texts, and technical and professional discourses to privilege and oppress - and as many of the social justice minded TPC scholars cited in this project stress (Savage; Haas and Eble; Bates; Jones and Walton; among others) — there is much more work to be done.

Case studies such as those presented in this project are one way in which TPC, rhetoric, and composition teacher-scholars can identify the shortcomings of current public policies, research and learn from multiply marginalized users, and use this knowledge to push for policies that are more usable for and respectful of underrepresented and complex users and their experiences. At a time when the U.S. administration lauds its reputation for overtly nationalistic, insular, and exclusionary public policies, it can be easy for those who occupy multiply privileged positions to focus only on those public policies that garner the most media attention or that directly impact our own lived experiences: We turn our attention away from the more subtle public policies that, while less belligerent or sensational in their language and promotion, can prompt or exacerbate the unjust treatment of already vulnerable users. In a similar way, the promotion of public policies that $d o$ benefit large sectors of the population too often fail to 
recognize how a single solution can neglect to address the realities of multiply marginalized groups. ${ }^{106}$ Thus, additional case studies that examine the impact of everyday public policy on vulnerable and multiply marginalized communities can highlight for the field and our students, as well as for larger publics, the disproportionate material effects of seemingly benign public policies on users and the importance of seeking out, and listening to, the experiences of users in order that policies better respond to their lived realities.

The work of this project might also be extended to engage the policy makers, politicians, and administrators charged with designing, documenting, and enacting public policies. Research that interrogates how public policies may certainly or potentially impact vulnerable, multiply marginalized communities can be included in reports designed for those in positions to directly influence and shape public policy. Rebecca Dingo, who at the 2017 Feminisms and Rhetorics conference described how her scholarly research was brought to bear in a United Kingdom Parliament International Development Committee report, provides a model for doing public policy research work. Charged with revising and updating disability and development policies in the UK, the committee requested Dingo's advice on how they might best revise their current programs (Dingo, UK). ${ }^{107}$ Dingo's report—-framed through disability studies and transnational feminist frameworks of mainstreaming — informed her recommendation that the group shift

\footnotetext{
${ }^{106}$ For instance, many politicians' proposed solution to the ongoing healthcare crisis is the promise of free or affordable healthcare for all. Yet this solution fails to address issues of healthcare access for many rural, predominately white, poor people in the U.S. (Warshaw). When the closest doctor and hospital are hundreds of miles away, there are insurmountable hurdles to simply accessing care for those without transportation, flexible work hours, and/or childcare, just getting to a medical facility might well supersede concerns of how an eventual medical bill will be paid.

${ }^{107}$ I am grateful to Rebecca Dingo for this presentation and for sharing her report with me in a follow-up email.
} 
programs away from "[m]ainstreaming and inclusion policies [that] emphasize that a PWD must fit into the mainstream" and instead (among other recommendations) acknowledge and address "the social, geopolitical, and economic reasons that PWD are unable to participate fully in the mainstream" (Dingo, "UK"). Scholars invested in intersectional feminist rhetorical approaches to public policy could likewise use this framework and accompanying case studies (such as those presented in Chapters III and IV of this project) as the foundation for formal reports or recommendations written for public policy makers, politicians, or institutional administrators.

But appealing to policy makers is not the only path toward changing unjust policies. The tenets of an intersectional feminist rhetorical methodology call on practitioners to foreground marginalized users, and this commitment extends to who we engage as agents of change. As Jeff Grabill argues, fundamental change requires a disruption of the current system that sponsors topdown approaches to creating and circulating public policy. Thus, it is not enough to work within the current system - appealing to, and making our research accessible for, only those in power. Grabill notes that "our greatest influence will be at the bottom: at local institutions in our communities and with others to whose well being we are committed" (48). Intersectional feminist rhetorical work recognizes that many "at the bottom" are already engaged in the hard work of making apparent and fighting against oppressive policies. As scholars versed in rhetoric, composition, and technical and professional communication, we need to build lasting, and coalitional alliances with community intellectuals and activists so that our field can learn from and amplify the work of those already drawing attention to the ways in which public policies fail to recognize or work for multiply marginalized users, and thereby contribute our expertise to furthering social justice causes. 
Another significant way for rhetoric, composition, and TPC scholars to enact intersectional feminist rhetorical values is to share our case studies and scholarship outside of academia, and in forms that are accessible for, and consumed by, the larger publics. ${ }^{108}$ Tracing the history, context, and rhetorical force of seemingly benign policy language requires extensive research and time; thus, disseminating intersectional feminist rhetorical analyses of public policies so that they are accessible to those outside of our field can be pivotal to garnering public support for more socially just public policy. Making the disparate effects of public policies apparent to a general audience is crucial, as policies are often prompted by or approved through public referendums and/or are reliant on public support for their continuation. Just a few possibilities for scholars interested in this type of work might include composing editorials for mainstream publications, interviewing for a podcast, or writing and posting in social media spaces. In each instance, public presentation of our scholarship increases the probability others will weigh in on the issue - even those who may not identify as users of a particular public policy (and are thus unlikely to seek out or invest time in researching the issues) - will be more likely to work to hold those in charge accountable.

Foregrounding the overlapping hurdles faced by multiply marginalized users, and the necessity that these realities be reflected in effective discourses and documents, an intersectional feminist rhetorical approach to usability can be incorporated in numerous ways in the TPC classroom. As has been noted by scholars in TPC, usability is an increasingly prevalent component of TPC coursework and a desired skill in the public and private sector (Chong;

${ }^{108}$ Co-presenting with Rebecca Dingo during the 2017 Feminisms and Rhetorics Conference, Jen Wingard's presentation "Writing for the Media: Translating Academic Research for the Popular Press" reinforced and extended my understanding of this import practice. 
Meloncon and Henschel). How future practitioners approach usability — the users they do or do not imagine, the goals they set, and their transparency with their findings—will have significant impacts on the ways in which our society engages in everything from business and education to policing and socialization via digital technologies. Teacher scholars can intentionally, systemically, and thoughtfully teach our students to understand and work with users in increasingly complex and respectful ways. We can model intersectional feminist rhetorical practice through our scholarship — explicitly seeking out and citing marginalized perspectives. Usability is a specialized course of study in its own right, teachers of introductory technical and professional communication courses - as well as rhetoric and composition courses-have an opportunity to introduce a larger segment of the student population to the social justice imperative to foregrounding complex, diverse users and their experiences.

Teacher scholars invested in social justice have an opportunity to seek out, listen to, learn from, and project the voices of individuals and groups who are calling attention to the negative impacts of specific public policies on the bodies and experiences of marginalized individuals and communities. Engaging in and expanding on such work is arguably the most pivotal way in which I hope to move forward with this project. The goal of learning from and propelling the agentive power of those whose embodied realities places them outside of the normative usergroup imagined by, and constructed through, a specific policy is an intersectional feminist rhetorical commitment that I am particularly invested in extending as I move forward with this project. The work of organizations such as Fed is Best or Fair Fight Action is crucial to highlighting the existence and embodied realities of those users ignored or oppressed by reductive public policies, yet many of the most multiply marginalized users may lack the necessary tools, knowledges, and/or access to engage with these organizations. Thus, I am 
particularly interested methods to reach those users whose experiences are still not being acknowledged by outside groups, nor reflected in public policy_to learn from and talk with users in the communities in which they reside. I would like to interview caretakers about their experiences with Baby Friendly hospitals or speak in-person with individuals who are deterred from or unable to access either the voting station or organizations such as Abram's Fair Fight Action. In this way, I hope to extend this project so that it can more fully account for the myriad embodied experiences of users.

Dawn Opel and Donnie Sackey's recent presentation on their project "Improving DataDriven Approaches to Michigan Food Security and Nutritional Health and Well-Being" might serve as a logistical model to continue my work. A central aspect of Opel and Sackey's research methods is interviews with Michigan foodbanks users that they transcribed into "data" that more accurately represents the localized numbers, needs, and struggles of users and thus provides a fuller (but still accessible) picture for those charged with allocating funds and outlining policy mandates. Opel and Sackey spoke of building coalitions with private, university, and government organizations and obtaining grants to facilitate the labor-intensive work of in-person, on-site interviews and the costly process of data analysis and information design. This type of front-end labor (researching and applying for grants, constructing and coding data collection systems, building relationships and trust with local organizations) will be an essential first step as I seek to engage users within their own spaces and communities.

Finally, on a somewhat more personal level, I would like to make the technical, professional, and rhetorical scholarship of this project of immediate use to the community in which I will eventually reside. As a former resident of the Uptown, Chicago neighborhood, I worked with an organization that provided job training and placement for residents battling 
homelessness, poverty, substance abuse, and the stigmas of criminal records. At the time, I used my culinary background to provide training for participants who, upon completion of the program, were hired by Chicago partner-restaurants as cooks. Although I served an important role in the kitchen, the greatest need was for individuals who could conduct one-on-one resume workshops, mock interviews, and job-skills training and dedicate time to talk through the unique, intersecting barriers that each program participant was facing. The work of this dissertation has positioned me to be of use in such a capacity. Moving forward, I hope to again be a part of such an organization and to put my intersectional feminist rhetorical values into action at the local level.

I recognize that the proposed implications and extensions of this project are informed by my own positionality, experiences, and spaces in which I reside, and are thus both contextual and incomplete. I hope that other technical and professional communication teacher scholars, as well as researchers and teachers outside of our discipline, will take-up and extend this work in a way that responds to the contexts and needs of their own communities. There are many ways in which this project might continue, and I look forward to learning from those within and outside of academia as they contribute to, create, and/or expand on actionable ways forward. 


\section{WORKS CITED}

@Todd. “Accessible Images for Everyone.” Twitter, Blog. 29 March 2016, www.blog.twitter.com/official/en_us/a/2016/accessible-images-for-everyone.html.

“About Us.” Baby-Friendly USA, www.babyfriendlyusa.org/about-us

Abrams, Stacey. "Non-Concession Speech: Acknowledgement that Kemp will be Governor." Press Conference, 16 Nov. 2018, Atlanta, GA. Speech.

---. "Full Speech: Stacey Abrams Ends Candidacy For Georgia Governor, NBC News." YouTube, uploaded by NBC news, 16 Nov. 2018, www.youtube.com/watch?v=G1YXTP7u8Ds

Ackerman, John M. "Rhetorical Engagement in the Cultural Economies of Cities." The Public Work of Rhetoric: Citizen-Scholars and Civic Engagement, edited by John M. Ackerman and David J. Coogan. The U of South Carolina P, 2010, pp. 76-97.

Ackerman, John M. and David J. Coogan, editors. The Public Work of Rhetoric: CitizenScholars and Civic Engagement. The U of South Carolina P, 2010.

Addison, Joanne. "Researching Literacy as a Lived Experience." Rhetorica in Motion: Feminist Rhetorical Methods and Methodologies, edited by Eileen E. Schell and K.J. Rawson, U of Pittsburgh P, 2010, pp. 136-51.

Agboka, Godwin. “Indigenous Contexts, New Questions: Integrating Human Rights Perspectives in Technical Communication." Key Theoretical Framework: Teaching Technical Communication in the Twenty-First Century, edited by Angela M. Haas and Michelle F. Eble, Utah State UP, 2018, pp. 114-37. 
---. "Participatory Localization: A Social Justice Approach to Navigating

Unenfranchised/Disenfranchised Cultural Sites," Technical Communication Quarterly, vol. 22 , no. 1,2013 , pp. $28-49$.

Agboka, Godwin Y., and Natalia Matveeva, editors. Citizenship and Advocacy in Technical Communication: Scholarly and Pedagogical Perspectives. Routledge, 2018.

Ahmed, Sara. Willful Subjects. Duke UP, 2014.

Alcoff, Linda. "The Problem of Speaking for Others." Just Methods: An Interdisciplinary Feminist Reader, edited by Alison M. Jaggar, Paradigm Publishers, 2008, pp. 484-95.

Almjeld, Jen and Kristine Blair. "Multimodal Methods for Multimodal Literacies: Establishing a Technofeminist Research Identity." Composing(Media) = Composing(Embodiment): Bodies, Technologies, Writing, the Teaching of Writing, edited by Kristin L. Arola and Anne Frances Wysocki, Utah State UP, 2012, pp. 97-109.

Anderson, Carol. "Brian Kemp's Lead in Georgia Needs an Asterisk." The Atlantic, 7 Nov. 2018, www.theatlantic.com/ideas/archive/2018/11/georgia-governor-kempabrams/575095.

Ang, Desmond. "Do 40-Year-Old Facts Still Matter?: Long-Run Effects of Federal Oversight under the Voting Rights Act.” The CATO Institute, Research Briefs in Economic Policy, no. 146, 16 Jan. 2019, www.cato.org/publications/research-briefs-economic-policy/do40-year-old-facts-still-matter-long-run-effects.

An Assessment of Minority Voting Rights Access in the United States: 2018 Statutory Enforcement Report. U.S. Commission on Civil Rights. 12 Sept. 2018, www.usccr.gov/pubs/2018/Minority_Voting_Access_2018.pdf. 
Anzaldúa, G. Borderlands: The New Mestiza = La Frontera, 25th Anniversary Edition. Aunt Lute Books, 2007.

Arola, Kristen. Technology Autobiography. Michigan Technological University, 2001. www.readwritethink.org/files/resources/lesson_images/lesson325/Sample_TA.pdf.

Astor, Maggie. "Georgia Governor Brian Kemp Faces Investigation by House Panel.” The New York Times, 6 Mar. 2019, www.nytimes.com/2019/03/06/us/politics/governor-briankemp-voter-suppression.html.

“The Baby-Friendly Hospital Initiative: Guidelines and Evaluation Criteria for Facilities Seeking Baby-Friendly Designation.” Baby Friendly USA, 2016, www.babyfriendlyusa.org/wpcontent/uploads/2018/10/GEC2016_v2-180716.pdf.

“Baby Friendly Hospital Initiative.” World Health Organization and UNICEF, WHO Press, 1991, www.who.int/nutrition/topics/bfhi/en/.

Baby-Friendly USA, www.babyfriendlyusa.org/.

Baldor, Lolita. "New Pentagon Transgender Policy Sets Limits for Treatment, New Recruits after April 12." Military Times, Associated Press, 12 Mar. 2019, www.militarytimes.com/news/pentagon-congress/2019/03/13/new-pentagon-transgenderpolicy-sets-limits-for-treatment-new-recruits-after-april-12/.

Barad, Karen. Meeting the Universe Halfway: Quantum Physics and the Entanglement of Matter and Meaning. Duke UP, 2007.

Barr, Liz. "Embodied Vernacularity at the FDA: Feminism, Epistemic Authority, and Biomedical Activism." Feminist Rhetorical Science Studies: Human Bodies, Posthumanist Worlds, edited by Amanda K. Booher and Julie Jung, Southern Illinois UP, 2018, pp. 205-26. 
Bass Joel, Tina Gartley, Ronald Kleinman. "Unintended Consequences of Current Breastfeeding Initiatives." JAMA Pediatrics, vol. 179, no. 10, 2016, pp. 923-24.

Bates, Julie. "Toward an Interventionary Rhetoric for Technical Communication Studies." Illinois State University, Dissertation, 2017.

Bates, Julie, Francis Macarthy and Sarah Warren-Riley. "Emphasizing Embodiment, Intersectionality, and Access: Social Justice Through Technofeminism Past, Present, and Future." Computers and Composition Online, March 2019.

Baynton, Douglas. "Bringing Disability to the Center as an Indispensable Category of Historical Analysis." Disability Studies Quarterly, vol. 1, 1997, pp. 33-57.

Bentele, Keith G. and Erin E. O’Brien “Jim Crow 2.0? Why States Consider and Adopt Restrictive Voter Access Policies." Perspectives on Politics, vol. 11, no. 4, 2013, pp. 1088-1116.

"BFUSA Response August 2016 Article in JAMA-Pediatrics." Baby-Friendly USA, October 2016, www.babyfriendlyusa.org/newsviews-pages/bfusa-response-to-unintendedconsequences-of-current-breastfeeding-initiatives.

Blythe, Stuart. "Wiring a Usable Center. Usability Research and Writing Center Practice." Wiring the Writing Center, edited by Eric H. Hobson, Utah State UP, 1998, pp. 103-16.

Blyler, Nancy Round. "Pedagogy and Social Action: A Role for Narrative in Professional Communication." Journal of Business and Technical Communication, vol. 9, no. 3, 1995, pp. 289-320.

Booher, Amanda K. and Julie Jung. “Introduction: Situating Feminist Rhetorical Science Studies." Feminist Rhetorical Science Studies: Human Bodies, Posthumanist Worlds, edited by Amanda K. Booher and Julie Jung, Southern Illinois UP, 2018, pp. 18-49. 
Bordo, Susan. Unbearable Weight: Feminism, Western Culture, And The Body. U of California P, 2003, pp.1-42.

Bowie, Jennifer L. "Beyond the Universal: The Universe of Users Approach to User-Centered Design." Rhetorically Rethinking Usability: Theories, Practices and Methodologies, edited by Susan Miller-Cochran and Rochelle L. Rodrigo, Hampton Press, 2009, pp. 13563.

Brady, Ann. "Interrupting Gender as Usual: Metis Goes to Work.” Women's Studies, vol. 32, no. 2, 2003, pp. 211-33.

Brady Aschauer, Ann. “Tinkering with Technological Skill: An Examination of the Gendered Uses of Technology." Computers and Composition, vol. 16, no. 1, 1999, pp. 7-23.

Brady, June P. "Marketing Breast Milk Substitutes: Problems and Perils throughout the World." Archives of Disease in Childhood, vol. 97, no. 6, 2012, pp. 529-32.

Brater, Jonathan and Rebecca Ayala. "What's the Matter with Georgia?" Brennan Center for Justice, 12 Oct. 2018, www.brennancenter.org/blog/whats-matter-georgia.

Brater, Jonathan, Kevin Morris, Myrna Pérez, and Christopher Deluzio. "Purges: A Growing Threat to the Right to Vote.” Brennan Center for Justice, 20 July 2018, www.brennancenter.org/publication/purges-growing-threat-right-vote\#Embed.

Bravin, Jess and Brent Kendall. "Supreme Court Backs Ohio Voter Purge." The Wall Street Journal, 11 June 2018, www.wsj.com/articles/supreme-court-upholds-ohio-rules-forcanceling-voter-registration-1528728340.

“Breastfeeding.” World Health Organization, Health Topics, 2018, www.who.int/topics/breastfeeding/en/. 
"Breastfeeding Resources." BFUSA, www.babyfriendlyusa.org/faqs/for-facilities/breastfeedingresources.

Brewer, Elizabeth, Cynthia Selfe, and Melanie Yergeau. "Creating a Culture of Access in Composition Studies.” Composition Studies, vol. 42, no. 2, 2014, pp. 151-54.

Bridgeford, Tracy, Michael J. Salvo, and Bill Williamson. "A Conscience of Diversity." Programmatic Perspectives, vol 3, no. 1, 2011, pp. 1-4.

Brueggemann, Brenda J. “An Enabling Pedagogy.” Disability Studies: Enabling the Humanities, edited by Sharon Snyder, Brenda Brueggemann, and Rosemarie Garland-Thomson, The Modern Language Association of America, 2002, pp. 317-36.

Brumback, Katie. "Candidate-backed Group Challenges Georgia Election Process.” AP News, 27 Nov. 2018, www.apnews.com/1e7726035c7c4c89955fe003cbe615b3?utm_medium=AP\&utm_sourc $\mathrm{e}=$ Twitter\&utm_campaign=SocialFlow.

Bruner, M. Lane. "The Public Work of Critical Political Communication.” The Public Work of Rhetoric: Citizen-Scholars and Civic Engagement, edited by John M. Ackerman and David J. Coogan. The U of South Carolina P, 2010, pp. 56-75.

Bush, George W. "2002 Voting Rights Act Signing.” C-Span, 29 Oct. 2002, www.cspan.org/video/?173571-1/2002-voting-rights-act-signing.

Bybee, Jay S. "Memorandum for John Rizzo, Acting General Counsel of the Central Intelligence Agency: Interrogation of al Qaeda Operative.” U.S. Department of Justice, Office of Legal Counsel, Washington, D.C., 1 Aug. 2002

Cedillo, Christina V. "What Does it Mean to Move?: Race, Disability, and Critical Embodiment Pedagogy." Composition Forum, vol. 39, Summer 2018. 
Cho, Sumi, Kimberlé Williams Crenshaw, and Leslie McCall. "Toward a Field of Intersectionality Studies: Theory, Applications, and Praxis." Signs: Journal of Women in Culture and Society, vol. 38, no. 4, Summer 2013, pp. 785-810.

Chong, Felicia. "The Pedagogy of Usability: An Analysis of Technical Communication Textbooks, Anthologies, and Course Syllabi and Descriptions.” Technical Communication Quarterly, 2016, vol. 25, no. 1, pp. 12-28.

Chung, Andrew. "U.S. Top Court Backs Ohio Voter Purge; Democrats Blast Ruling.” Reuters, 11 June 2018. www.reuters.com/article/us-usa-court-purge/us-top-court-backs-ohiovoter-purge-democrats-blast-ruling-idUSKBN1J71QQ.

“Citizens without Proof: A Survey of Americans' Possession of Documentary Proof of Citizenship and Photo Identification." Voting Rights and Election Series, Brennan Centers for Justice, Nov. 2006, www.brennancenter.org/sites/default/files/legacy/d/download_file_39242.pdf.

Clinton, Bill. Speech: Signing of NVRA. C-Span, 20 May 1993.

"Code of Ethics." Associations of Teachers of Technical Writing, attw.org/about-attw/code-ofethics.

Colen, Cynthia G, and David M Ramey. "Is Breast Truly Best? Estimating the Effects of Breastfeeding on Long-term Child Health and Wellbeing in the United States Using Sibling Comparisons.” Social Science Medicine, May 2014, vol. 109, pp. 55-65, www.ncbi.nlm.nih.gov/pmc/articles/PMC4077166/.

Collins, Vicki Tolar. "The Speaker Respoken: Material Rhetoric as Feminist Methodology." Walking and Talking Feminist Rhetorics, edited by Lindal Buchanan and Kathleen J. Ryan, Parlor Press, 2010, pp. 146-69. 
“Confirmation Notice.” Ohio Secretary of State, Form No. 10-S-1. Jan. 2019.

Crenshaw, Kimberlé. "Demarginalizing the Intersection of Race and Sex: A Black Feminist Critique of Antidiscrimination Doctrine, Feminist Theory and Antiracist Politics.” Critical Race Feminism: A Reader, 2nd ed., edited by Adrien Wing, New York UP, 2003, pp. 23-33.

---. "Mapping the Margins: Intersectionality, Identity Politics, and Violence against Women of Color." Stanford Law Review, vol. 43, no. 6, 1991, pp. 1241-299

---. “The Urgency of Intersectionality.” TedWomen, 27 Oct. 2016, www.ted.com/talks/Kimberlé_crenshaw_the_urgency_of_intersectionality?language=en.

Crocker, Royce. "The National Voter Registration Act of 1993: History, Implementation, and Effects." Congressional Research Service, 18 Sep. 2013, //fas.org/sgp/crs/misc/R40609.pdf.

Cushman, Ellen. "The Rhetorician as Agent of Social Change." College Composition and Communication, vol. 47, no. 1, 1996, pp. 7-28.

Del Hierro, Marcos. “'Stayin' on Our Grind: What Hiphop Pedagogies offer to Technical Writing." Key Theoretical Frameworks, edited by Angela M. Haas and Michelle F. Eble, UP of Colorado P, 2018, pp.163-84.

Dilger, Bradley. "Extreme Usability and Technical Communication." Critical Power Tools: Technical Communication and Cultural Studies, edited by J.B. Scott, B. Longo, \& K. V. Wills, State University of New York Press, 2006, pp. 47-69.

Dingo, Rebecca. Networking Arguments: Rhetoric, Transnational Feminism, and Public Policy Writing. U of Pittsburgh P, 2012. 
---. “UK Department for International Development's (DFID) Inquiry on Disability and Development.” Columbia: University of Missouri, 5 Dec. 2013.

---. "Writing to Change the World: Writing to Effect Change(s) in Policy." Writing for a (R)evolution: Public Writing Workshop/Maker Session, Feminisms and Rhetorics Conference, 5 Oct. 2017, The University of Dayton, Dayton, Ohio. Conference Presentation.

Dingo, Rebecca and J. Blake Scott. "Introduction." The Megarhetorics of Global Development, edited by Rebecca Dingo and J. Blake Scott, U of Pittsburgh P, 2012, p. 1-25.

The Discourse of Public Policy. Special issue of Technical Communication Quarterly, vol. 9, no. $1,2000$.

"Discriminatory North Dakota Law Still in Effect" Native American Rights Fund, 1 Mar. 2019, narf.org/spirit-lake-voter-id/.

Dobrin, Sidney I., Christopher J. Keller, and Christian R. Weisser. Technical Communication in the Twenty-First Century, 2nd Edition. Pearson, 2010.

Dolmage, Jay. Disability Rhetoric. Syracuse UP, 2014.

---. "Disability, Usability, Universal Design." Rhetorically Rethinking Usability: Theories, Practices and Methodologies, edited by Susan Miller-Cochran and Rochelle L. Rodrigo, Hampton Press, 2009, pp. 167-90.

---. "Mapping Composition: Inviting Disability in the Front Door." Disability and the Teaching of Writing: A Critical Sourcebook, edited by Cynthia Lewiecki-Wilson and B.J. Brueggemann, Bedford-St. Martin's, 2008, pp. 14-27.

---. "Metis, Mêtis, Mestiza, Medusa: Rhetorical Bodies Across Rhetorical Traditions." Rhetoric Review, vol. 28, no. 1, 2009, pp. 1-28. 
---. "Writing against Normal: Navigating a Corporeal Turn." Composing Media, Composing Embodiment, edited by Kristen L. Arola and Anne Frances Wysocki, U of Colorado P, pp. 110-44.

Dolmage, Jay, and Cynthia Lewiecki-Wilson. "Refiguring Rhetorica: Linking Feminist Rhetoric and Disability Studies." Rhetorica In Motion: Feminist Rhetorical Methods and Methodologies, edited by Eileen E. Schell and K. J. Rawson, U of Pittsburgh P, 2010, pp. 23-38.

Duffy, John, and Melanie Yergeau. “Guest Editor's Introduction.” Disability Studies Quarterly, vol. 31 , no. 3,2011 , n.p.

Dumas, Joseph and Janish Redish. A Practical Guide to Usability Testing. Ablex, 1993.

Durack, Katherine T. "Gender, Technology, and the History of Technical Communication." Technical Communication Quarterly, vol. 6, no. 3, 1997, pp. 249-60.

Durkin, Erin. “GOP Candidate Improperly Purged 340,000 from Georgia Voter Rolls, Investigation Claims." The Guardian, 19 Oct. 2018, www.theguardian.com/usnews/2018/oct/19/georgia-governor-race-voter-suppression-brian-kemp.

Eble, Michelle F., and Lynee L. Gaillet. "Educating 'Community Intellectuals': Rhetoric, Moral Philosophy, and Civic Engagement.” Technical Communication Quarterly, vol. 13, no. 3, 2004, pp. 341-54.

Edwards, Jessica. "Inclusive Practices in the Technical Communication Classroom." Citizenship and Advocacy in Technical Communication: Scholarly and Pedagogical Perspectives, edited by Godwin Y. Agboka and Natalia Matveeva, Routledge, 2018, pp. 201-22. 
---. "Race and the Workplace: Toward a Critically Conscious Pedagogy." Key Theoretical Frameworks, edited by Angela M. Haas and Michelle F. Eble. UP of Colorado, 2018, pp. 268-86.

“The Effects of Shelby County v. Holder.” The Brennan Center for Justice. 6 Aug, 2018, www.brennancenter.org/analysis/effects-shelby-county-v-holder.

"Election 2016: Restrictive Voting Laws by the Numbers." The Brennan Center for Justice. 28 Sept. 2016, www.brennancenter.org/analysis/election-2016-restrictive-voting-lawsnumbers\#raceandvoting.

Ellis, Emma Grey. "Meet the Blind Youtubers Making the Internet more Accessible." Wired, 22 Jan. 2019, www.wired.com/story/blind-youtube-creators.

"ENG 249 - Technical and Professional Writing." Course Directory, Illinois State University, coursefinder.illinoisstate.edu/eng/249.

Enoch, Jessica. "Survival Stories: Feminist Historiographic Approaches to Chicana Rhetorics of Sterilization Abuse.” Rhetoric Society Quarterly, vol. 35, no. 3, 2005, pp. 5-30.

Epps, Garrett. "The Supreme Court Blesses Voter Purges.” The Atlantic, 12 June 2018, www.theatlantic.com/politics/archive/2018/06/the-supreme-court-blesses-voterpurges $/ 562589 /$.

Eyman, Douglas. "Methodology and Design Practice for Writing Processes and Pedagogies." Rhetorically Rethinking Usability: Theories, Practices, and Methodologies, edited by Susan Miller-Cochran and Rochelle L. Rodrigo, Hampton Press, 2009, pp. 213-28. Fair Fight Action. Fair Fight Action, fairfightaction.com/. 
Fausset, Richard. "How Voting Became a Central Issue in the Georgia Governor's Race.” The New York Times, 3 Nov. 2018, www.nytimes.com/2018/11/03/us/politics/georgiagovernor-voting-irregularities.html.

---. “'Large-Scale Reforms' of Georgia Elections Sought in Federal Lawsuit.” The New York Times, 27, Nov. 2018, www.nytimes.com/2018/11/27/us/georgia-elections-federallawsuit.html.

The Fed Is Best Foundation. www.fedisbest.org

Flynn, J. “Toward a Feminist Historiography of Technical Communication.” Technical Communication Quarterly, vol. 6, no. 3, 1997, pp. 321-30.

"Forms and Petitions." Ohio Secretary of State, www.sos.state.oh.us/elections/electionsofficials/forms-petitions/\#gref.

"Forward Mail." USPS. www.usps.com/manage/forward.htm

Foss, Sonja K and Cindy L. Griffin. "Beyond Persuasion: A Proposal for Invitational Rhetoric." Walking And Talking Feminist Rhetorics: Landmark Essays And Controversies, edited by Lindal Buchanan and Kathleen J. Ryan, Parlor Press, 2010, pp. 362-80.

Frost, Erin A. “Apparent Feminism As A Methodology For Technical Communication and Rhetoric.” Journal Of Business and Technical Communication, vol. 30, no. 1, 2016, pp. $3-28$.

---. "Apparent Feminism and Risk Communication: Hazard, Outrage, Environment, and Embodiment." Key Theoretical Frameworks, edited by Angela M. Haas and Michelle F. Eble. UP of Colorado, 2018, pp. 23-45.

---. "Theorizing an Apparent Feminism in Technical Communication." Dissertation, Illinois State University, 2013. 
Frost, Erin A. and Angela M. Haas. "Seeing and Knowing the Womb: A Technofeminist Reframing of Fetal Ultrasound toward a Decolonization of Our Bodies." Computers and Composition, vol. 43, 2017, pp. 88-105.

Galloway, Jim. "Stacey Abrams: 'I will not concede because the erosion of our democracy is not right."” AJC, 16 Nov. 2018, www.ajc.com/blog/politics/stacey-abrams-will-not-concedebecause-the-erosion-our-democracy-not-right/JQqttbuF09NYkMQbIYx9BM/.

Garfield, Shaina. “When Empathy Isn't Enough.” Medium, 19 Dec. 2018, medium.com/frogvoices/when-empathy-isnt-enough-87ccdb6ae072.

Garland-Thomson, Rosemarie. Extraordinary Bodies: Figuring Physical Disability in American Culture And Literature, Columbia UP, 1997.

---. "Integrating Disability, Transforming Feminist Theory." Feminist Disability Studies, edited by Kim Q. Hall, Indiana UP, 2011, pp. 13-47.

Gearhart, Sally Miller. “The Womanization of Rhetoric.” Feminism And Composition: A Critical Sourcebook, edited by Gesa E. Kirsch, et al., Bedford/St. Martin's, 2003, pp. 53-60.

Georgia Secretary of State. “Kemp Recognized National Voter Registration Day.” Elections, //sos.ga.gov/index.php/general/kemp_recognizes_national_voter_registration_day. “Georgia’s 127,000 Missing Votes-Disproportionate Vote Loss in African American Neighborhoods.” Coalition for Good Governance. 8 Feb. 2019, coaltionforgoodgovernance.sharefile.com/share/view/sa100c250cf8408e8.

Gilson, Oriana. “The Genres of Grandma's Letters.” Grassroots Writing Research Journal, vol. 6, no. 1, Illinois State University English Department Publications Unit, 2015, pp. 9-21. 
Girard, Lisa-Christine, Orla Doyle, and Richard E. Tremblay. "Breastfeeding, Cognitive and Noncognitive Development in Early Childhood: A Population Study." Pediatrics, vol. 139, no. 4, 2017, pp. 1-9.

Glenn, Cheryl. Interviewed by Jessica Enoch. "Feminist Rhetorical Studies-Past, Present, Future: An Interview with Cheryl Glenn.” Composition Forum, vol. 29, Spring 2014, pp. 7.

Global Strategy for Infant and Young Child Feeding. World Health Organization, 2003.

Goel, Sharad, et al. "One Person, One Vote: Estimating the Prevalence of Double Voting in U.S. Presidential Elections." scholar.harvard.edu, scholar.harvard.edu/files/morse/files/1plv.pdf.

Gouge, Catherine. "Improving Patient Discharge Communication." Journal of Technical Writing and Communication, vol. 47, no. 4, 2017, pp. 419-39.

---. "The Inconvenience of Meeting You: Rereading Non/Compliance, Enabling Care." Feminist Rhetorical Science Studies: Human Bodies, Posthumanist Worlds, edited by Amanda K. Booher and Julie Jung, Southern Illinois UP, 2018, pp. 114-40.

Gouge, Catherine, and John Jones. "Wearables, Wearing, and the Rhetorics that Attend to Them." Rhetoric Society Quarterly, vol. 46, no. 3, pp. 199-206.

Grabill, Jeffrey T. "On Being Useful: Rhetoric and the Work of Engagement." The Public Work of Rhetoric, edited by John Ackerman and David Coogan, The U of South Carolina P. 2010, pp. 193-210.

---. "Shaping Local HIV/AIDS Services Policy through Activist Research: The Problem of Client Involvement.” Technical Communication Quarterly, vol. 9, no. 1, 2000, pp. 29-50. 
Grabill, Jeff and Michelle Simmons. "Toward a Critical Rhetoric of Risk Communication:

Producing Citizens and the Role of Technical Communicators.” Technical

Communication Quarterly, vol. 7, no. 4., 1998, pp. 415-41.

Graham, David A. “Ohio's Questionable Voter Purge.” The Atlantic. 3 June 2016.

"The Guidelines and Evaluation Criteria for Facilities Seeking Baby Friendly Designation, 2016

Revision.” Baby-Friendly USA, www.babyfriendlyusa.org/get-started/the-guidelinesevaluation-criteria.

Gurak, Laura. J., and Nancy L. Bayer. "Making Gender Visible: Extending Feminist Critiques of Technology to Technical Communication." Technical Communication Quarterly, vol. 3, no. 3, 1994, pp. 257-70.

Haas, Angela M. "Race, Rhetoric, and Technology: A Case Study of Decolonial Technical Communication Theory, Methodology, and Pedagogy." Journal of Business and Technical Communication, vol. 26, no. 3, 2012, pp. 277-310.

---. "Wampum as Hypertext: An American Indian Intellectual Tradition of Multimedia Theory and Practice." Studies in American Indian Literatures, no. 4, Winter 2007, pp. 77-100.

Haas, Angela M., Jackie Rhodes, and Dànielle Nicole DeVoss. "Introduction by the Guest Editors." Technofeminism: (Re)Generations and Intersectional Futures, special issue of Computers and Composition, vol. 51, 2019, pp. 1-3.

Haas, Angela M., and Michelle F. Eble, editors. Key Theoretical Frameworks: Teaching Technical Communication in the Twenty-first Century. Utah State UP, 2018.

Haas, Angela M, and Medina Cruz. "Intersectionality" Plenary Session. Association for the Teachers of Technical Writing, 2018. 
Hall WJ, et al. "Implicit Racial/ethnic Bias among Health Care Professionals and its Influence on Health Care Outcomes: A Systematic Review." American Journal of Public Health, 2015, vol. 105 , no. 60 , pp. $60-76$.

Hallenbeck, Sarah. "User Agency, Technical Communication, and the 19th-Century Woman Bicyclist.” Technical Communication Quarterly, vol. 21, no. 4, 2012, pp. 290-306.

Harding, Sandra. "Introduction: Is there a Feminist Methodology?" Feminism and Methodology: Social Science Issue, edited by Sandra Harding, Indiana UP, 1987, pp. 1-14.

Harriot, Michael. “The Wizard of Voter Suppression: Brian Kemp's Long History of Making Black Votes Disappear.” The Root, 11 Oct. 2018, www.theroot.com/the-wizard-of-votersuppression-brian-kemp-s-long-hist-1829696413.

Hauser, Gerard. Vernacular Voices: The Rhetoric of Publics and Public Spheres. U of South Carolina P, 1999.

Hayles, N. Katherine. How We Became Posthuman: Virtual Bodies in Cybernetics, Literature, and Informatics. U of Chicago P, 1999.

Heidiger, ML, et al. "Association between Infant Breastfeeding and Overweight in Young Children. JAMA, 2001, vol. 285, no. 19, pp. 2453-460.

“Help America Vote Act of 2002.” H.R. 3295. 23 Jan. 2002, www.eac.gov/assets/1/6/HAVA41.PDF.

Hesford, Wendy. "Cosmopolitanism and the Geopolitics of Feminist Rhetoric." Rhetorica in Motion: Feminist Rhetorical Methods and Methodologies, edited by Eileen E. Schell and K.J. Rawson, U of Pittsburgh P, 2010, pp. 53-70.

---. Spectacular Rhetorics: Human Rights Visions, Recognitions, and Feminisms. Duke UP, 2011. 
Hill Collins, Patricia. Black Feminist Thought: Knowledge, Consciousness, And The Politics Of Empowerment. Routledge, 2009.

Hill Collins, Patricia and Sirma Bilge. Intersectionality. Polity Press, 2016.

hooks, bell. Teaching to Transgress: Education as the Practice of Freedom. Routledge, 1994.

---. Teaching Community: A Pedagogy of Hope. Routledge, 2003.

Husted, Jon. "Directive 2018-20: General Voter Records Maintenance Program - Supplemental Process." 9 July 2018, drive.google.com/drive/folders/1yGb2liOdGHI7ghFBRfVkDGM1A10s62G.

Husted, Ohio Secretary of State v. A. Philip Randolph Institute et al. Supreme Court of the United States, 11 June 2018, www.supremecourt.gov/opinions/17pdf/16-980_f2q3.pdf. "Importance of Breastfeeding." Baby-Friendly USA,www.babyfriendlyusa.org/aboutus/importance-of-breastfeeding.

“Improving Breastfeeding, Complementary Foods and Feeding Practices." UNICEF, Nutrition, Updated 1 May 2018, www.unicef.org/nutrition/index_breastfeeding.html.

Innocenti Declaration: On the Protection, Promotion and Support of Breastfeeding. UNICEF. Florence: 1990. Web. 6 May, 2015, www.unicef.org/programme/breastfeeding/innocenti.htm.

Innocenti Declaration 2005: On Infant and Young Child Feeding. Florence, Italy. 22 November 2005 , www.unicef.org/nutrition/files/innocenti2005m_FINAL_ARTWORK_3_MAR.pdf. International Code of Marketing of Breastmilk Substances. World Health Organization. Geneva: 1981, www.who.int/nutrition/publications/infantfeeding/breastmilk-substitutesFAQ2017/en/. 
International Code of Marketing of Breastmilk Substances: Frequently Asked Questions. 2017 Update. World Health Organization. Geneva, Switzerland. World Health Organization: 2017, www.apps.who.int/iris/bitstream/handle/10665/254911/WHO-NMH-NHD-17.1eng.pdf? sequence $=1$.

Jack, Jordynn. "Leviathan and the Breast Pump: Toward an Embodied Rhetoric of Wearable Technology.” Rhetoric Society Quarterly, vol. 46, no. 3, 2016, p. 207-21.

Jaggar, Alison M. "Love and Knowledge: Emotion in Feminist Epistemology." Just Methods: An Interdisciplinary Feminist Reader, edited by Alison M. Jaggar, Paradigm Publishers, 2008, pp. 378-91.

Jeliffe, Derrick B. “Commerciogenic Malnutrition.” Nutrition Reviews, vol. 30, no. 9, 1972, pp. 199-205. doi.org/10.1111/j.1753-4887.1972.tb04042.x.

Johnson, Maureen, Daisy Levy, Katie Manthey, and Maria Novotny. "Embodiment: Embodying Feminist Rhetorics." Peitho, vol. 18, no. 1, 2015, pp. 39-44.

Johnson, Robert. User-centered Technology: A Rhetorical Theory for Computers and other Mundane Artifacts. SUNY P, 1998.

Jones, Natasha N. "Rhetorical Narratives of Black Entrepreneurs: The Business of Race, Agency, and Cultural Empowerment.” Journal of Business and Technical Communication, vol. 31, no. 3, pp. 319-49.

---. "The Technical Communicator as Advocate: Integrating a Social Justice Approach in Technical Communication." Journal of Technical Writing and Communication, vol. 46, no. 3 , 2016, pp. 342-61. 
Jones, Natasha, Kristen R. Moore, and Rebecca R. Walton. "Disrupting the Past to Disrupt the Future: An Antennarative of Technical Communication." Technical Communication Quarterly, vol. 25, no. 4, 2016, pp. 1-19.

Jones, Natasha N. and Miriam F. Williams. "The Social Justice Impact of Plain Language: A Critical Approach to Plain-Language Analysis.” IEEE Transactions on Professional Communication, vol. 60, No. 4, Dec. 2017, pp. 412-29.

Jones, Natasha, and Rebecca Walton. "Using Narratives to Foster Critical Thinking about Diversity and Social Justice.” Key Theoretical Frameworks, edited by Angela M. Haas and Michelle F. Eble. UP of Colorado, 2018, pp. 241-67.

Judd, Alan. “Georgia's Strict Laws Lead to Huge Purge of Voters.” Atlanta Journal Constitution, 27 Oct. 2018, www.ajc.com/news/state--regional-govt--politics/voterpurge-begs-question-what-the-matter-with-georgia/YAFvuk3Bu95kJIMaDiDFqJ/.

“Judge Rules in Favor of One Wisconsin Institute Voter Rights Claims." One Wisconsin Institute, 29 July 2016, onewisconsinnow.org/institute/press/judge-rules-in-favor-of-onewisconsin-institute-voter-rights-claims/.

Jung, Julie. “Textual Mainstreaming And Rhetorics Of Accommodation.” Rhetoric Review, vol. 26, no. 2, 2007, pp. 160-78.

Jung, Karen. “Chronic Illness and Academic Accomodation: Meeting Disabled Students' 'Unique Needs' and Preserving the Institutional Order of the University.” Journal of Sociology and Social Welfare, vol. 30, 2003, pp. 91-112.

Katz, Steven B. "The Ethic of Expediency: Classical Rhetoric, Technology, and the Holocaust." College English, vol. 25, no. 5, 1992, pp. 255-75. 
Kauffman, Johnny. “6 Takeaways From Georgia's 'Use It Or Lose It' Voter Purge Investigation.” $N P R, 22$ Oct. 2018, www.npr.org/2018/10/22/659591998/6-takeaways-from-georgiasuse-it-or-lose-it-voter-purge-investigation.

Kerschbaum, Stephanie. “Inclusion.” Peitho Journal, vol. 18, no. 1, 2015, pp. 19-24.

Kessler, Molly Margaret. "Wearing an Ostomy Pouch and Becoming and Ostomate: A Kairological Approach to Wearability." Rhetoric Society Quarterly, vol. 46, no. 3, 2016, pp. 236-50.

Kirsch, Gesa E. and Joy S. Ritchie. "Beyond the Personal: Theorizing a Politics of Location in Composition Research." College Composition and Communication, vol. 46, no. 1, 1995, pp. 7-29.

Kitalong, Karla, Tracy Bridgeford, Michael Moore, and Dickie Selfe. "Variations on a Theme: The Technology Autobiography as a Versatile Writing Assignment.” Teaching Writing with Computers, edited by Pamela Takayoshi and Brian Huot. Houghton Mifflin, 2003, pp. 219-33.

Knight, Melinda. "Accessibility and Disability: Absent Keywords in Business and Professional Communication." Business and Professional Communication Quarterly, vol. 8, no. 1, pp. 22-33.

Koerber, Amy. Breast or Bottle?: Contemporary Controversies in Infant Feeding Policy and Practice. The U of South Carolina P, 2013.

---. "Toward a Feminist Rhetoric of Technology." Journal of Business and Technical Communication, vol. 14, no. 1, 2000, pp. 58-73. 
Kramer-Simpson and Simpson. "Technical Communication Client Project and Nonprofit Partnerships." Citizenship and Advocacy in Technical Communication, edited by Godwin Y. Agboka and Natalia Matveeva, Routledge, 2018, pp. 91-109.

LaDuke, Winona. All Our Relations: Native Struggles for Land and Life. South End P, 1999.

---. "Not Afraid to Look the White Man in the Face the Art of Indigenous Resistance." Public Art Review, no. 2, 2017, p. 55.

Lannon, John, and Laura Gurak. Technical Communication, 14th edition. Pearson, 2017.

Lapowski, Issie. “A Dead-Simple Algorithm Reveals The True Toll Of Voter ID Laws.” Wired, 4 Jan. 2018. www.wired.com/story/voter-id-law-algorithm/

Lawson, Betsy. "Reminiscing: 22 Years after the National Voter Registration Act." LWV, 2 Aug. 2015, www.lwv.org/blog/reminiscing-22-years-after-national-voter-registration-act.

Lay, Mary. "Feminist Theory and the Redefinition of Technical Communication." Journal of Business and Technical Communication, vol. 5, no. 4, 1991, pp. 348-70.

Levine, Sam. "Wisconsin Voting Rights Groups Promise Lawsuit Over Early Voting Cuts." Huffpost, 14 Dec. 2018, www.huffingtonpost.com/entry/wisconsin-earlyvoting_us_5c141be8e4b049efa7524568.

Levy, Pemy. "Supreme Court Deals a Blow to Voting Rights and Invites More States to Purge Their Rolls.” Mother Jones, 11 June 2018, www.motherjones.com/politics/2018/06/supreme-court-deals-a-blow-to-voting-rightsand-invites-more-states-to-purge-their-rolls/.

Li, Quan, Michael J. Pomante II, and Scot Schraufnagel. "Cost of Voting in the American States." Election Law Journal, Vol. 17, No. 3, 2018, DOI: 10.1089/elj.2017.0478 
Liptak, Adam. “Supreme Court Invalidates Key Part of Voting Rights Act.” The New York Times, 25 June 2013, www.nytimes.com/2013/06/26/us/supreme-court-ruling.html.

Lockhart, P.R. "House Democrats have Launched an Investigation into Voter Suppression in Georgia."Vox, 6 Mar. 2019, www.vox.com/policy-andpolitics/2019/3/6/18253689/voter-suppression-georgia-kemp-investigation-cummings.

Lopez, Lindsay Hunter. "Breastfeeding at Any Cost?” The Atlantic, Health, Aug. 15, 2017, www.theatlantic.com/health/archive/2017/08/when-the-pressure-to-breastfeed-putsmoms-and-babies-at-risk/536562/.

MacNamara, Elisabeth. "The Fight for the National Voter Registration Act (NVRA): 'It's Now Up to Us to See That It Gets Done." HuffPost, 6 Dec. 2017, www.huffingtonpost.com/elisabeth-macnamara/the-fight-for-thenationa_b_2855094.html.

Martin, Michel. "Why Millions of Americans Have No Government ID.” NPR: Tell Me More/Elections, 1 Feb. 2012, www.npr.org/2012/02/01/146204308/why-millions-ofamericans-have-no-government-id.

Martinez, Aja. "Core-Coursing Counterstory: On Master Narrative Histories of Rhetorical Studies Curricula.” Rhetoric Review, vol. 38, no. 4, forthcoming Oct. 2019.

Martinez, Diane. "Teaching Proposal Writing: Advocacy and Autonomy in the Technical Communication Classroom." Citizenship and Advocacy in Technical Communication, edited by Godwin Y. Agboka and Natalie Matveeva, Routledge, 2018, pp. 243-64.

McCall, Leslie. "The Complexity of Intersectionality." Signs: Journal of Women in Culture and Society, 2005, vol. 30, no. 3, pp. 1771-1800. 
Mears, Bill, and Brooke Singman. "Supreme Court Gives Green Light to Ohio's Voting Roll Purge.” Fox News, 11 June 2018, www.foxnews.com/politics/supreme-court-gives-greenlight-to-ohios-voting-roll-purge.

Meloncon, Lisa. "Patient Experience Design: Expanding Usability Methodologies for Healthcare." Communication Design Quarterly, vol. 5, no. 2, 2017, pp. 19-28.

Meloncon, Lisa, and Erin A. Frost. "Charting an Emerging Field: The Rhetorics of Health and Medicine and its Importance in Communication Design.” Communication Design Quarterly, vol. 3, no. 4, 2015, pp. 7-14.

Meloncon, Lisa, and Sally Henschel. "Current State of U.S. Undergraduate Degree Programs in Technical and Professional Communication." Technical Communication, vol. 60, no. 1, 2013, pp. 45-64.

Micciche, Laura R. "Writing as Feminist Rhetorical Theory" Rhetorica in Motion: Feminist Rhetorical Methods and Methodologies, edited by Eileen Schell and K.J. Rawson, U of Pittsburgh P, 2010, pp. 173-88.

Miller-Cochran, Susan. K., and Rochelle L. Rodrigo. Rhetorically Rethinking Usability: Theories, Practices, Methodologies, Hampton P, 2009.

Minnite, Lorraine. The Myth of Voter Fraud. Cornell UP, 2010.

---. The Misleading Myth of Voter Fraud in American Elections. Scholars Strategy Network. 28 Jan. 2014, scholars.org/sites/scholars/files/ssn_key_findings_minnite_on_the_myth_of_voter_fraud. pdf. 
---. United States District Court for the Western District of Wisconsin. One Wisconsin Institute Inc., et al v. Gerald Nichol, et al. 29 July 2016. Deposition, moritzlaw.osu.edu/electionlaw/litigation/documents/DepositionofLorraineMinnitetakeno n41316051116.pdf.

Moeller, Marie E. “Advocacy Engagement, Medical Rhetoric, and Expediency: Teaching Technical Communication in the Age of Altruism." Key Theoretical Frameworks, edited by Angela M. Haas and Michelle F. Eble. UP of Colorado, 2018, pp. 212-40.

Moeller, Marie E. and Erin A. Frost. "Food Fights: Cookbook Rhetorics, Monolithic Constructions of Womanhood, and Field Narratives in Technical Communication.” Technical Communication Quarterly, vol. 25, no. 1, 2016, pp. 1-11.

Mohanty, Chandra Talpade. "Transnational Feminist Crossings: On Neoliberalism and Radical Critique.” Signs: Journal of Women in Culture and Society, vol. 38, no. 4, 2013, pp. 96791.

---. "Under Western Eyes: Feminist Scholarship and Colonial Discourses.” Boundary 2, vol. 12, no. 3 , 1984 , pp. $333-58$.

---. “'Under Western Eyes' Revisited: Feminist Solidarity through Anticapitalist Struggles." Signs: Journal of Women in Culture and Society, vol. 28, no. 2, 2002, pp. 499-535.

Moore, Patrick. "Questioning the Motives of Technical Communication And Rhetoric: Steven Katz's 'Ethic Of Expediency."” Journal of Technical Writing \& Communication, vol. 34, no. 1,2004, pp. 5-29. 
Moore, Kristen. "Black Feminist Epistemology as a Framework for Community-Based Teaching." Key Theoretical Frameworks: Teaching Technical Communication in the Twenty-First Century, edited by Angela M. Haas and Michelle F. Eble, Utah State UP, 2018, pp. 185-211.

---. "Exposing Hidden Relations: Storytelling, Pedagogy, and the Study of Policy." Technical Writing and Communication, vol. 43, no. 1, 2013, pp. 63-78.

Morris, Kevin and Myrna Pérez. "Florida, Georgia, North Carolina Still Purging Voters at High Rates." Brennan Center for Justice, 1 Oct. 2018, www.brennancenter.org/blog/floridageorgia-north-carolina-still-purging-voters-high-rates.

Muller, Mike. "The Baby Killer: A War on Want Investigation into the Promotion and Sale of Powdered Baby Milks in the Third World." War on Want, 1974.

Muwakkil, Salim. "The 'Post-Racial' President.” In These Times, 24 Aug. 2009, inthesetimes.com/article/4750/the_post-racial_president.

Nanos, Janelle. "Wayfair Walkout: Read the Letter Employees Sent to Leadership, and the Company's Response.” Boston Globe, 25 June 2019, www.bostonglobe.com/business/2019/06/25/wayfair-walkout-read-letter-employees-sentleadership-and-company-response/233ZTGDsdf1SAZOGPdWo8O/story.html.

Nash, Jennifer. “Re-thinking Intersectionality.” Feminist Review, vol. 89, 2008, pp. 1-15.

“National Voter Registration Act of 1993.” Public Law 103-31, May 20, 1993...Pub. L. 103-31, May 20, 1993, 107 Stat. 77

Nielson, Jakob. Usability Engineering. Academic Press, 1993.

“92-Year-Old Black Woman Overcame Hurdles to Vote in Georgia in 2018." YouTube, uploaded by Now This, 14 Nov. 2018, www.youtube.com/watch?v=ARDa2THzPzs. 
O’Hara, Frederick M. “A Brief History of Technical Communication,” STC’s 48th Annual Conference Proceedings, Society for Technical Communication, Arlington, Va., 2001, pp. 500-04.

O'Hara, Karen. '“Curb Cuts' on the Information Highway: Older Adults and the Internet." Technical Communication Quarterly, vol. 13, no. 4, 2004, pp. 426-55.

Opel, Dawn, and Donnie Sackey. “Access and Equity in Data-Driven Food Justice DecisionMaking." Community Activism Panel, Computers and Writing Conference, 21 June 2019, Michigan State University, East Lansing, Michigan. Conference Presentation.

Ornatowski, Cesar. "Between Efficiency and Politics Rhetoric and Ethics in Technical Writing." Technical Communication Quarterly, vol. 1, no. 1, 1992, pp. 91-103.

"Our Philosophy." BFUSA. www.babyfriendlyusa.org/about-us/our-philosophy

Palast, Greg. @Greg_Palast. “This 92 Year Old...” Twitter, 6 Nov. 2018, twitter.com/Greg_Palast/status/1059906779033694208.

Palmeri, Jason. "Disability Studies, Cultural Analysis, and the Critical Practice of Technical Communication Pedagogy.” Technical Communication Quarterly, vol. 15, no. 1, 2006, pp. $49-65$.

Panette, Grace, and Olivia Reaney. "The Evolution of American Voting Rights in 242 years Shows How Far We've Come — and How Far We Still Have to Go.” Business Insider, 15 Feb. 2019, www.businessinsider.com/when-women-got-the-right-to-vote-americanvoting-rights-timeline-2018-10.

Pérez, Myrna. Voter Purges. Brennan Center for Justice and New York University School of Law, 2008. 
Pérez, Myrna and Jonathen Brater. "Ohio Voting Rights Decision not a Green Light for Reckless Voter Purges.” The Brennan Center for Justice, 12 June 2018, www.brennancenter.org/blog/ohio-voting-rights-decision-not-green-light-reckless-voterpurges.

Petersen, Emily January. “Female Practitioners’ Advocacy and Activism: Using Technical Communication for Social Justice Goals." Citizenship and Advocacy in Technical Communication, edited by Godwin Y. Agboka and Natalia Matveeva, Routledge, 2018, pp. 3-22.

---. "Redefining the Workplace: The Professionalization of Motherhood through Blogging." Journal of Technical Writing and Communication, vol. 44, no. 3, 2014, pp. 277-96.

Phillips, Lisa. "Shifting Sensations: Using a Feminist Sensory-Rhetorical Framework in Social and Environmental Justice, Technical Communication, and Pedagogy.” Dissertation, Illinois State University, 2016.

"Philosophy." La Leche League International, 2018, www.llli.org/about/philosophy/. “Phone Scams Pose Serious Threat; Remain on IRS ‘Dirty Dozen’ List of Tax Scams.” IRS, 6 Mar. 2018, www.irs.gov/newsroom/phone-scams-pose-serious-threat-remain-on-irsdirty-dozen-list-of-tax-scams.

Plato. Phaedo. in Plato: The Collected Dialogues, edited by Edith Hamilton and Huntington Cairns, Princeton UP, 1961. Web.

Porter, James E., Sullivan, Patricia, Blythe, Stuart, Grabill, Jeffrey T., and Miles, Libby. "Institutional Critique: A Rhetorical Methodology for Change." College Composition and Communication, vol. 4, no. 2000, pp. 610. 
Potts, Lisa. Social Media in Disaster Response: How Experience Architects can Build for Participation. Routledge, 2013.

Powell, Malea. "Custer's Very Last Stand: Rhetoric, the Academy, and the Un-Seeing of the American Indian." Unpublished essay. 1995. Quoted in Cushman, Ellen. "The Rhetorician as an Agent of Social Change." College Composition and Communication, vol. 47 , no. 1,1996, pp. $7-28$.

Pugh, Tony. "Decision Allows Georgia to Remove Inactive Voters from the Rolls." McClatchy, D.C. Bureau. 12 June 2018, www.mcclatchydc.com/news/nationworld/national/article213001299.html.

“Quick Facts: Ohio.” United States Census Bureau, www.census.gov/quickfacts/oh.

Rai, Candice. "Power, Publics, and the Rhetorical Uses of Democracy." The Public Work of Rhetoric. U of South Carolina P, 2012, pp. 39-55.

Rawson, K.J. “Queering Feminist Rhetorical Canonization.” Rhetorica in Motion: Feminist Rhetorical Methods and Methodologies, edited by Eileen Schell and K.J. Rawson, U of Pittsburg P, 2010, pp. 39-52.

Reid, Tim and Grant Smith. "Missing Hyphens will Make it Hard for Some People to Vote in U.S. Election.” Reuters, www.reuters.com/article/us-usa-election-laws/missing-hyphenswill-make-it-hard-for-some-people-to-vote-in-u-s-election-idUSKBN1HI1PX.

Reilly, Colleen A. "Sexualities and Technologies: How Vibrators Help to Explain Computers." Computers and Composition, vol. 21, 2004, pp. 363-85.

Rhodan, Maya. "Here Are the Facts About President Trump's Family Separation Policy.” Time, 20 June 2018, time.com/5314769/family-separation-policy-donald-trump/. 
Richardson, Flourice. "The Eugenics Agenda: Deliberative Rhetoric and Therapeutic Discourse of Hate." Communicating Race, Ethnicity, and Identity in Technical Communication, edited by Miriam F. Williams and Octavio Pimentel, Baywood Publishing Company, 2014, pp. 7-20.

Riedner, Rachel and Kevin Mahoney. Democracies to Come: Rhetorical Action, Neoliberalism, and Communities of Resistance. Rowman and Littlefield Publishers, 2008.

Rivers, Nathaniel and Lars Söderlund. "Speculative Usability." Journal of Technical Writing and Communication, vol. 46, no. 1, 2016, pp. 125-46.

Roberts, Sam. "2008 Surge in Black Voters Nearly Erased Racial Gap” The New York Times, 20 July 2009, www.nytimes.com/2009/07/21/us/politics/21vote.html.

Rose, Emma J. “Design as Advocacy: Using a Human-Centered Approach to Investigate the Needs of Vulnerable Populations." Journal of Technical Writing and Communication, vol. 46, no. 4, 2016, pp. 427-45.

Rose, Emma, Avery Edenfield, Rebecca Walton, Laura Gonzales, Ann Shivers McNair, Tetyana Zhvotovska, Natasha Jones, Genevieve I. Garcia de Mueller, and Kristen Moore. "Social Justice in UX: Centering Marginalized Users.” Extended Abstract, SIGDOC ‘18, August 3-5, 2018, Milwaukee, WI.

Ross, Susan M. “A Feminist Perspective on Technical Communicative Action: Exploring how Alternative Worldviews Affect Environmental Remediation Efforts.” Technical Communication Quarterly, vol. 5, no. 3, 1994, pp. 325-42.

Ross, Loretta and Rickie Solinger. Reproductive Justice: An Introduction. U of California P, 2017. 
Rowland, Darrel. "Ohio Voter Roll Purges Beginning Again After Husted Directive." The Columbus Dispatch, 21 Nov. 2018, www.dispatch.com/news/20181120/ohio-voter-rollpurges-beginning-again-after-husted-directive.

Royster, Jacqueline Jones, and Gesa E. Kirsch. Feminist Rhetorical Practices: New Horizons For Rhetoric, Composition, And Literacy Studies. Southern Illinois UP, 2012.

Rude, Carolyn. “Guest Editor’s Column.” Technical Communication Quarterly, vol. 9, no. 1, 2000, pp. 5-7.

---. "Mapping the Research Question in Technical Communication." Journal of Business and Technical Communication, vol. 23, no. 2, pp. 174-215.

Salvavatori, Mariolina R. “The Scholarship of Teaching: Beyond the Anecdotal.” Pedagogy, vol. 2, no. 3, 2002, pp. 297-310.

Salvo, Michael J. "Ethics of Engagement: User-Centered Design and Rhetorical Methodology." Technical Communication Quarterly, vol. 10, no. 3, 2001, pp. 273-90.

Sandoval, Chela. Methodology of The Oppressed. U of Minnesota P, 2000.

Sauers, Jenna. “Why Women Really Quit Breastfeeding.” Harper's Bazaar, July 17, 2018. www.harpersbazaar.com/culture/features/a21203672/why-women-stop-breastfeedingpumping-at-work/

Savage, Gerald. “Foreword.”. Key theoretical frameworks: Teaching Technical Communication in the Twenty-First Century, edited by Angela M. Haas and Michelle. F. Eble, Utah State UP, 2018, pp. ix-xi.

Savage, Gerald, and Kyle Mattson. "Persepctions of Racial and Ethnic Diversity in Technical Communication Programs." Programmatic Perspective, vo. 3, no. 1, 2011, pp. 5-57. 
Savage, Gerald, and Matveeva, Natalia. "Toward Racial and Ethnic Diversity in Technical Communication Programs: A Study of Technical Communication in Historically Black Colleges and Universities and Tribal Colleges and Universities in the United States.” Programmatic Perspectives, 2011, vol. 3, no. 1, pp. 152-79.

"Scams and Frauds, Identity Theft." AARP, www.aarp.org/money/scams-fraud/identity-theft/.

Schneider, Stephen. "Usable Pedagogies: Usability, Rhetoric, and Sociocultural Pedagogy in the Technical Writing Classroom.” Technical Communication Quarterly, vol. 14, no. 4, 2005, pp. 447-67

Science and Public Policy. Special Issue of Technical Communication Quarterly, vol. 19, no. 1, 2008.

Scott, J. Blake. “The Practice of Usability: Teaching User Engagement Through ServiceLearning." Technical Communication Quarterly, vol. 17, no. 4, 2008, pp. 381-412.

Scott, Blake, Bernadette Longo, and Katherine V. Wills. Critical Power Tools: Technical Communication and Cultural Studies, SUNY P, 2007.

Scott, Blake, and Bernadette Longo. "Guest Editors' Introduction: Making the Cultural Turn." Technical Communication Quarterly, vol. 15, no. 1, 2006, pp. 3-7.

Scott, J. Blake, Bernadette Longo, and Katherine V. Wills. "Introduction, Why Cultural Studies?: Expanding Technical Communication's Critical Toolbox." Critical Power Tools: Technical Communication and Cultural Studies, edited by J. Blake Scott, Bernadette Longo, and Katherine V. Wills, SUNY P, 2006, pp. 1-24.

Segal, Judy Z. Health and Rhetoric of Medicine. Southern Illinois UP, 2005. 
Selfe, Cynthia, and Richard Selfe. "The Politics of the Interface: Power and its Exercise in Electronic Contact Zones." College Composition and Communication, vol. 45, no. 4, 1994, pp. 480-504.

Selznick, Hilary. "Enabling Pain, Enabling Insight: Opening up Possibilities for Chronic Pain in Disability Rhetoric and Rhetoric and Composition.” Dissertation, Illinois State University, 2017.

Shelby County, Alabama v. Holder, Attorney General, et al. No. 12-96. 25 June 2013. Supreme Court of the United States, www.supremecourt.gov/opinions/12pdf/12-96_6k47.pdf.

Shivers-McNair, Ann and Clarissa San-Diego. "Localizing Communities, Goals, Communication, and Inclusion: A Collaborative Approach." Technical Communication Quarterly, vol. 64, no. 2, 2017, pp. 97-112.

Shivers-McNair, Ann, Joy Phillips, Alyse Campbell, Hanh H. Mai, Alice Yan, John Forrest Macy, James Wenlock, Savannah Fry, Yishan Guan. "User-Centered Design In and Beyond the Classroom: Toward an Accountable Practice." Computers and Composition, vol. 49, 2018, pp. 36-47

Simmons, Michele W. and Jeffrey T. Grabill. "Toward a Civic Rhetoric for Technologically and Scientifically Complex Places: Invention, Performance, and Participation.” College Composition and Communication, vol. 58, no. 3, 2007, pp. 419-48

Simmons, Michele W. and Meredith W. Zoetewey. "Productive Usability: Fostering Civic Engagement and Creating More Useful Online Spaces for Public Deliberation.” Technical Communication Quarterly, vol. 21, 2012, pp. 251-76. 
Singer, Natasha. "Amazon Is Pushing Facial Technology That a Study Says Could Be Biased." The New York Times, 24 Jan. 2019, https://www.nytimes.com/2019/01/24/technology/amazon-facial-technology-study.html. Skeen, Thomas. "The Rhetoric of the Human-Computer Interaction." Rhetorically Rethinking Usability: Theories, Practices and Methodologies, edited by Susan Miller-Cochran and Rochelle L. Rodrigo, Hampton P, 2009, pp. 91-104.

Sozan, Michael. “On HAVA's 15th Anniversary, Congress Needs to Make U.S. Elections More Secure." Center for American Progress, 26 Oct. 2017, www.americanprogress.org/issues/democracy/reports/2017/10/26/441417/on-havas-15thanniversary-congress-needs-to-make-u-s-elections-more-secure/.

Smyser-Fauble, Barbi. "The University Required Accommodations Statement." Key Theoretical Frameworks, edited by Angela M. Haas and Michelle F. Eble. UP of Colorado, 2018, pp. $68-92$.

Snyder, Sharon L., Brenda Jo Brueggemann, and Rosemarie Garland-Thomson. "Introduction: Integrating Disability into Teaching and Scholarship." Disability Studies: Enabling the Humanities, MLA, 2002.

Solinger, Rickie. Reproductive Politics: What Everyone Needs to Know. Oxford UP, 2013.

Sourer, Bill. “The Code I'm Still Ashamed Of.” Medium, 13 Nov. 2016, medium.freecodecamp.org/the-code-im-still-ashamed-of-e4c021dff55e.

Spinuzzi, Clay. "Introduction: Tyrants, Heroes, and Victims in Information Design.” Tracing Genres Through Organizations: A Sociocultural Approach to Information Design, MIT Press, 2003, pp. 1-23. 
---. "Investigating the Technology-Work Relationship: A Critical Comparison of Three Qualitative Field Methods." IEEE PCS/ACM SIGDOC 2000 Conference Proceedings, pp. 208-15.

Steele, Shelby. “Obama’s Post-racial Promise.” LATimes, 5 Nov. 2008, www.latimes.com/opinion/opinion-la/la-oe-steele5-2008nov05-story.html.

Sulleyman, Aatif. "Little-Known Twitter Feature can Help Blind and Visually Impaired People Use the Site." Independent, www.independent.co.uk/life-style/gadgets-andtech/news/twitter-blind-users-alt-text-accessibility-features-ios-android-app-websitecompose-image-a8143391.html.

Sun, Huatong. Cross-Cultural Technology Design: Creating Culture-Sensitive Technology for Local Users. Oxford UP, 2012.

Takayoshi, Pamela. "Complicated Women: Examining Methodologies for Understanding the Uses of Technology." Computers and Composition, vol. 17, no. 2, 2000, pp. 123-38.

Takeshita, Chikako. The Global Biopolitics of the IUD. MIT P, 2012.

Taylor, Adam. "The Undeniable Sexism in Textbooks Designed for the World's Children." The Washington Post, 8 March 2016, www.washingtonpost.com/news/worldviews/wp/2016/03/08/the-undeniable-sexism-intextbooks-designed-for-the-worlds-children/?noredirect=on\&utm_term=.cb10042d5d03.

Teston, Christa. "Rhetoric, Precarity and mHealth Technologies." Rhetoric Society Quarterly, vol. 46 , no. 3 , pp. 251-68.

Totenberg, Nina. Supreme Court Upholds Controversial Ohio Voter-Purge Law.” All Things Considered, NPR, 11 June 2018, www.npr.org/2018/06/11/618870982/supreme-courtupholds-controversial-ohio-voter-purge-law. 
“Understanding Trump’s Muslim Bans.” National Immigration Law Center. 8 March 2019.

United States Congress. House of Representatives Committee on Oversight and Reform. Letter to Brian P. Kemp, Washington, D.C., 6 March 2019, oversight.house.gov/sites/democrats.oversight.house.gov/files/2019-0306.EEC\%20Raskin\%20to\%20Kemp-GA\%20Governor.pdf.

Varathan, Preeti. "Economics Textbooks Go out of Their Way to be Sexist." Quartz, 25 Jan. 2018, qz.com/1187410/women-are-underrepresented-in-economics-textbooks-a-studyfinds/.

Verzosa Hurley, Elise. "Spatial Orientations: Cultivating Critical Spatial Perspectives in Teaching Communication Pedagogy.” Key Theoretical Frameworks, edited by Angela M. Haas and Michelle F. Eble. UP of Colorado, 2018, pp. 93-113.

"Veterans: Protect Yourself, Your Information from "Phishing" Attempts." United States Department of Veterans Affairs, www.blogs.va.gov/VAntage/26332/veterans-protectyourself-your-information-from-phishing-attempts/.

"Voting Rights Act.” NAACP, www.naacp.org/naacp-history-voting-rights-act/.

"Voting Rights Act: Major Dates in History." ACLU, www.aclu.org/voting-rights-act-majordates-history.

“Understanding Trump’s Muslim Ban.” No Muslim Ban Ever, 8 Mar. 2019, www.nilc.org/wpcontent/uploads/2018/01/understanding-the-Muslim-bans.pdf.

Walton, Rebecca, Kristen R. Moore, and Natasha N. Jones. Technical Communication after the Social Justice Turn: Building Coaltions for Action, Routledge, 2019.

Ward, M. "The Ethic of Exigence Information Design, Postmodern Ethics, And The Holocaust." Journal of Business And Technical Communication, vol. 24, no. 1, pp. 60-90. 
Warner, Michael. "Publics and Counterpublics." Public Culture, vol. 14 no. 1, 2002, pp. 49-90.

Warshaw, Robin. "Health Disparities Affect Millions in Rural U.S. Communities." AAMC News, 31 Oct. 2017, news.aamc.org/patient-care/article/health-disparities-affect-millionsrural-us-commun/

Weiser, Wendy R. "Voter Suppression: How Bad? (Pretty Bad)." The American Prospect, 1 Oct. 2014, prospect.org/article/22-states-wave-new-voting-restrictions-threatens-shiftoutcomes-tight-races.

Weiser, Wendy R. and Opsal, Erik. "The State of Voting in 2014." The Brennan Center for Justice, 17 June 2014, www.brennancenter.org/analysis/state-voting-2014.

Wells, Susan. "Preface." Democracies to Come: Rhetorical Action, Neoliberalism, and Communities of Resistance. Rowman and Littlefield Publishers, 2008, pp. xiii-xix.

Williams, Miriam F. From Black Codes to Recodification: Removing the Veil from Regulatory Writing. Routledge, 2010.

--- "Reimagining NASA: A Cultural and Visual Analysis of the U.S. Space Program." Journal of Business and Technical Communication, vol. 26, no. 3, 2012, pp. 368-89.

---. "A Survey of Emerging Research: Debunking the Fallacy of Colorblind Technical Communication." Programmatic Perspectives, Spring 2013, pp. 86-93.

Williams, Miriam F., and Octavio Pimentel. "Introduction: Race, Ethnicity, and Technical Communication." Journal of Business and Technical Communication, vol. 26, no. 3, 2012, pp. 271-76. 
Wingard, Jen. "Writing for the Media: Translating Academic Research for the Popular Press." Writing for a (R)evolution: Public Writing Workshop/Maker Session, Feminisms and Rhetorics Conference, 5 Oct. 2017, The University of Dayton, Dayton, Ohio. Conference Presentation.

Wolf, Joan. Is Breast Best?: Taking on the Breastfeeding Experts and the New High Stakes of Motherhood. New York UP, 2011.

Wray, Amanda. "Race, Region, and Ethos: One Teacher's Story of Racism in Two Classrooms." Pedagogy, vol. 17, no. 1, 2017, pp. 59-76.

"Writing Your Hospital and the Joint Commission about Your Baby’s Feeding Complications." Fed is Best, Connect, The Fed Is Best Foundation, www.fedisbest.org/resources-forparents/writing-hospital-babys-feeding-complications/.

Wysocki, Anne Frances and Kristin Arola. Composing(Media) $=$ Composing(Embodiment): Bodies, Technologies, Writing, the Teaching of Writing. UP Press, 2012. 